\title{
Examining Strain Propagation in the Lateral and Codominant Branch Attachment Using Digital Image Correlation
}

\author{
Robert T. Eckenrode IV
}

Follow this and additional works at: https://researchrepository.wvu.edu/etd

\section{Recommended Citation}

Eckenrode IV, Robert T., "Examining Strain Propagation in the Lateral and Codominant Branch Attachment Using Digital Image Correlation" (2017). Graduate Theses, Dissertations, and Problem Reports. 7081.

https://researchrepository.wvu.edu/etd/7081

This Thesis is protected by copyright and/or related rights. It has been brought to you by the The Research Repository @ WVU with permission from the rights-holder(s). You are free to use this Thesis in any way that is permitted by the copyright and related rights legislation that applies to your use. For other uses you must obtain permission from the rights-holder(s) directly, unless additional rights are indicated by a Creative Commons license in the record and/ or on the work itself. This Thesis has been accepted for inclusion in WVU Graduate Theses, Dissertations, and Problem Reports collection by an authorized administrator of The Research Repository @ WVU. For more information, please contact researchrepository@mail.wvu.edu. 
Examining Strain Propagation in the Lateral and Codominant Branch Attachment Using Digital Image Correlation

\title{
Robert T. Eckenrode IV
}

Thesis submitted to the

Davis College of Agriculture, Natural Resources, and Design

at West Virginia University

in partial fulfillment of the requirements for the degree of

\section{Master of Science}

in

Forest Resources Management

\author{
Gregory A. Dahle, Ph.D., Chair \\ David B. DeVallance, Ph.D. \\ E.T Smiley, Ph.D.
}

Division of Forestry and Natural Resources

Morgantown, West Virginia

2017

Keywords: Tree Biomechanics, Digital Image Correlation, Quercus, Acer, Codominance Copyright 2017 Robert T. Eckenrode IV 


\begin{abstract}
Static load testing of branches is a well-established method for examining attachment strength of trees. Information gathered from these experiments is used to better understand how branches fail, and predict how they are attached to their parent stem. Digital image correlation (DIC) is used to directly measure strain on the surface of materials during static load testing. By examining how strain moves through the branch attachment, a better understanding of how trees carry loads can also be attained. In these experiments, strain propagation in the branch connection zone of lateral and codominant stems was measured utilizing digital image correlation. In chapter 2, the lateral branch attachment of two oak species (Quercus alba L. \& Quercus prinus L.) was examined and strain was mapped and analyzed. Little strain propagates into the main stem during branch failure exercise. In chapter 3, the codominant branch attachment of red maple (Acer rubrum L.) was examined, and differences between the two attachment types are compared. Strain was shown to propagate further into the surrounding stem wood in codominant branch unions. Change in angle to failure ( $\Delta$ angle) was also examined in both chapters, and was a predictor of maximum compressive strain on the underside of branches during static loading. $\Delta$ angle was also correlated with branch length and diameter. By qualitatively examining branch failures, a close relationship was found between aspect ratio and different failure types. This leads us to believe that from a mechanical perspective, a stem becomes codominant at an aspect ratio of around 0.8. Lateral branch attachments are more mechanically sound than codominant branches
\end{abstract}




\section{Acknowledgments}

I must thank my advisor Dr. Greg Dahle who has provided me the mentorship that made this project possible. His passion for teaching, advising, and most importantly listening to students have inspired me as an instructor and a person. His care, compassion, and intelligence made this project not only possible, but a pleasure. Also a thank you to committee member Dr. David DeVallance with intellectual assistance in wood mechanics and committee member Dr. E.T. Smiley with Bartlett Tree Experts.

I must thank my family for the continued support throughout my life. My father for teaching me the love and respect for the natural world that helped me find my passion. My mother, who instilled in me a strong work ethic and a drive to always better myself and continue learning throughout my life. To my sister and brother in law whose inquisitive nature and drive are a continuing inspiration to me. To my girlfriend Amy who supported me at every step and inspires me to be a better man every day.

I must thank my mentors and friends Shawn Lucas and Nate Keller who taught me the skills necessary to become an arborist, and the importance of hard work and dedication in all aspects of life.

I must thank Gene’s Beer Garden for providing an environment that inspires creativity, fosters friendships, and supplies the relaxation necessary to complete this project. 


\section{Table of Contents}

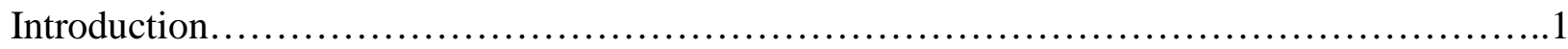

Chapter 1

Literature Review.......................................................................

Chapter 2 - Examining Strain Propagation in the Lateral Branch Attachment of White Oak (Quercus alba L.) and Chestnut Oak (Quercus prinus L.)

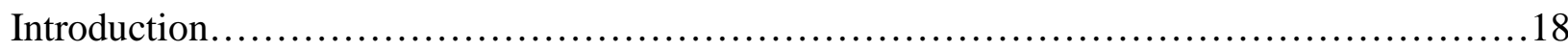

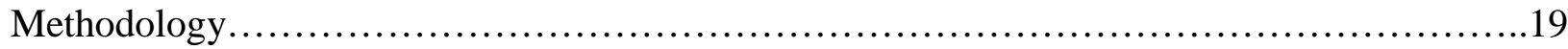

Results........................................................................27

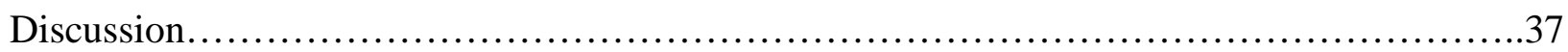

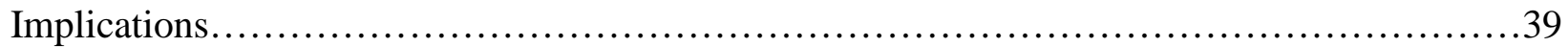

$\underline{\text { Chapter } 3}$ - Variations in Strain Propagation at Different Aspect Ratios in Red Maple (Acer Rubrum L.)

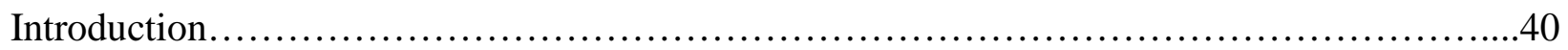

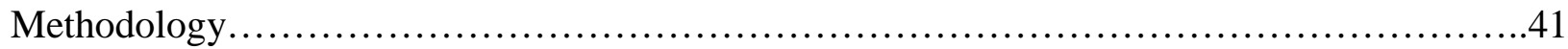

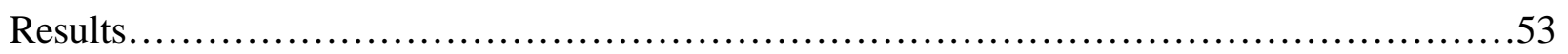

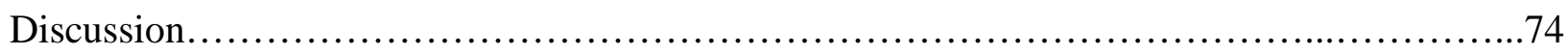

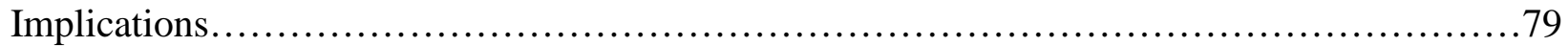

References................................................................... 80

Additional Acknowledgments...................................................... 85 


\section{List of Tables}

Table 1: White and chestnut oak branch sample attribute table. Means \pm standard error.........28

Table 2: Mean maximum strain by zone at each time period. Means with the same letter were not found to differ using a Tukey HSD ....................................................34

Table 3: Mean maximum strain by zone at midpoint of test. Means with the same letter were not

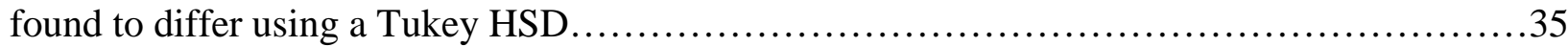

Table 4: Mean maximum strain by zone at prefailure. Means with the same letter were not found

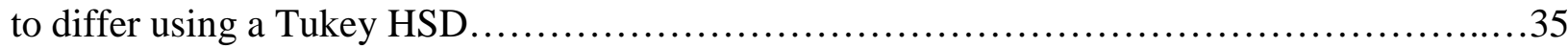

Table 5: Mean maximum strain by zone at failure. Means with the same letter were not found to

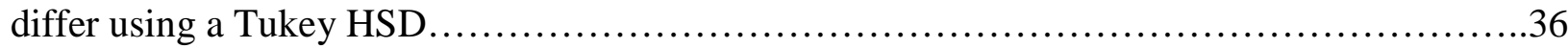

Table 6: Proportion of Strain type by Zone at each Time Period.............................36

Table 7: Red maple branch sample attribute table. Means \pm standard error.....................55

Table 8: Proportion of Strain type by Zone at failure....................................69

Table 9: Discovered clever clips after static pull testing.................................69

Table 10: Summary of linear models developed for lower branch max strain vs aspect ratio by

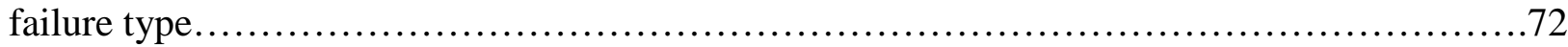

Table 11: Mean $( \pm$ SE) aspect ratio and $\Delta$ angle by failure type. Mean with different letters were

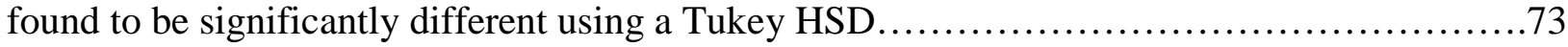

Table 12: Mean for Max strain by each branch zone for 32 Acer rubrum samples. Mean with different letters were found to be significantly different using a Tukey HSD. Data was analyzed using the natural log of max stain and back transformed for presentation purposes....................73 


\section{List of Figures}

Figure 1: The Shigo branch attachment model, showing overlapping layers of branch and stem tissue which form the branch collar. Illustration courtesy of Shigo

(1985)

Figure 2. (a) Proposed anatomy of a hazel (Corylus avallana Dcne.) fork featuring interlocking wood grain for mechanical support. Each grain line passes from parent stem to one branch fork ensuring sap movement from source to sink. (b) Schematic diagram showing the arrangement of piths (yellow), vessels (blue) fibers (white) and rays (red) Diagram courtesy Ozden et al. (2017)

Figure 3: (a) A common oak (Quercus robur L.) branch fork after breaking exercise exhibiting a spur of tissue (white arrow) associated with the "clever clip" model of branch attachment. (b) A debarked fork of common ash (Fraxinus excelsior L.) showing an interlocking grain pattern for mechanical support. Photos courtesy of Slater et al.

(2014)

Figure 4: A hazel (Corylus avellana L.) after breaking exercise exhibiting the "clever clip" tissue spur. Photo courtesy of Slater and Harbonson

(2010)

Figure 5: Example of branch failure types clockwise from top left: embedded branch failure on white oak (Quercus rubra L.) flat surface failure on sawtooth oak (Quercus acutissima Carruth.) and ball and socket failure on callery pear (Pyrus calleryana Dcne.). Photo courtesy of Kane et al. (2008)

Figure 6: Factors affecting quality of digital image correlation results. $d=$ distance between camera and specimen, $\mathrm{f}=$ focal length of lens, $\mathrm{h}=$ height of specimen $\mathrm{w}=$ width of specimen, $\mathrm{c}=$ pixel columns r=pixel rows. Illustration courtesy of Cintron and Saouma (2008)

Figure 7: Custom fabricated steel bracket and electric winch used for static pull testing. Photo courtesy of Ken Beezley.

Figure 8: Branch sample secured in steel bracket prior to testing. Photo courtesy of Ken Beezley

Figure 9: Diagram of stage point orientation for lateral branch study depicting 8 zones of interest.

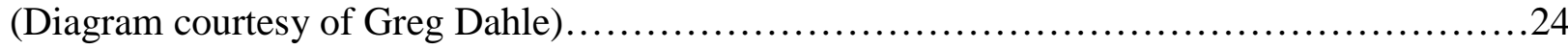

Figure 10: ARAMIS output depicting stage point orientation within software................24

Figure 11: Example of attachment angle in ARAMIS software on lateral white oak branch prior

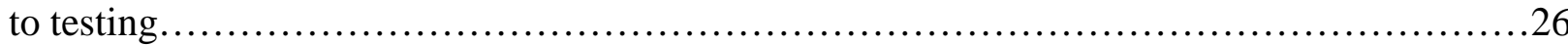

Figure 12: Example of attachment angle in ARAMIS software on lateral white oak branch at

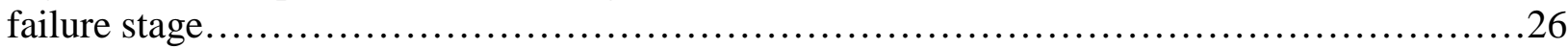


Figure 13: Minor (compressive) strain contour map (a) and major (tensile) strain contour map (b) at failure stage for tested chestnut oak branch..........................................

Figure 14: Minor (compressive) strain contour map (a) and major (tensile) strain contour map (b)

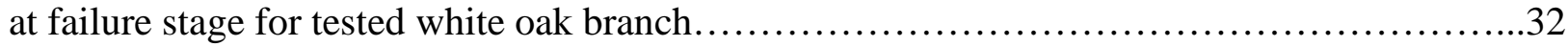

Figure 15: Diagram of field measured attachment angle..................................42

Figure 16: Example of attachment angle and rope angle in ARAMIS software on codominant red

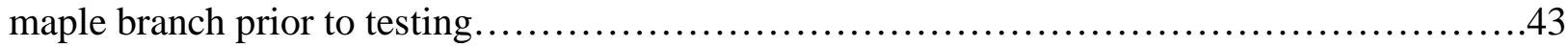

Figure 17: Example of failure angle in ARAMIS software on codominant red maple stem at failure stage

Figure 18: Example of stochastic pattern on sample branch............................45

Figure 19: Branch pull system diagram. Red arrows indicate direction of winch pull..........46

Figure 20: Example of failure types: Ball and socket (A), flat (B), imbedded branch (C), and

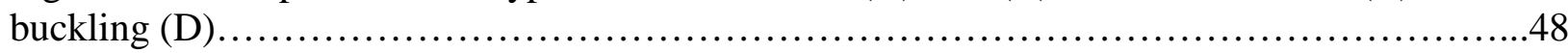

Figure 21: Grid system of stage points used for post processing of codominant branch data......49

Figure 22: Branch zone map.................................................... 50

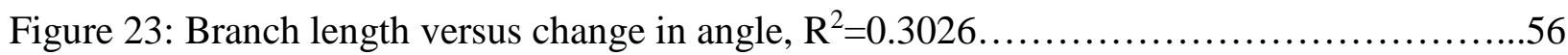

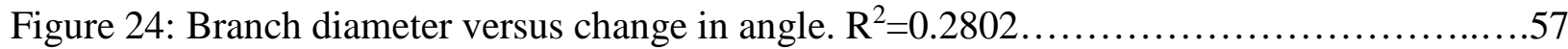

Figure 25: Minor (compressive) strain contour map (a) and major (tensile) strain contour map (b) at failure stage for tested red maple branch with aspect ratio of $0.5 \ldots \ldots \ldots \ldots \ldots \ldots \ldots \ldots \ldots \ldots . . .59$

Figure 26: Minor (compressive) strain contour map (a) and major (tensile) strain contour map (b)

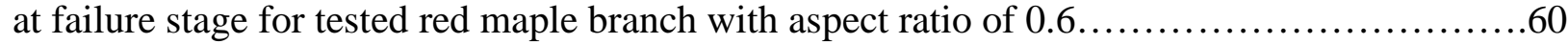

Figure 27: Minor (compressive) strain contour map (a) and major (tensile) strain contour map (b)

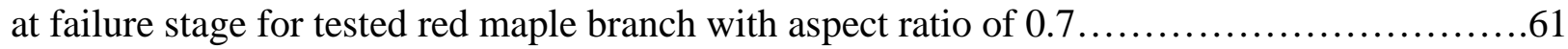

Figure 28: Minor (compressive) strain contour map (a) and major (tensile) strain contour map (b) at failure stage for tested red maple branch with aspect ratio of $0.8 \ldots \ldots \ldots \ldots \ldots \ldots \ldots \ldots \ldots . . . .62$

Figure 29: Minor (compressive) strain contour map (a) and major (tensile) strain contour map (b)

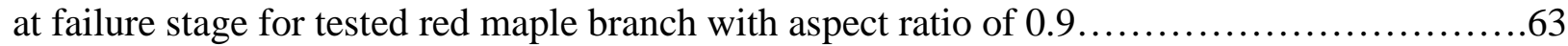

Figure 30: Minor (compressive) strain contour map (a) and major (tensile) strain contour map (b)

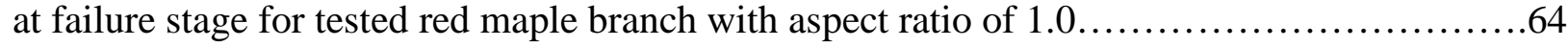

Figure 31: Minor (compressive) strain contour map (a) and major (tensile) strain contour map (b) at failure stage for tested red maple branch exhibiting a ball and socket type failure..............65 
Figure 32: Minor (compressive) strain contour map (a) and major (tensile) strain contour map (b) at failure stage for tested red maple branch exhibiting a buckling type failure......................66

Figure 33: Minor (compressive) strain contour map (a) and major (tensile) strain contour map (b) at failure stage for tested red maple branch exhibiting a flat type failure

Figure 34: Minor (compressive) strain contour map (a) and major (tensile) strain contour map (b) at failure stage for tested red maple branch exhibiting an imbedded branch type failure.........68

Figure 35: Lower branch max strain (log) versus Aspect ratio of 32 tested red maple branches.

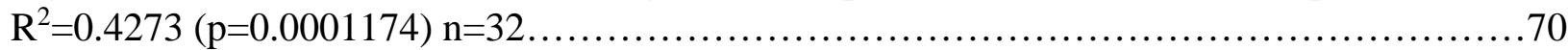

Figure 36: Lower branch max strain versus change in angle $\left(R^{2}=0.4983, p=3.847 e-06\right.$,

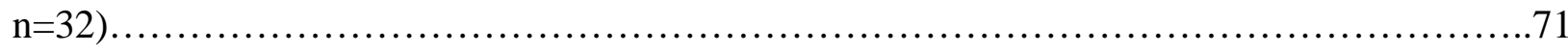

Figure 37: Lower branch max strain versus aspect ratio by failure type......................72 


\section{$\underline{\text { Introduction }}$}

Branch failure during static loading events can cause expensive property damage and power outages. Static loads can be snow and ice loads, or a climber working in a tree. When discussing climbers and branch failure the consequences become more than monetary. During loading events, force is dissipated from the branch to the trunk. If failure occurs it can take place in the parent stem, at the junction where the branch is attached to the parent stem (branch connection zone), or along the branch distal to the branch connection zone (Lilly and Sydnor 1995; Dahle et al. 2006; Kane et al. 2008). The branch connection region has been the subject of numerous studies investigating overall strength (MacDaniels 1923 \& 1932; Miller 1959; Lilly and Sydnor 1995; Smiley et al. 2000; Smiley 2003; Gilman 2003; Dahle et al. 2006; Kane 2007; Kane et al. 2008). Little research has concentrated on how loads move from a branch, across the branch connection, and into the parent stem. Knowing how loads transfer through the branch connection zone is important in advancing the overall knowledge of how a branch withstands and responds to loading; or fails during a loading event

A codominant stem is defined as two stems growing at about the same rate, with nearly the same diameter, where often times the piths are connected at the union (Gilman 2002). They typically arise from simultaneous vegetative development of axillary buds at the branch apex (Gilman 2003; Smith 2012) or simultaneous development of collateral buds, likely after branch breakage at the apex (Core \& Ammons 1958).

The strength of branch attachments has been shown to increase as the union moves from a codominant union with included bark, to a codominant union without included bark (Smiley 2003), to a lateral branch union (lateral branch smaller than the parent branch) (MacDaniels 1923 \& 1932; Miller 1959; Smiley 2003; Gilman 2003). While it is often easy to identify included 
bark, it is not always clear (from the ground prior to ascent) whether a union without included bark is a codominant union or the stronger lateral branch union. The presence of a branch collar is thought to be one indicator of a lateral branch union, but collars are not always present. Aspect ratio (diameter lateral branch / diameter parent stem) is a way to quantify codominance. Eisner et al. (2002) found that an aspect ratio above 0.75 was more likely to be a codominant union in terms of hydraulic segmentation. However, it was unknown if aspect ratio translates to attachment strength.

The adoption of aspect ratio as a visual model for predicting whether a branch union is strong (lateral) versus weak (codominant) can aid an arborist in targeting branches with an increased likelihood of failure, whether they are looking for a tie-in location or deciding which branches to retain during pruning.

According to the National Institute of Occupational Safety and Health (2009), there were 1,285 worker fatalities in the tree care industry from 1992 to 2007. Of these fatalities, 441 (34\%) were attributed to falls. A total of 45 accidents were investigated between 1985 and 2007. 14 were fall deaths. Of these, 4 or $8.9 \%$ of the NIOSH investigated fatalities were attributed to breaking of a branch or limb while tied in at a height of $30-60$ feet.

There are very few well defined guidelines for tie in points for climbers. If the branch is codominant, then the ability to support a climber is likely reduced. There is no established ANSI Z-133 standard that directly specifies a tie in point. The ISA Arborists' Study Guide (2010) gives the following:

"For tying in, select a crotch that is wide enough for the rope to pass through easily. The size of the limb varies with species and wood strength, but generally, the main branch should be 
at least 4 inches $(10 \mathrm{~cm})$ in diameter, and the rope should be in the union against the trunk. If the branch is sufficiently large and strong enough, you may choose to tie in over the branch.” (p. 283)

This guideline leaves the choice of tie in point largely to the climber's discretion. There is obvious room for advancement. Aspect ratio is an easy metric for a climber to estimate visually prior to ascent. Determining if loads are carried differently in lateral and codominant branches with and without collars will increase our understanding of how branches are securely attached to their parent stems.

Breaking strength is typically measured as the maximum bending stress $(\sigma)$ and is a function of applied bending load over resistance of the wood (Niklas 1992; Kane et al. 2008; Dahle and Grabosky 2009; Özden et al. 2017). Resistance is determined using the moment of inertia (I), a function of the geometric shape (Beer et al. 2001). While it is simple to measure the shape of a branch or stem, it is difficult determine the geometric shape when the failure takes place in the branch attachment zone. This is because the shape is often irregular and it is difficult to determine which portion of the geometry in the parent stem is a result of the initial failure and which portion is due to the secondary rip out. This is especially true in codominant unions, as failures result in long axial separation between the two branches (Niklas 1992; Niklas 1997a, 1997b; Kane et al. 2008; Dahle et al. 2006; Dahle and Grabosky 2009; Dahle et al. 2017). Hence it can be challenging to use information from branch failure exercises to understand how loads are transferred to the parent stem. Digital image correlation can measure strain (tissue deformation) during loading applications (Hesse et al. 2016; Sebera et al. 2016; Sebera et al. 2014; Löchteken and Rust 2015; Dahle [In review]). In elastic materials like wood, strain $(\varepsilon)$ is the result of load and linearly proportional to $\sigma$ until initial failure occurs at the yield point (Beer 
et al. 2001, Niklas 1992). The ability to map $\varepsilon$ could allow a direct comparison of how failure occurs in branches of varying aspect ratios regardless of the difficulty in determining the geometric shape of the zone of failure.

The purpose of this work was to map strain in branches during static loading trials. We are interested in determining if strain can be used to identify the difference between a lateral and codominant branch based on aspect ratio. Ultimately this work will help the arboricultural community better understand how trees react during static loading events such as during ice and snow storms. This work will also benefit climber safety and help guide pruning decision making. Eventually, enough information will be gathered to produce a mathematical model to describe static and dynamic loading events in trees. The research presented in these experiments will provide information about strain moves through the branch attachment, which will aid in the development of a dynamic model. 


\section{Chapter 1:}

\section{Literature Review}

Plants must balance four functions in order to survive: hydraulics, mechanical support, reproduction, and photosynthesis (Niklas 1992). Branches add leaf surface area to capture light and conduct photosynthesis, adding weight to the end of branches. (Pallardy 2008). Branch architecture varies widely among species and site and can influence growth rate (Cannell and Morgan 1989; Farnsworth and Niklas 1995). Reproductive plant organs are located on branches which enable pollination and reproduction (Pallardy 2008), but also add static loads to branch tips.

Trees must balance the need for mechanical support and translocation of water and nutrients in branches in order to survive (Niklas 1992; Woodrum et al. 2003; Dahle and Grabosky 2010b). Branches must be stiff enough to maintain structure under their own weight, yet flexible enough to bend and twist to dampen dynamic loads without breaking (Niklas 1999). As branches grow in size, their role shifts from that of a sun branch displaying the photosynthetic tissue (leaves) to a structural role that supports smaller sun branches (Dahle and Grabosky 2010a). This transition takes place by radial growth increasing in order to support the added weight (Farnsworth and Niklas 1995). Annual branch length extension decreases (Dahle and Grabosky 2010a), mean vessel element diameter decreases (Gartner 1991; Chiu and Evers 1992; Dahle and Grabosky 2014) and a thickening of the fiber cell walls occurs (Dahle and Grabosky 2010b). This is achieved by different anatomic features in the branch, it's attachment, and surrounding trunk wood. The $S_{2}$ cell wall cellulose microfibril angle decrease as you move from pith to bark, aiding in mechanical optimization. Cells in young plant parts have higher microfibril angles to allow more flexibility, while more mature plant parts have lower microfibril angles, making them 
stiffer (Lichtenegger et al. 1999). A decrease in microfibril angle was shown to increase the strain to fracture or toughness (Dahle and Grabosky 2009a).

The branch and stem tissues increase radially as the tree grows and adds biomass which increases self-loading, and adds more surface area for external load interception. Branch failure is the rupturing of branch tissue as a result of an applied load. Branches fail as a result of either dynamic loading (wind) or static loading (snow, ice, fruit set, climber) (Niklas 1999; James 2003; James et al.2006, 2014; Kane 2007; Kane et al. 2008; Kane and Clouston 2008; Dahle and Grabosky 2009; James et al. 2014; Dahle et al. 2017). It has been found that trees can fail under dynamic loads significantly lower than tested static load (Peltola 2006). There is not currently enough information available to develop a dynamic model for tree failure (James et al. 2014). By mapping strain in the branch connection zone during static loading, a piece can be added to the puzzle for creating a dynamic model.

\section{$\underline{\text { Area of Interest }}$}

The area of interest for this thesis is the branch, its connection zone, and adjacent stem wood. Vessels in the branch connection zone orient vertically then bend sharply to match the angle of the branch vessels. The vessels and fibers form a swollen collar at the base of the branch on the underside (Shigo 1985). This forms what is commonly referred to as the branch collar. Above the branch, there is also an area with fewer vessels on the upper side of the branch at the junction of branch and trunk. (Shigo 1985). Trunk cambial tissue growth outpaces branch tissue growth over the growing season, causing trunk tissue to grow over the branch collar. Trunk tissue forms a collar over the branch tissue. This process is repeated year after year which forms a ball and socket type lateral branch attachment summarized in figure 1 . 


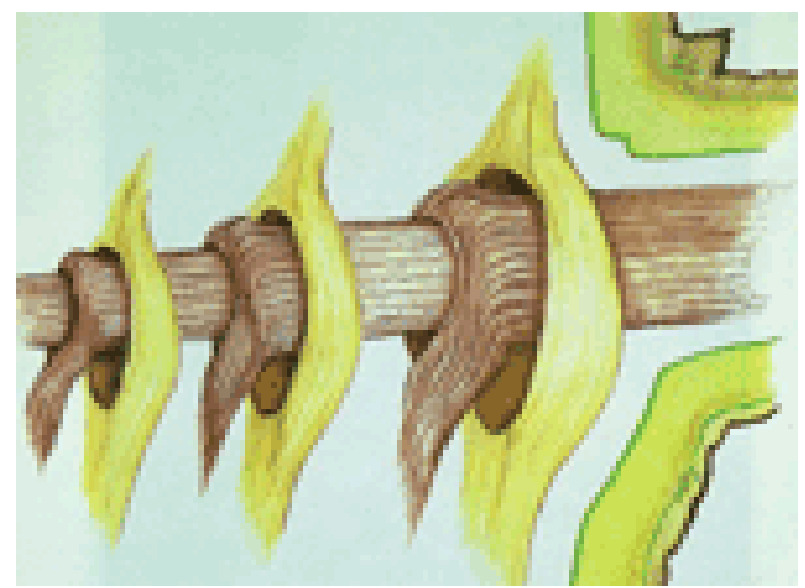

Figure 2: The Shigo branch attachment model, showing overlapping layers of branch and stem tissue which form the branch collar. Illustration courtesy of Shigo (1985).

This area is physiologically different than other parts of the stem, therefore we anticipate the mechanical properties to be different as well. Absence of a branch collar is a good indicator of a codominant stem, at least in trees that readily develop branch collars such as sycamore and London plane tree (Platanus spp.), honeylocust (Glenditsia triacanthos L.), holly (Ilex spp.), magnolia (Magnolia spp.), red maple (Acer rubrum), dogwood (Cornus spp.), black olive (Bucida buceras), ficus (Ficus spp.), and crape-myrtle (Lagerstroemia spp.). Species like oaks (Quercus spp.) and elms (Ulmus spp.) have less visible collars and lack visible swelling (Gilman 2002).

Recently, Slater and Harbonson (2010) examined codominant branch anatomy and challenge the Shigo model of branch attachment, stating that the conventional model of overlapping branch and stem tissue at the area of attachment would make conduction of water and solutes impossible in codominant stems. They propose an alternative "clever clip" model. This model likens the branch and stem tissue to two hoses that are connected by a clip. The clip reduces the diameter slightly, which restricts flow, but provides the mechanical support necessary to support the 
branch. The "clip" described is a small area of tissue that forms at a right angle to the main grain direction of the branch on the upper side of the branch. X-ray and CT scans reveal this area to be a dense anatomically complex region that likely has a branching network of rays to allow for additional support and transport (figures 2, 3 and 4) (Slater 2010; Slater et al.2014). It is important to note that this work concentrated on codominant branches in contrast to the Shigo experiments (1985), which examined lateral branch attachments. There are anatomical and therefore structural differences between codominant and lateral branches. Codominant stems arise from concurrent vegetative development of axillary buds at the branch or stem apex, whereas lateral branches arise from vegetative development of lateral or epicormics buds. (Gilman 2003; Smith 2012) It is likely that codominant branches lack the overlapping layers of tissue that Shigo (1985) describes. Codominant branches must have some mechanical feature that enables branch retention as the tree grows however. It is quite possible that this model describes the codominant branch attachment, just as Shigo (1985) described the lateral branch attachment (Slater and Harbonson 2010; Slater 2017) This work does not seek to evaluate either model, but seeks to gain insight into how mechanical loads are carried in this region, and if this changes with aspect ratio. 


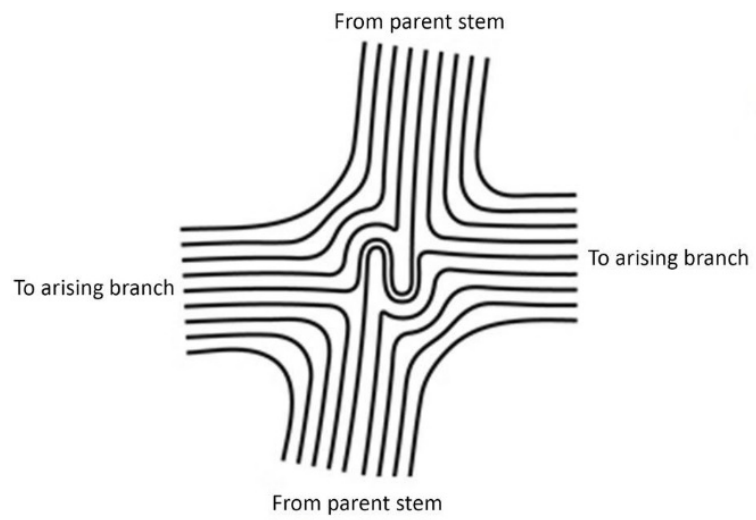

(a)

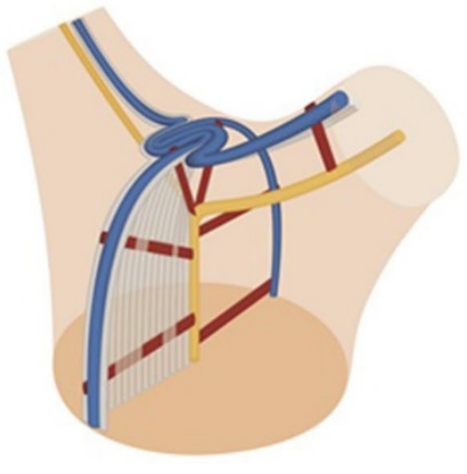

(b)

Figure 2. (a) Proposed anatomy of a hazel (Corylus avallana Dcne.) fork featuring interlocking wood grain for mechanical support. Each grain line passes from parent stem to one branch fork ensuring sap movement from source to sink. (b) Schematic diagram showing the arrangement of piths (yellow), vessels (blue) fibers (white) and rays (red) Diagram courtesy Ozden et al. (2017)
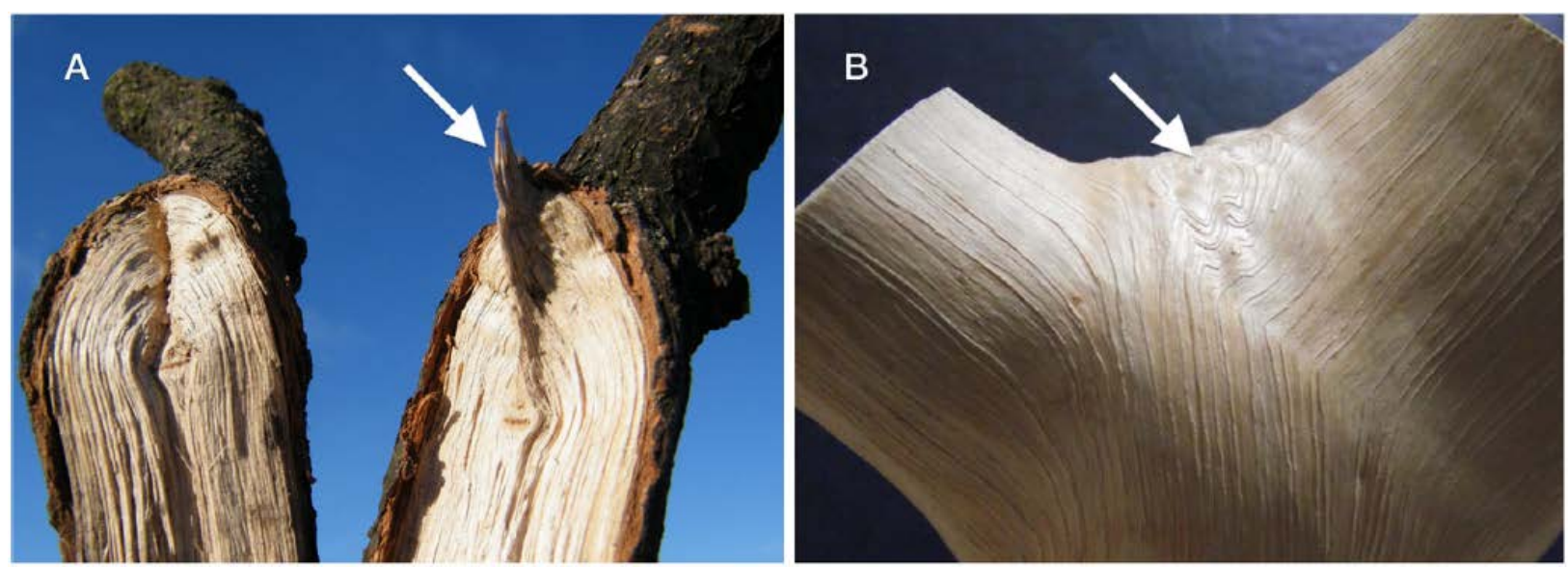

Figure 3: (a) A common oak (Quercus robur L.) branch fork after breaking exercise exhibiting a spur of tissue (white arrow) associated with the "clever clip" model of branch attachment. (b) A debarked fork of common ash (Fraxinus excelsior L.) showing an interlocking grain pattern for mechanical support. Photos courtesy of Slater et al. (2014) 


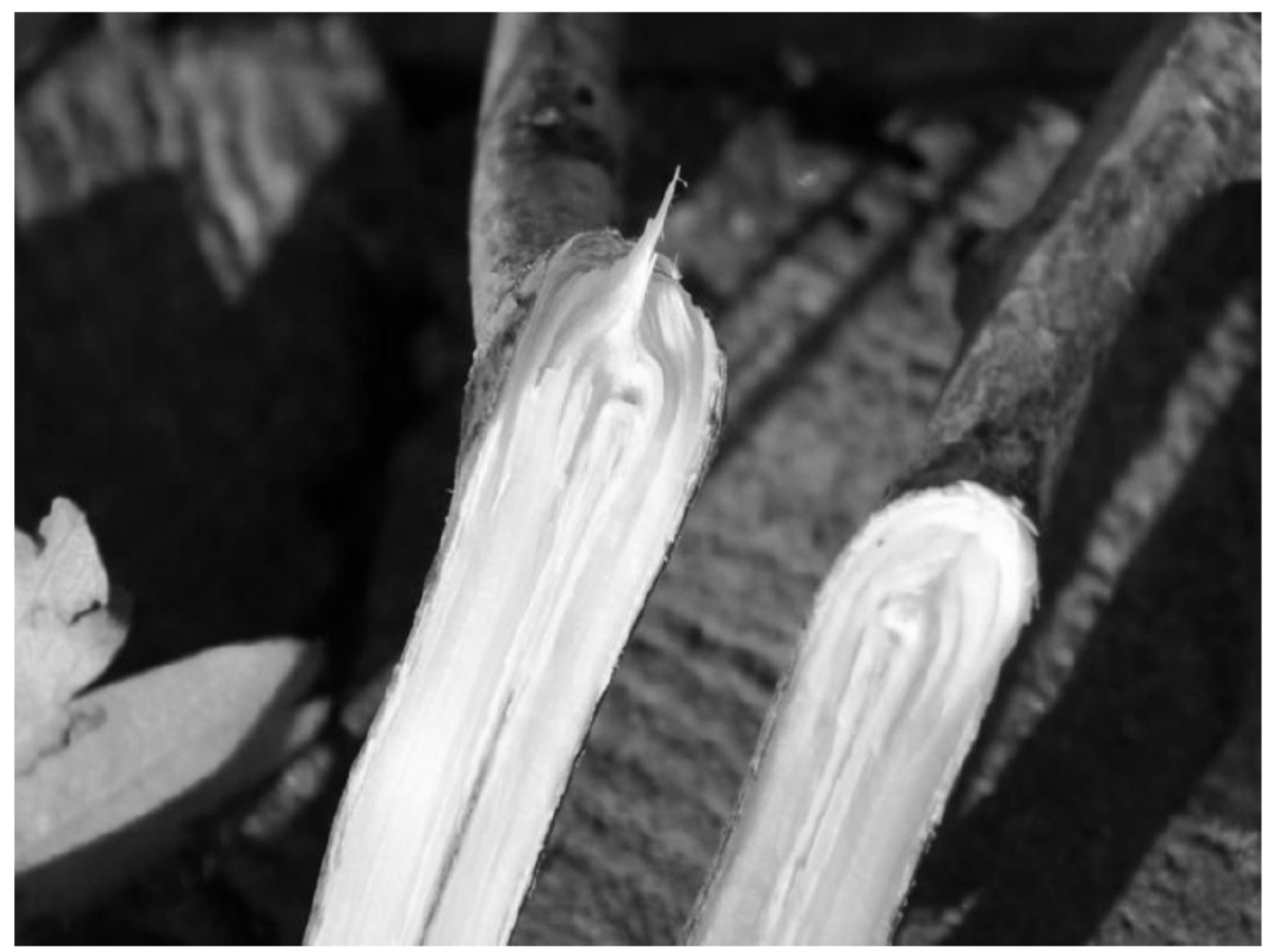

Figure 4: A hazel (Corylus avellana L.) after breaking exercise exhibiting the "clever clip" tissue spur. Photo courtesy of Slater and Harbonson (2010)

In Jungnikl et al. (2009), computer tomography (CT) scanning and wide angle x-ray scattering was employed to measure microfibril angle and distribution in the branch connection zone. They discovered that tissue at the branch base is less dense with a higher $\mathrm{S}_{2}$ cell wall microfibril angle, which provides more flexibility. They concluded that this physiological feature helps limit the spread of $\varepsilon$ into the main stem during branch loading events. Only three samples were examined during this study, so more information about how load moves through the branch connection zone is needed. 
In a larger study examining codominant hazel (Corylus avellana Dcne.) forks Özden et al. (2017) found that wood is stronger and denser at the branch union. Scanning electron microscopy showed an interlocking grain pattern that aids in tensile strength of branches (figure 2). They also observed thicker secondary cell walls in this region. Spiral or helical type cell failures were observed during tensile testing. These type of failures require large amounts of energy to propagate (Jeronimidis 1980). Also, slower, ductile failures (plastic yielding) occurred rather than sudden, brittle failures (snapping). Ductile materials are characterized by a materials ability to yield or stretch under loading at room temperature while brittle materials fail without any noticeable change in rate of elongation, or plastic deformation (Beer et al. 2009). All things considered, the wood was about five times stronger in the branch attachment region than in surrounding tissue, likely due to higher density and lower microfibril angle (Slater and Ennos 2013; Slater et al. 2014; Özden et al. 2017).

Beer et al. (2009) note that the strength of a material is related to the strength of the elements that make up that material, and bound by its weakest element. Indeed, this is an adaption of Weibull’s weakest link theory (Weibull 1939; Zok 2017) which suggest a failure will occur at the weakest element. Furthermore, the size effect model suggests that as a sample gets larger, it becomes weaker due to the greater likelihood of defects in the sample due to statistical material strength randomness (Beer et al. 2009; Zok 2017). This effect is particularly profound when examining biological materials like wood; as they are anisotropic in nature (Steiger and Köhler 2005). In theory, failure should initiate at the weakest element of the specimen. While it is worthwhile to examine small branch attachments, it is unwise to extrapolate these findings to failure mechanisms of larger branches; which generally have higher consequences associated with failure. 
It remains unclear when a branch becomes codominant from a mechanical perspective. It is clear there are anatomical differences in the wood which cause differences in strength of attachment (Gilman 2003), but it is unclear at what aspect ratio this begins to occur. This work seeks to gain insight into when a branch becomes codominant by load testing branches of different aspect ratios and examining differences in strain propagation.

\section{$\underline{\text { Aspect Ratio and Codominance }}$}

Branch failures associated with codominance is an issue in urban trees due to poor training of nursery stock, open growth habit, and proximity to valuable targets (Gilman 2002). There is no established aspect ratio at which a stem becomes codominant. Eisner et al. (2002) found that at an aspect ratio of $75 \%$ and above, a branch is considered codominant in terms of hydraulic segmentation. Aspect ratio has shown to be a reliable indicator of failure stress in branches and branch unions.(Gilman 2003; Kane 2007; Kane and Clouston 2008; Kane et al. 2008). Kane and Clouston (2008) found that failure occurred under much lower stresses on codominant stems during tree pulling tests on the genus Acer. An inverse relationship between aspect ratio and attachment strength in Acer rubrum has been found, (Gilman 2003; Smiley 2003) and codominant branches becomes even weaker when included bark is present (Smiley 2003).

Kane et al. (2008) qualitatively classified branch failures into three groups (figure 5) in a study examining failure strength, and failure type with aspect ratio. Flat surface failures are described as longitudinal splitting of the stem at the branch attachment, leaving equal stem wood on either side of the sample. Embedded branch failures were similar to flat failures but wood associated with the branch separates from the trunk leaving a distinct groove in the stem portion and unequal division of stem wood after failure. Ball and socket failures occur when a branch is pulled from the trunk leaving a distinct ball shape and relatively undamaged stem. 

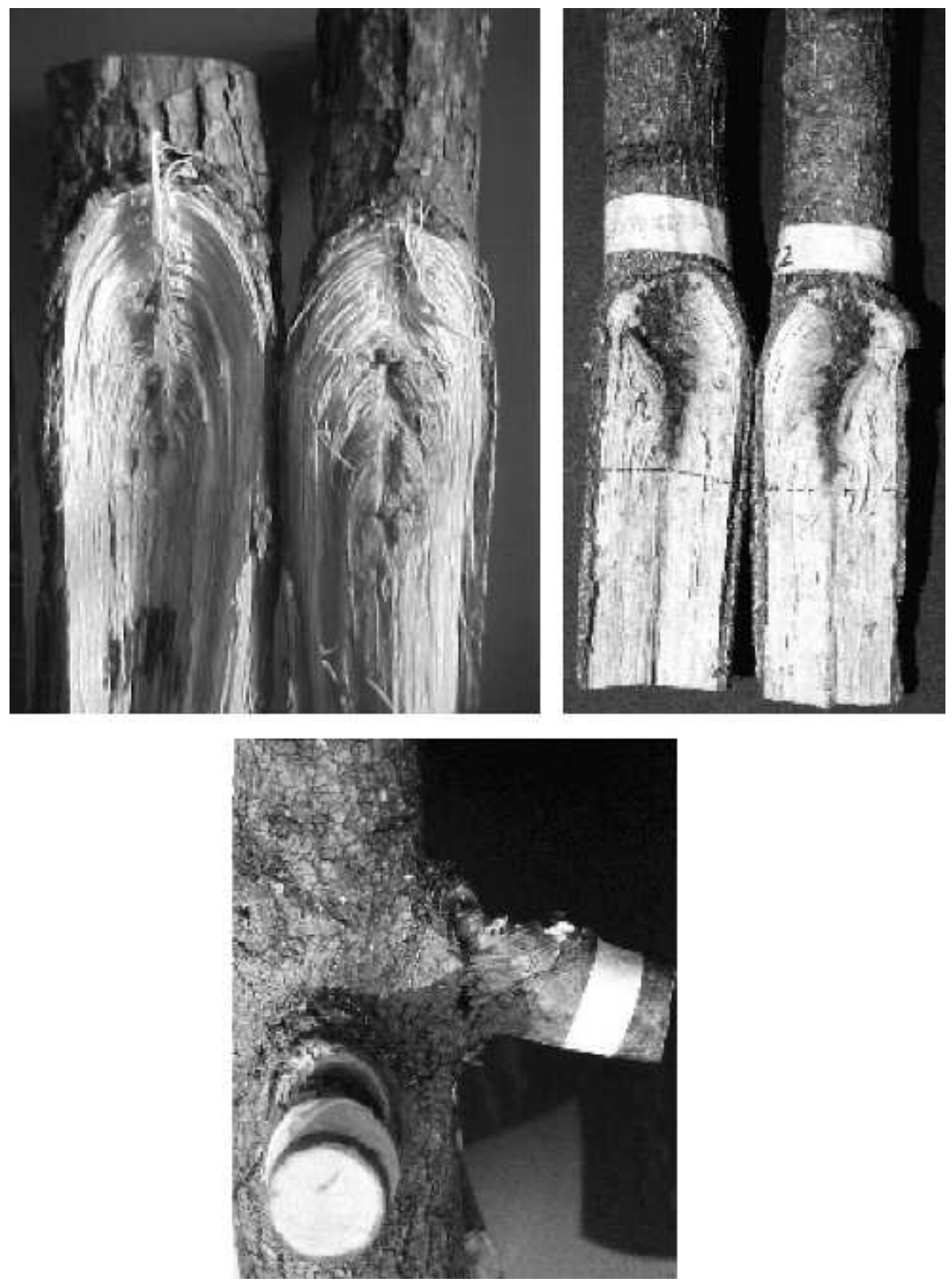

Figure 5: Example of branch failure types clockwise from top left: embedded branch failure on white oak (Quercus rubra L.) flat surface failure on sawtooth oak (Quercus acutissima Carruth.) and ball and socket failure on callery pear (Pyrus calleryana Dcne.). Photo courtesy of Kane et al. (2008). 
Included bark failures typically occur at the point of attachment (Smiley 2003; Kane et al. 2008) in a flat type failure (Kane et al. 2008). A relatively high coefficient of variation (17\%57\%) was seen in Kane et al. (2008) possibly due to the calculation of the moment of inertia (I) in the bending stress $(\sigma)$ calculation. Stress is defined as the applied force per unit area $I$ is based on the geometry in the zone of failure. I can be obtained easily if the failure occurs on the relatively uniformed shape of a branch portion, but is very difficult to calculate in ball and socket or flat type failures (Kane et al. 2008). As $\sigma$ and $\varepsilon$ are linearly proportional in elastic materials, employing digital image correlation to measure $\varepsilon$ may prove insight into how stresses develop during loading events and failure. It remains unclear how loads moves through the branch attachment region during loading events and whether there is a difference in the strains patterns between lateral branches and codominant branches.

\section{Attachment Angle}

The angle of branch attachment has long been thought to be an indicator of attachment strength, especially by practitioners. Yet numerous studies have shown that the angle of branch in relation to the stem has little to do with the strength of that attachment (MacDaniels 1932; Miller 1959; Lilly and Sydnor 1995; Gilman 2003; Pfisterer 2003; Kane 2007; Buckley et al. 2015). In a large study of red maple (Acer rubrum), callery pear (Pyrus calleryana), and sawtooth oak (Quercus acutissima) by Farrell (2003), several structural features were examined to explain differences in branch connection strength. Aspect ratio and branch angle showed almost the same correlation to strength $\left(\mathrm{R}^{2} \approx 0.40\right)$ among all species examined. It is possible that codominant branches are usually oriented vertically, leading to a smaller attachment angle and higher aspect ratios. 
The change in angle ( $\Delta$ angle) to failure (failure angle - initial angle) could be an interesting an interesting descriptor of branch failures. We were not able to find any information in the literature dealing with $\Delta$ angle. It is difficult to obtain this data during branch pull testing without filming the failure at the time it took place. Digital image correlation makes measuring angles and pinpointing the moment of failure possible (Chu et al.1985) and we will explore whether the change in angle at the point of failure provides any explanatory power.

\section{Digital Image Correlation}

Digital image correlation (DIC) can accurately map $\varepsilon$ of prepared specimens using digital cameras and software. The software works by mapping the movement of a stochastic speckling pattern on the surface of a sample during testing. The software interpolates these speckled points and creates a map of $\varepsilon$ throughout testing of a sample. This enables researchers to examine how $\varepsilon$ moves through a sample during a loading event in a non-destructive manner (Tyson et al.2002; Sebera et al.2014).

Cintron and Saouma (2008) prepared a guide to preparing and testing a sample using DIC. Results of the DIC will depend on several factors including the digital image resolution (pixel columns (c) * pixel rows (r)), the width (w) and height (h) of the specimen tested, the distance between camera and specimen (d), the focal length of lens (f) and the application of the stochastic speckling pattern. in figure 6: 


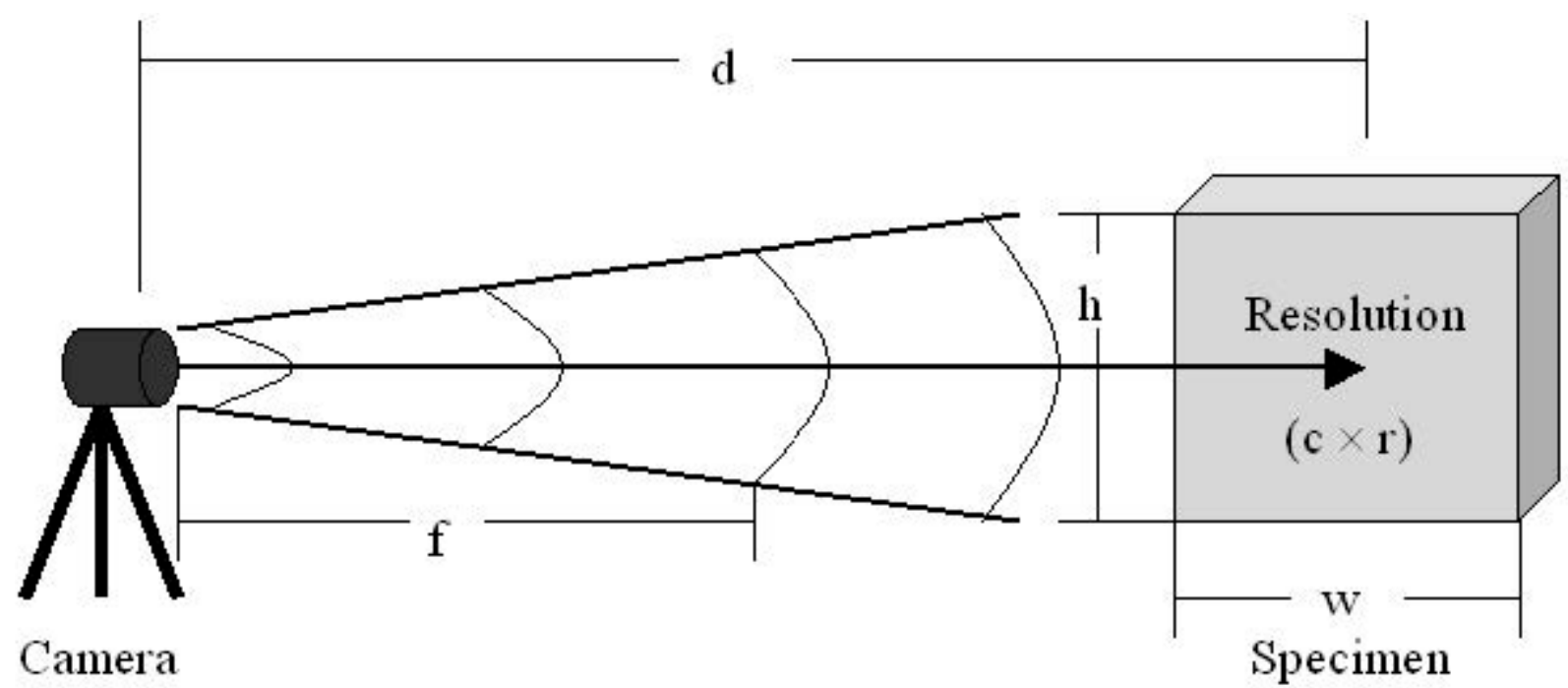

Figure 6: Factors affecting quality of digital image correlation results. $d=$ distance between camera and specimen, $f=$ focal length of lens, $h=$ height of specimen $w=$ width of specimen, $c=$ pixel columns $r=$ pixel rows. Illustration courtesy of Cintron and Saouma (2008)

Digital image correlation (DIC) represents the cutting edge of $\varepsilon$ measuring technology. Sebera et al. (2014) found it to be comparable to using tensometers screwed directly into the wood to measure strain. The non-destructive nature of DIC technology gives us a more realistic testing scenario that would be found in nature. We are able to measure $\varepsilon$ on the surface of a material without screwing tensometers into the material; potentially altering the material properties in the process or creating stress concentration points. DIC enables the mapping of $\varepsilon$ on the entire stem, rather than only where instruments are attached and inferring strain throughout the rest of the stem. In Bjurhager et al. (2008) European aspen (Populus tremula) and hybrid aspen (Populus tremula x Populus tremuloides) saplings were tensile tested in green condition using a DIC system in order to examine differences in material properties between the two species. Digital image correlation has also been used to map strain in roots during standing tree pulls in order get a better idea of how the root-stem transition zone reacts in response to wind loading (Beezley 2016). Dahle [in review] also examined bark influence on strain measurement 
using DIC, and suggests bark surface mapping as a surrogate for directly testing wood surface. In that study, red oak stump sprouts were tested in a 3-point bend test. While it is impossible to speculate what exactly is occurring beneath the bark during testing, the strain pattern should similar between the bark and wood tissue directly beneath, particularly when the bark is tight, thin, and lacking in deep furrows (Dahle [in review]). The sprouts examined matched these attributes.

\section{$\underline{\text { Research Questions }}$}

The overall goal of this research is to understand how loads move through branches during static loading. The ability to map strain provides an opportunity to examine how the tissues in the branch attachment zone responds to static loading events. We will use DIC to map strain patterns during failure exercises of lateral branches (aspect ratio $<0.5$ ) in chapter 2 to determine how applied static loads build up in the attachment zone. In chapter 3 we repeat the failure exercises on branch connections with larger aspect ratios (0.6-1.0) to determine if DIC can help determine a predictive measurement for when a branch becomes codominant from a mechanical perspective. We have selected strain as our descriptor of loading as it can be measured throughout the failure exercises without the need to define the geometry of the failed portion. We are interested in learning how localized static loads lead to tissue deformation (strain, $\varepsilon$ ) in the branch attachment zone. Does $\varepsilon$ move through the branch connection zone differently in codominant stems than in lateral branches? Is there a relationship between aspect ratio and patterns of $\varepsilon$ ? Can it explain differences in strength in codominant stems and therefore be used to define as a predictor of stability? 


\section{Chapter 2:}

\section{Examining Strain Propagation in the Lateral Branch Attachment of White Oak (Quercus alba L.) and Chestnut Oak (Quercus prinus L.)}

\section{Introduction}

Branch failure as a result of static loading events can be caused by ice, snow or a climber aloft in a tree. Failures as a result of snow and ice storms can result in power outages, road blockage, and costly property damage (Cannell \& Morgan 1989). A large ice storm in 1998 that affected Maine, New Hampshire, Vermont, and New York caused \$202,041,000 in property damage, left 500,000 homes and businesses without power, and caused significant losses to the tourism, dairy and syrup industries in the region. (Lecomte et al. 1998)

Trees are living structures that deal with static loads through their own complex anatomy. The lateral branch attachment is designed in such a way to provide added strength at the union of branch and trunk. As the tree grows, cambial tissue outgrows branch tissue year after year resulting in an overlapping of the two tissues. This forms what is commonly referred to as a branch collar. (Shigo 1985) The cross lamination of tissue and grain arrangement gives added strength to the attachment.

When trees are unable to carry these static loads failure occurs; either in the branch attachment, along the branch distal to the parent stem, or in the surrounding trunk tissue of the parent stem. (Lilly and Sydnor 1995; Dahle et al. 2006; Kane et al. 2008). Many studies have examined the ultimate strength and material properties of the wood in this region, but very little work has concentrated on how the load is carried and potentially dissipated. Strain can be used to 
measure how this load is carried or dissipated by the branch in various sections of a tree (Beezley 2016; Dahle et al. 2017) including the branch connection zone.

Strain is a measure of deformation in materials as a result of an applied load. It is represented as $\varepsilon$ and defined as change in length over original length. It is a ratio of state change and is therefore unit less (Beer et al. 2001).

In this chapter, strain patterns are examined in the lateral branch attachment of two species of oak using the ARAMIS digital image correlation system (DIC) during static branch pull testing. Strain is mapped throughout the area of interest and compared in different zones within the area of interest. Strain propagation patterns between the species are also compared.

\section{Methodology}

\section{$\underline{\text { Sample Collection }}$}

Samples were collected from the WVU Agronomy farm plantation during March and April of 2015. The plantation was developed in 1985 with five oak species planted on the site for an oak wilt study conducted in 1996. Three North American species: white oak (Quercus alba L.), chestnut oak (Quercus montana Willd.), and northern red oak (Quercus rubra L.) and two European species: English oak (Quercus robur L.) and sessile oak (Quercus petraea Matt.) were planted. Trees were planted in twenty-five rows at twenty-six trees per row.

Thirty-one branch samples were collected and tested from this plantation in the current study. Seventeen samples from four chestnut oak trees, and fourteen from six white oak trees. Diameter at breast height (DBH) and total tree height (TTH) were recorded in the field prior to sample collection. Lateral branches were targeted that were between 2.54 and $7.6 \mathrm{~cm}$ in diameter, with an aspect ratio below 0.5 . 
Identified portions of the main stem meeting the minimum desired branch attributes were harvested. The midpoint of the branch fork (location where the lateral bud originated) was estimated and the stem was cut at a distance of 31 to $46 \mathrm{~cm}$ in both the axial and distal direction from the midpoint. The branch arising from the branch attachment zone was reduced to approximately $91 \mathrm{~cm}$ in length from the branch union. Severed branch unions were lowered to the ground in a controlled manner to reduce wounding. Cut stem and branch end cross sections were wrapped in plastic for transfer to retain moisture and returned to the lab for testing. All testing occurred within 2 days of harvest and all samples were kept moist until after testing was completed.

Diameter measurements of the stem above, branch, and stem were taken prior to testing with a caliper. The length of the branch bark ridge was also measured. Branch attachment angle was measured using a protractor prior to testing, and then again using ARAMIS software.

\section{$\underline{\text { Sample Preparation and Testing }}$}

Samples were prepared for testing by applying a coat of white spray paint (Rustoleum flat finish) directly to the bark of the sample in order to cover the branch and stem area within one foot of the branch attachment zone. The paint was left to dry for several minutes then a stochastic speckling pattern was added using black spray paint (Rustoleum flat finish). The samples were painted to produce speckles that were 5-10 pixels across when examined by the ARAMIS digital image correlation system.

The DIC system was calibrated using the provided ISO-9001 certified calibration panel $\left(350 \times 280 \mathrm{~mm}^{2}\right)$. Calibration routine consisted of 13 images to form 3D calibration area centered on a working depth (distance from camera to center of the calibration area), with a 
calibration deviation of less 0.3 Facet size was set to 20 x 20 pixels with a facet overlap of $25 \%$. A facet is a unique correlation area with measurement point at the center. During post processing the intersection deviation for the starting facet point (reference location on the test sample for the right and left image) was below 0.3 for each stage (stereo photographs) which provided an accuracy of at least $0.1 \%$ throughout the tests at each stage point. Stage points are individually definable points that are placed on the 3D surface of the sample in the ARAMIS software. Strain was measured at various stage points throughout the area of interest (defined in post processing).

A full calibration of the camera system was performed prior to testing. The working depth (distance) was set at $130 \mathrm{~cm}$. This distance was close enough to capture the area of interest in detail while far enough to be out of harm's way during testing. The original calibration and working distance was used for all sample testing. A quick calibration was used when necessary and camera was moved slightly on a sample by sample basis to get the best strain map available. A maximum intersect deviation of 0.30 was maintained throughout testing, as per manufacture's recommendations (GOM 2007).

Samples were placed in a custom fabricated steel bracket (figure 7) and secured with nylon ratchet straps around the stem and bracket above and below the branch. (figure 8). A battery powered cable winch (Reese, Plymouth MI) was secured to a nylon rigging strap distal to the branch attachment. 


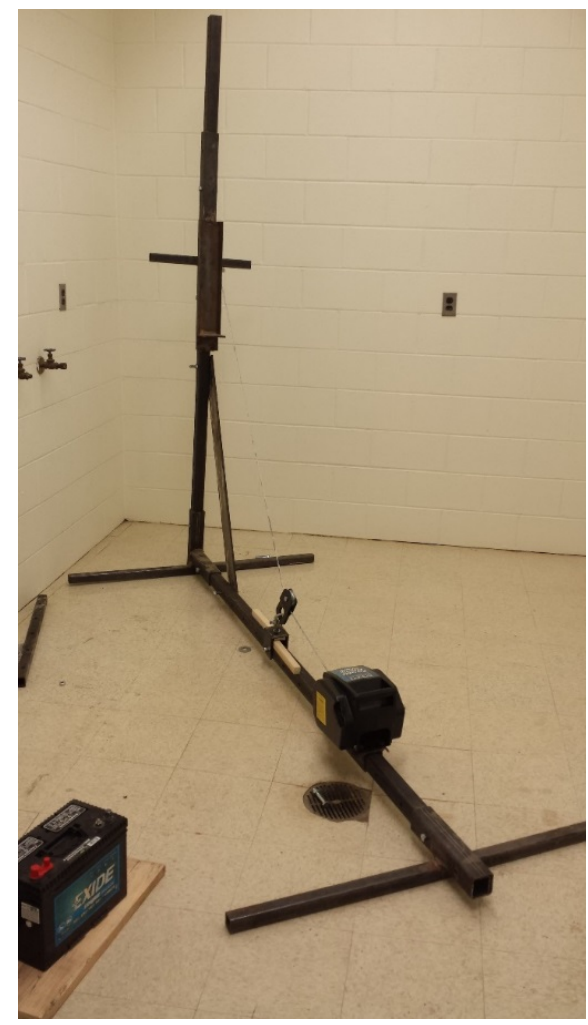

Figure 7: Custom fabricated steel bracket and electric winch used for static pull testing. Photo courtesy of Ken Beezley.

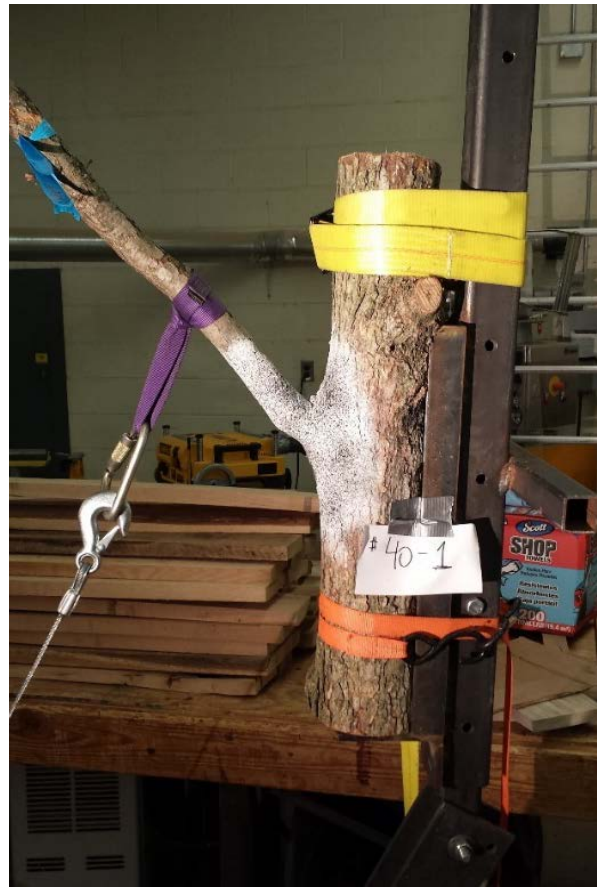

Figure 8: Branch sample secured in steel bracket prior to testing. Photo courtesy of Ken Beezley. 
Two reference photographs were taken in the ARAMIS software to create a base map for strain mapping during static pull testing. Samples were pulled to failure as the ARAMIS system recorded data at 3 frames per second.

\section{$\underline{\text { Post processing }}$}

Stage points were set up along an alpha numeric grid pattern, rotated to match the branch angle, encompassing the area of interest. Stage points were set on a $4 \times 4$ grid and divided into 8 zones. (figure 9 and 10) The branch zone encompassed branch tissue immediately distal to the branch attachment. The branch protection zone (BPZ) was immediately proximal to the branch zone. The width was defined by the branch diameter and extended about $1 / 3$ of the way into the stem. The stem zone lay below the BPZ zone and extended the width of the stem. Its width was also defined by the diameter of the branch. The collar zone ran the length of the branch and BZP zones on the abaxial branch surface and captured the branch collar. The below collar zone was comprised of stem wood and lay below the collar and stem sections. The above stem and stem below zones were the upper stem compliments to the collar and below collar zones (respectively). All points within each zone were included in statistical calculations. 


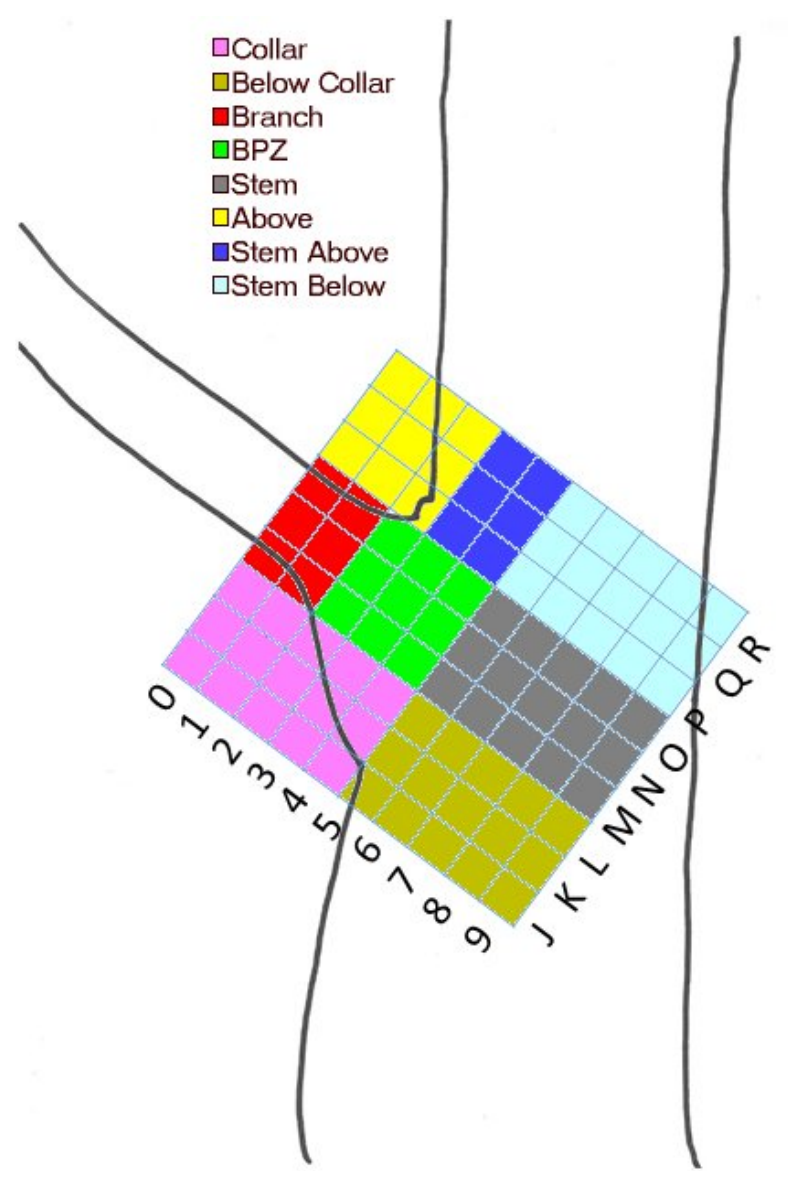

Figure 9: Diagram of stage point orientation for lateral branch study depicting 8 zones of interest. (Diagram courtesy of Greg Dahle)

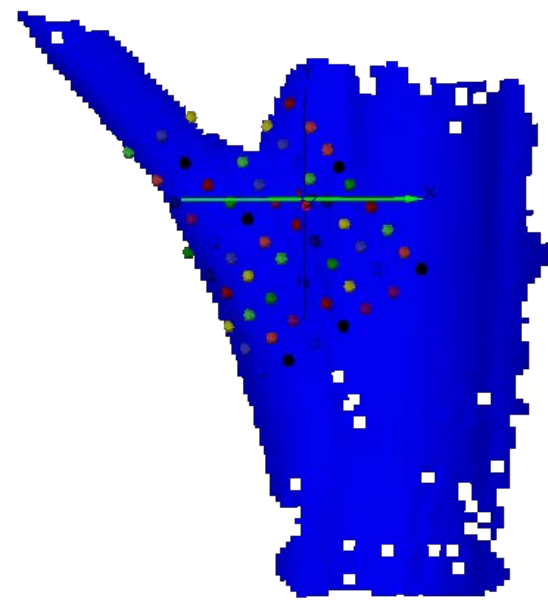

Figure 10: ARAMIS output depicting stage point orientation within software 
Time periods were distinguished and differences in strain were analyzed. Midpoint of test was defined by examining the map when load was first captured by the software and the stage of tissue failure. The midpoint stage between these two points was considered the midpoint of test. The failure time period was defined as the stage where crack initiation or tissue rupture was observed. Prefailure was defined as 1 second (3 stages) prior to crack initiation.

The proportion of strain type was calculated by taking each stage point in each zone and determining whether that point was in tension or compression at each time period. Negative values were classified as a compressive strain while positive values were classified as a tensile strain. Proportions were calculated by dividing the number of points of a given strain type (compressive or tensile) by the total number of stage points in that zone.

Attachment angle in ARAMIS was measured using 3 reference points. The first two reference points lie on the y plane of the strain map at the midpoint of the stem (figure 11). The lower point was established by following the midpoint of the stem (diameter) to the origin on the stem. This origin was estimated by examining branch morphology of the sample and by examining the strain map. The upper stage point on the stem was placed directly above the lower point in the y plane. The final stage point was set on the middle of the branch (diameter) immediately distal to the branch attachment. A shorter line segment traveling outward removes variability due to branch bending during testing, enabling us to examine the attachment angle rather than the branch angle. These three points formed the angle used to determine ARAMIS attachment and failure angle (figure 11 and figure 12). The software measures the angle throughout testing, ensuring that failure angle is derived from the same points as initial angle. The difference between these angles ( $\Delta$ Angle $=$ failure angle - initial angle) represents change in angle to failure ( $\triangle$ Angle ) 


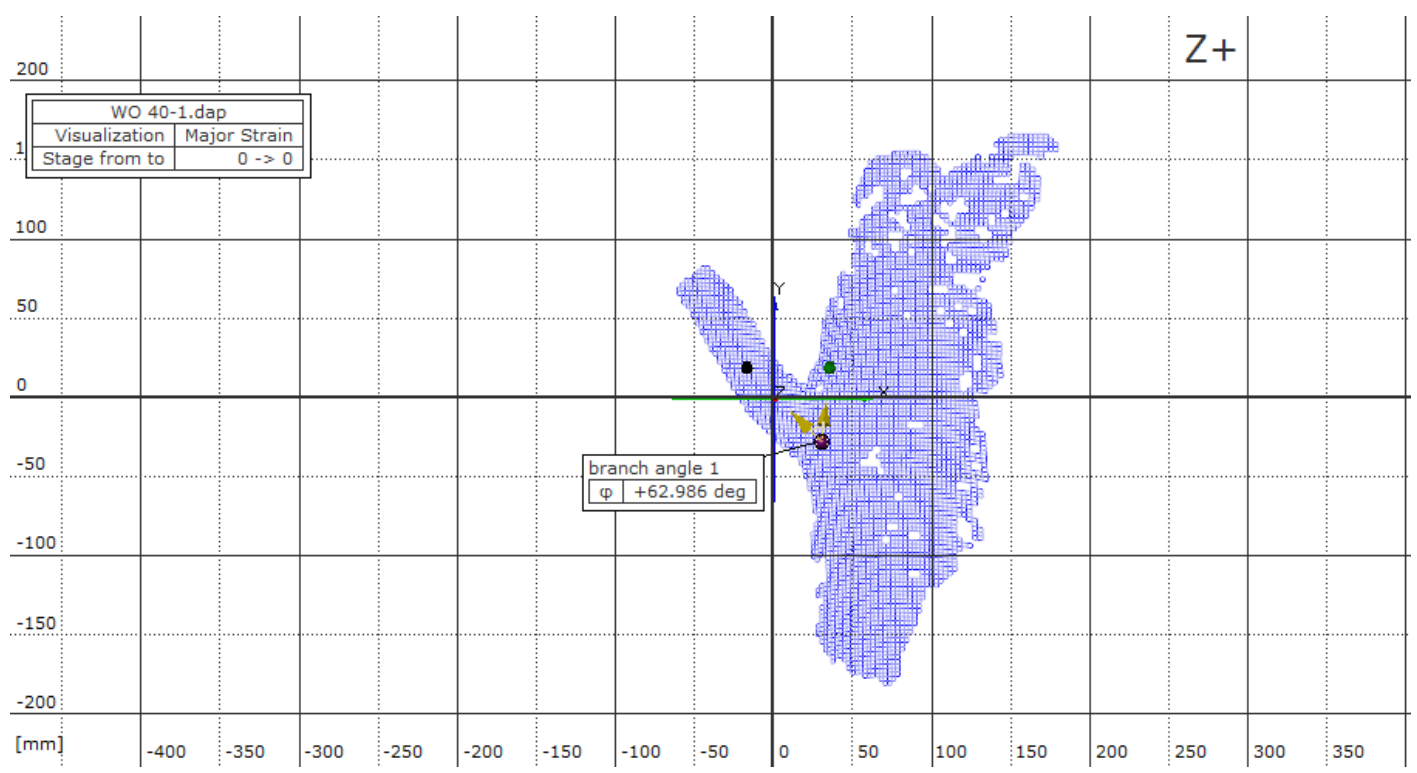

Figure 11: Example of attachment angle in ARAMIS software on lateral white oak branch prior to testing

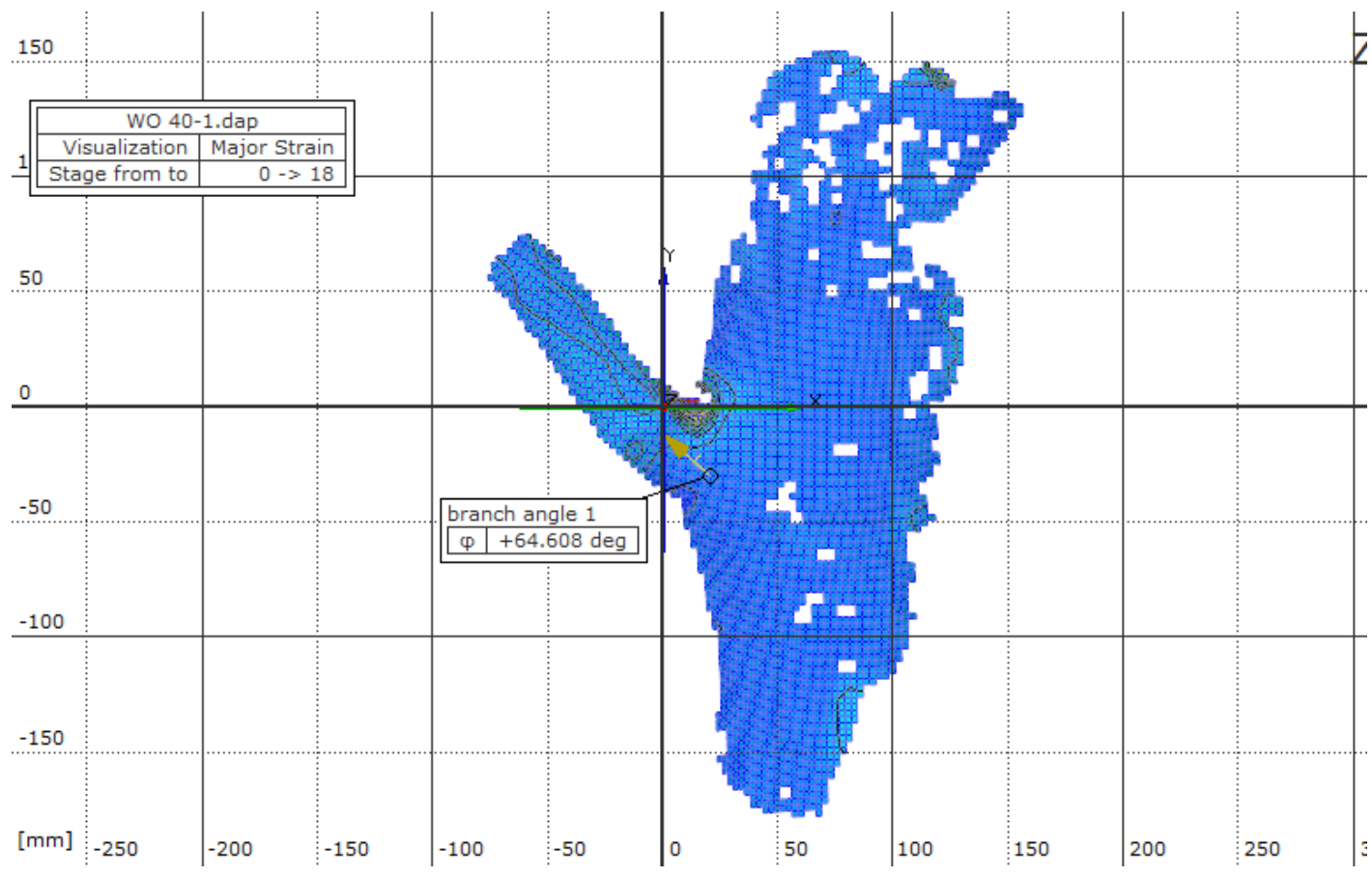

Figure 12: Example of attachment angle in ARAMIS software on lateral white oak branch at failure stage 
Statistical analysis was performed SAS version 9.4. Normality of variables was assessed with Proc Univariate and observing qq plots, histograms, and residual plots. $\log _{10}$ was used to correct for normality where necessary. Tukey HSD post hoc test was used to analyze interclass correlation of variables and alpha was set to 0.05

\section{Results}

A total of 24 samples were successfully tested in this experiment. Twelve samples were tested from six white oak (Quercus alba L.) trees. Tree DBH ranged from $14.73-21.34 \mathrm{~cm}$ and the average $\mathrm{DBH}$ was $16.68 \pm 0.97 \mathrm{~cm}$. The average height of trees was $12.9 \pm 0.52 \mathrm{~m}$, ranging from $12.19 \mathrm{~m}$ to $15.24 \mathrm{~m}$. Twelve chestnut oak (Quercus prinus L.) samples were collected from four trees. The average diameter was $21.27 \pm 1.46 \mathrm{~cm}$ (range: $17.78-24.89 \mathrm{~cm}$ ) and height was $15.24 \pm 0.88 \mathrm{~m}$ (range: $13.72-16.76 \mathrm{~m})$.

Branch diameters of white oak samples ranged from $3.30-6.60 \mathrm{~cm}(\overline{\mathrm{x}}=4.70 \pm 0.16 \mathrm{~cm})$. Above branch stem diameter ranged from $7.37-16.26 \mathrm{~cm}(\overline{\mathrm{x}}=10.57 \pm 0.65 \mathrm{~cm})$ and below branch stem diameter ranged from $7.62-16.26 \mathrm{~cm}(\overline{\mathrm{x}}=11.26 \pm 0.65 \mathrm{~cm})$. Mean aspect ratio was $0.43 \pm 0.02$ for tested white oak branches. The mean branch bark ridge length was $6.46 \pm 0.79$ $\mathrm{cm}$. The branch attachment angles of white oak branches ranged from $35.87^{\circ}-75.36^{\circ}(\overline{\mathrm{x}}=53.88$ $\pm 3.66^{\circ}$ ). The average failure angle was $56.70 \pm 3.56^{\circ}$ so the average $\Delta$ angle was $2.83 \pm 0.39^{\circ}$ for white oak branches. Branch diameters of chestnut oak samples ranged from $3.30-5.33 \mathrm{~cm}(\overline{\mathrm{x}}$ $=4.49 \pm 0.17 \mathrm{~cm})$. Above branch stem diameter ranged from $9.65-22.10 \mathrm{~cm}(\overline{\mathrm{x}}=14.86 \pm 1.06$ $\mathrm{cm})$ and below branch stem diameter ranged from $10.93-22.10 \mathrm{~cm}(\overline{\mathrm{x}}=15.66 \pm 1.03 \mathrm{~cm})$. The branch diameter and above branch stem diameter was used to calculate aspect ratio. Mean aspect ratio was $0.31 \pm 0.02$ for tested chestnut oak branches. The mean branch bark ridge length was $17.36 \pm 6.55 \mathrm{~cm}$. The branch attachment angles of chestnut oak branches ranged from $30.18^{\circ}-$ 
$84.46^{\circ}\left(\overline{\mathrm{x}}=46.56 \pm 4.76^{\circ}\right)$. The average failure angle was $49.67 \pm 5.35^{\circ}$ so the average $\Delta$ angle was $3.11 \pm 0.90^{\circ}$ for chestnut oak branches. Branch data is summarized in Table 1 below:

Table 1: White and chestnut oak branch sample attribute table. Means \pm standard error

\begin{tabular}{|l|c|c|}
\hline Attribute & \multicolumn{2}{|c|}{ Mean \pm SE } \\
\hline Species & White oak & Chestnut oak \\
\hline $\mathrm{n}($ sample) & 12 & 12 \\
\hline $\mathrm{n}($ tree$)$ & 6 & 4 \\
\hline $\mathrm{DBH}(\mathrm{cm})$ & $16.68 \pm 0.97$ & $21.27 \pm 1.46$ \\
\hline Height $(\mathrm{m})$ & $12.9 \pm 0.52$ & $15.24 \pm 0.88$ \\
\hline Branch diameter $(\mathrm{cm})$ & $4.70 \pm 0.16$ & $4.49 \pm 0.17$ \\
\hline Above branch stem diameter $(\mathrm{cm})$ & $10.57 \pm 0.65$ & $14.86 \pm 1.06$ \\
\hline Below branch stem diameter $(\mathrm{cm})$ & $11.26 \pm 0.65$ & $15.66 \pm 1.03$ \\
\hline Aspect ratio & $0.43 \pm 0.02$ & $0.31 \pm 0.02$ \\
\hline Branch bark ridge length $(\mathrm{cm})$ & $6.46 \pm 0.79$ & $17.36 \pm 6.55$ \\
\hline Attachment angle $\left(^{\circ}\right)$ & $53.88 \pm 3.66$ & $46.56 \pm 4.76$ \\
\hline Failure angle $\left(^{\circ}\right)$ & $56.70 \pm 3.56$ & $49.67 \pm 5.35$ \\
\hline$\Delta$ angle $\left(^{\circ}\right)$ & $2.83 \pm 0.39$ & $3.11 \pm 0.90$ \\
\hline
\end{tabular}

Strain contour maps for both major (tensile) and minor (compressive) strain were created and analyzed for each sample tested. Figures 13 and 14 give examples of contour maps for each species. 


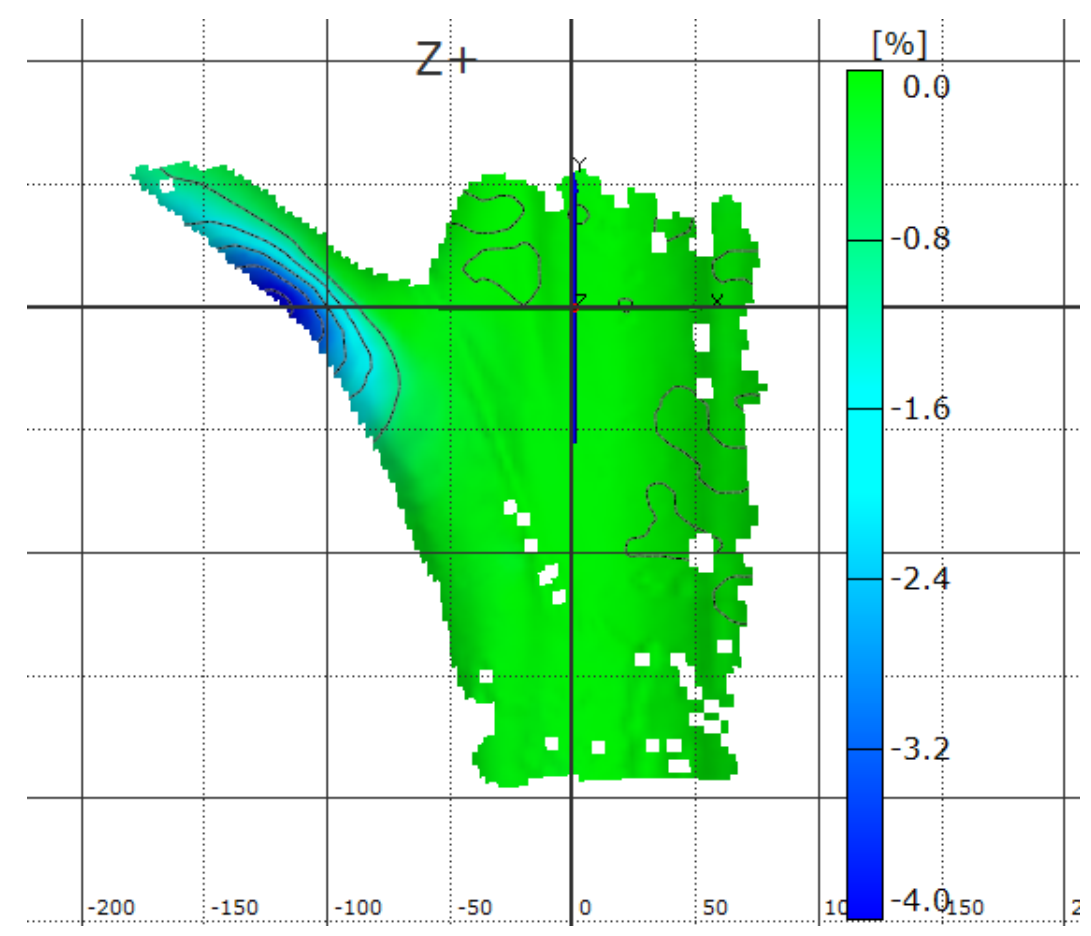

(a)

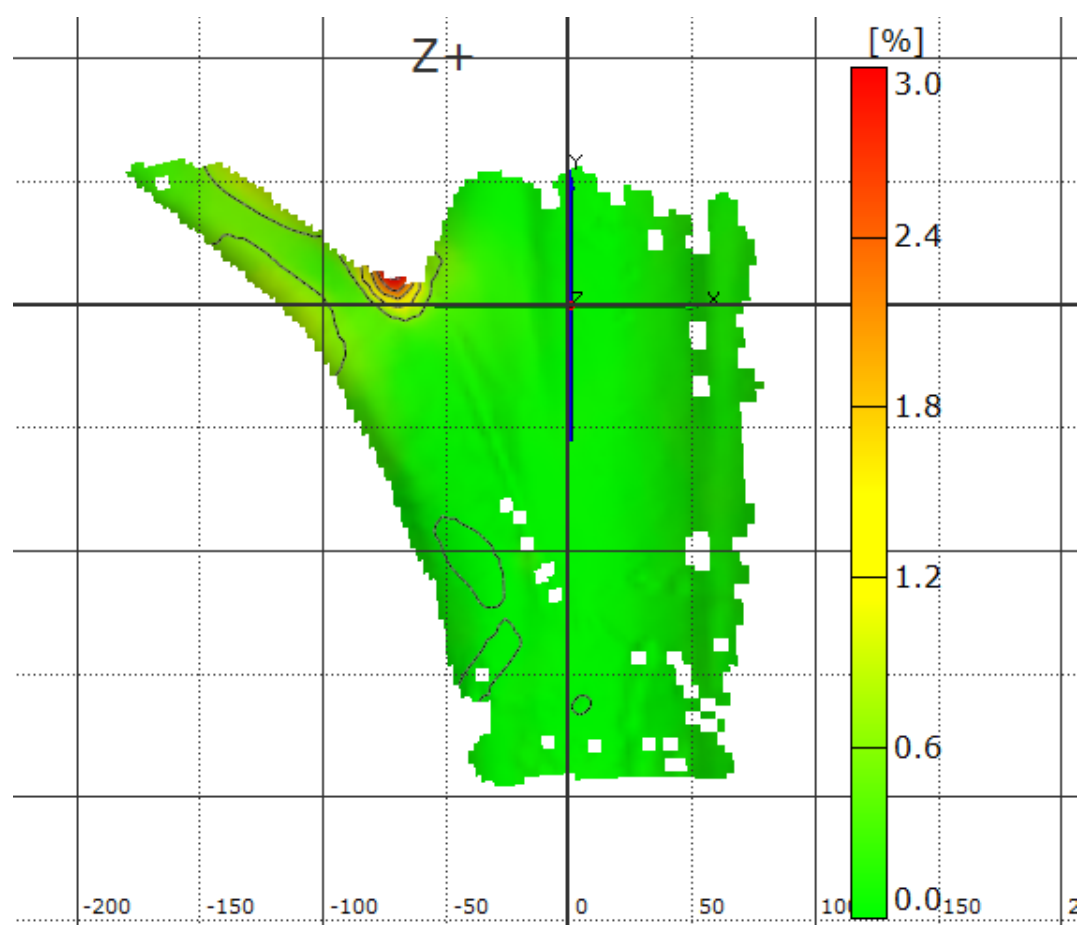

(b)

Figure 13: Minor (compressive) strain contour map (a) and major (tensile) strain contour map (b) at failure stage for tested chestnut oak branch. 


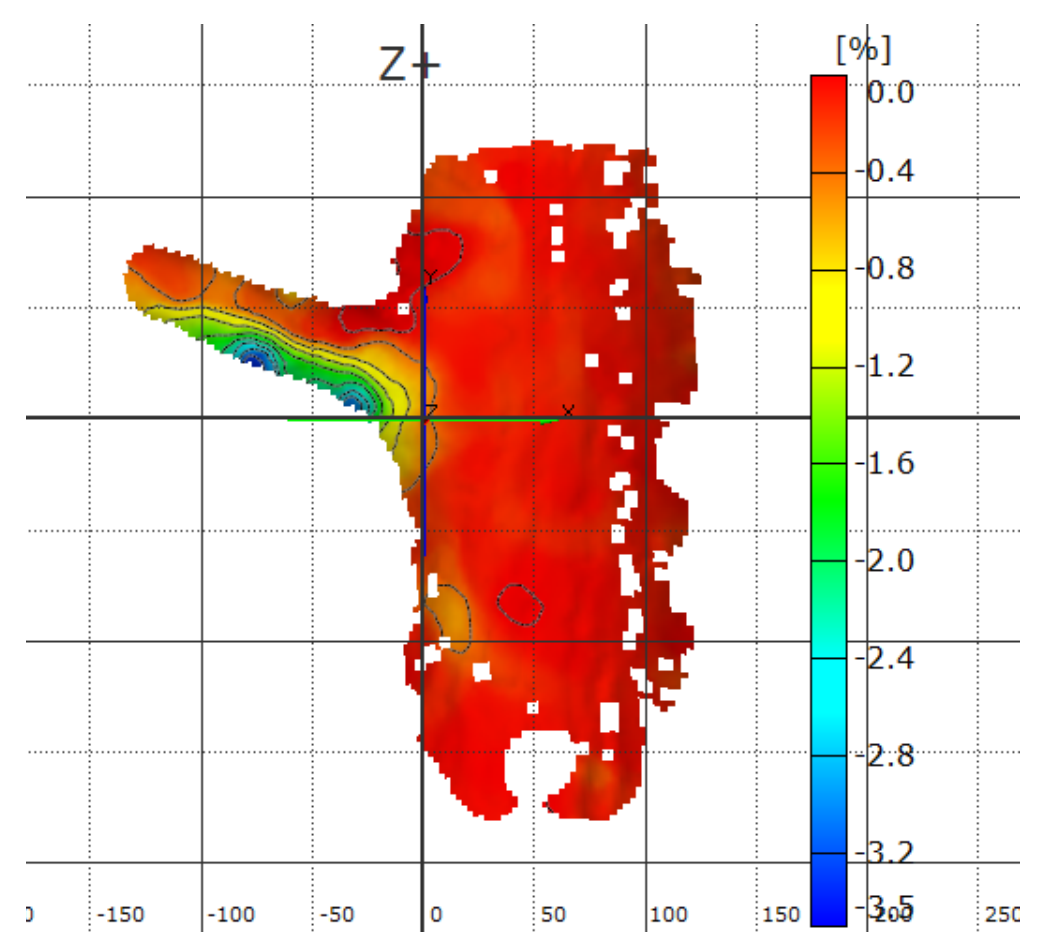

(a)

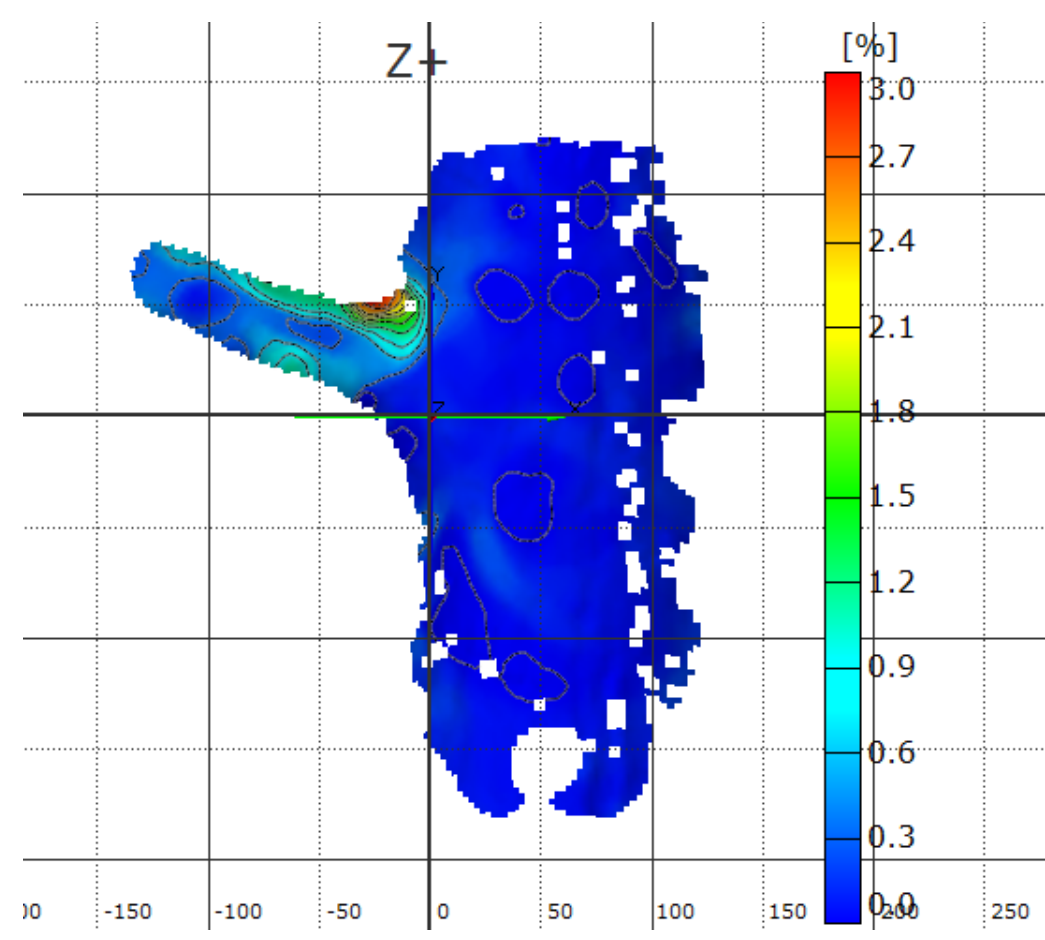

(b)

Figure 14: Minor (compressive) strain contour map (a) and major (tensile) strain contour map (b) at failure stage for tested white oak branch. 
Strain was found to increase during testing until failure occurred (Table 2). A relationship was not identified $(\mathrm{p}=0.1535, \mathrm{n}=32)$ between $\Delta$ angle and attachment angle of all branches. A weak relationship was found between failure angle and $\Delta$ angle $\left(R^{2}=0.1528, p=0.0369, n=\right.$ 23). A strong relationship exists between attachment angle and failure angle $\left(\mathrm{R}^{2}=0.9796, \mathrm{p}=<\right.$ $0.0001, \mathrm{n}=23)$. 
Table 2: Mean maximum strain by zone at each time period. Means with the same letter were not found to differ using a Tukey HSD.

\begin{tabular}{|c|c|c|c|c|c|}
\hline \multirow[t]{2}{*}{ Zone } & \multirow[t]{2}{*}{ Time Period } & \multicolumn{2}{|c|}{ White oak } & \multicolumn{2}{|c|}{ Chestnut oak } \\
\hline & & $\begin{array}{l}\text { abs max } \\
\text { strain }\end{array}$ & $\mathrm{n}$ & $\begin{array}{l}\text { abs max } \\
\text { strain }\end{array}$ & $\mathrm{n}$ \\
\hline \multirow{4}{*}{ Collar } & Midpoint & 0.2427 (b) & 10 & 0.3248 (b) & 12 \\
\hline & Pre failure & $0.4048(\mathrm{ab})$ & 10 & 0.5222 (b) & 11 \\
\hline & failure & 0.5212 (a) & 10 & 0.9987 (a) & 12 \\
\hline & p-value & & 0.0198 & & $<0.0001$ \\
\hline \multirow{4}{*}{$\begin{array}{l}\text { Below } \\
\text { Collar }\end{array}$} & Midpoint & 0.1112 (b) & 88 & 0.0740 (b) & 85 \\
\hline & Pre failure & $0.1610(\mathrm{ab})$ & 88 & 0.0965 (ab) & 83 \\
\hline & failure & 0.1999 (a) & 88 & 0.1245 (a) & 78 \\
\hline & p-value & & 0.0016 & & 0.002 \\
\hline \multirow{4}{*}{ Branch } & Midpoint & 0.4218 (c) & 65 & 0.2646 (c) & 61 \\
\hline & Pre failure & 0.6682 (b) & 69 & 0.7145 (b) & 60 \\
\hline & failure & 1.0792 (a) & 70 & $1.2840(\mathrm{a})$ & 52 \\
\hline & p-value & & $<0.0001$ & & $<0.0001$ \\
\hline \multirow{4}{*}{ BPZ } & Midpoint & 0.2252 (c) & 105 & 0.1359 (c) & 92 \\
\hline & Pre failure & 0.3823 (b) & 106 & 0.2678 (b) & 92 \\
\hline & failure & 0.5878 (a) & 105 & 0.3963 (a) & 84 \\
\hline & p-value & & $<0.0001$ & & $<0.0001$ \\
\hline \multirow{4}{*}{ Stem } & Midpoint & 0.0893 (b) & 163 & 0.0478 (b) & 155 \\
\hline & Pre failure & 0.1194 (a) & 165 & 0.0663 (a) & 155 \\
\hline & failure & 0.1433 (a) & 168 & 0.0766 (a) & 140 \\
\hline & p-value & & $<0.0001$ & & $<0.0001$ \\
\hline \multirow{4}{*}{ Above } & Midpoint & 0.1788 (a) & 49 & 0.1445 (b) & 37 \\
\hline & Pre failure & 0.2177 (a) & 49 & $0.2176(\mathrm{ab})$ & 38 \\
\hline & failure & 0.2663 (a) & 48 & 0.2790 (a) & 35 \\
\hline & p-value & & 0.2288 & & 0.0235 \\
\hline \multirow{4}{*}{$\begin{array}{l}\text { Stem } \\
\text { Above }\end{array}$} & Midpoint & 0.0821 (b) & 80 & 0.0525 (b) & 85 \\
\hline & Pre failure & $0.0967(\mathrm{ab})$ & 79 & $0.0659(\mathrm{ab})$ & 85 \\
\hline & failure & 0.1249 (a) & 80 & 0.0812 (a) & 76 \\
\hline & p-value & & 0.0136 & & 0.0078 \\
\hline \multirow{4}{*}{$\begin{array}{l}\text { Stem } \\
\text { Below }\end{array}$} & Midpoint & 0.1167 (a) & 46 & 0.0628 (b) & 39 \\
\hline & Pre failure & $0.1521(\mathrm{a})$ & 48 & $0.1078(\mathrm{ab})$ & 39 \\
\hline & failure & 0.1748 (a) & 48 & 0.0628 (a) & 35 \\
\hline & p-value & & 0.1602 & & 0.0129 \\
\hline
\end{tabular}


Mean maximum strain by zone at each time period of interest was also calculated, and differences were determined using a Tukey HSD. Results are shown in Tables 3, 4 and 5.

Proportion of strain in each zone reflects the amount of strain points that were in either tension or compression over the total number of strain points in that zone at a given time period (Table 6).

Table 3: Mean maximum strain by zone at midpoint of test. Means with the same letter were not found to differ using a Tukey HSD.

\begin{tabular}{|c|c|c|c|c|}
\hline \multicolumn{5}{|c|}{ Time Period = Midpoint } \\
\hline Zone & \multicolumn{2}{|l|}{ White oak } & \multicolumn{2}{|l|}{ Chestnut oak } \\
\hline & abs max strain & $\mathrm{n}$ & abs max strain & $\mathrm{n}$ \\
\hline Collar & $0.2427(\mathrm{ab})$ & 10 & $0.3248(\mathrm{a})$ & 12 \\
\hline Below Collar & 0.1112 (de) & 88 & 0.0740 (c) & 85 \\
\hline Branch & 0.4218 (a) & 65 & 0.2646 (a) & 61 \\
\hline BPZ & 0.2252 (abc) & 105 & 0.1359 (b) & 92 \\
\hline Stem & $0.0893(\mathrm{e})$ & 163 & 0.0478 (c) & 155 \\
\hline Above & 0.1788 (bcd) & 49 & 0.1445 (b) & 37 \\
\hline Stem Above & $0.0821(\mathrm{e})$ & 80 & 0.0525 (c) & 85 \\
\hline Stem Below & 0.1167 (de) & 46 & 0.0628 (c) & 39 \\
\hline p-value & \multicolumn{2}{|c|}{$<0.0001$} & \multicolumn{2}{|c|}{$<0.0001$} \\
\hline
\end{tabular}

Table 4: Mean maximum strain by zone at prefailure. Means with the same letter were not found to differ using a Tukey HSD.

\begin{tabular}{|l|r|r|r|r|}
\hline Time Period $=$ Prefailure \\
\hline Zone & \multicolumn{1}{l|}{ White oak } & \multicolumn{2}{l|}{ Chestnut oak } \\
\hline & abs max strain & \multicolumn{1}{c|}{$\mathrm{n}$} & abs max strain & \multicolumn{1}{c|}{$\mathrm{n}$} \\
\hline Collar & $0.4048(\mathrm{a})$ & 10 & $0.5221(\mathrm{a})$ & 11 \\
\hline Below Collar & $0.161(\mathrm{dc})$ & 88 & $0.0972(\mathrm{c})$ & 83 \\
\hline Branch & $0.6682(\mathrm{a})$ & 69 & $0.7145(\mathrm{a})$ & 60 \\
\hline BPZ & $0.3823(\mathrm{ab})$ & 106 & $0.2678(\mathrm{~b})$ & 92 \\
\hline Stem & $0.1194(\mathrm{~cd})$ & 165 & $0.0663(\mathrm{c})$ & 155 \\
\hline Above & $0.2177(\mathrm{bc})$ & 49 & $0.2176(\mathrm{~b})$ & 38 \\
\hline Stem Above & $0.0967(\mathrm{~d})$ & 79 & $0.0659(\mathrm{c})$ & 85 \\
\hline Stem Below & $0.1521(\mathrm{~cd})$ & 48 & $0.1078(\mathrm{c})$ & 39 \\
\hline p-value & $<0.0001$ & & $<0.0001$ \\
\hline
\end{tabular}


Table 5: Mean maximum strain by zone at failure. Means with the same letter were not found to differ using a Tukey HSD.

\begin{tabular}{|c|c|c|c|c|}
\hline \multicolumn{5}{|c|}{ Time Period $=$ Failure } \\
\hline \multirow[t]{2}{*}{ Zone } & \multicolumn{2}{|l|}{ White oak } & \multicolumn{2}{|l|}{ Chestnut oak } \\
\hline & abs max strain & $\mathrm{n}$ & abs max strain & $\mathrm{n}$ \\
\hline Collar & 0.5212 (b) & 10 & $0.9986(\mathrm{a})$ & 12 \\
\hline Below Collar & 0.1999 (cd) & 88 & $0.1245(\mathrm{c})$ & 78 \\
\hline Branch & $1.0792(\mathrm{a})$ & 70 & $1.2841(\mathrm{a})$ & 52 \\
\hline $\mathrm{BPZ}$ & $0.5878(\mathrm{ab})$ & 105 & $0.3963(\mathrm{~b})$ & 84 \\
\hline Stem & $0.1433(\mathrm{~d})$ & 168 & $0.0766(\mathrm{c})$ & 140 \\
\hline Above & 0.2662 (c) & 48 & 0.2790 (b) & 35 \\
\hline Stem Above & $0.1249(\mathrm{~d})$ & 80 & $0.0812(\mathrm{c})$ & 76 \\
\hline Stem Below & $0.1748(\mathrm{~cd})$ & 48 & $0.1246(\mathrm{c})$ & 35 \\
\hline p-value & \multicolumn{2}{|c|}{$<0.0001$} & \multicolumn{2}{|c|}{$<0.0001$} \\
\hline
\end{tabular}

Table 6: Proportion of Strain type by Zone at each Time Period

\begin{tabular}{|c|c|c|c|c|}
\hline Zone & Time Period & $\%$ of Strain & Strain Type & $\mathrm{n}$ \\
\hline \multirow{3}{*}{ Above } & Midpoint & $83.7 \%$ & Tension & \multirow{3}{*}{362} \\
\hline & Prefailure & $79.3 \%$ & Tension & \\
\hline & Failure & $85.5 \%$ & Tension & \\
\hline \multirow{3}{*}{ Above Stem } & Midpoint & $78.8 \%$ & Tension & \multirow{3}{*}{361} \\
\hline & Prefailure & $87.4 \%$ & Tension & \\
\hline & Failure & $83.1 \%$ & Tension & \\
\hline \multirow{3}{*}{ Stem Above } & Midpoint & $63.0 \%$ & Tension & \multirow{3}{*}{696} \\
\hline & Prefailure & $71.3 \%$ & Tension & \\
\hline & Failure & $74.4 \%$ & Tension & \\
\hline \multirow{3}{*}{$\begin{array}{l}\text { Below } \\
\text { Collar }\end{array}$} & Midpoint & $72.3 \%$ & Compression & \multirow{3}{*}{716} \\
\hline & Prefailure & $81.3 \%$ & Compression & \\
\hline & Failure & $84.9 \%$ & Compression & \\
\hline \multirow{3}{*}{ Branch } & Midpoint & $60.3 \%$ & Compression & \multirow{3}{*}{524} \\
\hline & Prefailure & $62.8 \%$ & Compression & \\
\hline & Failure & $65.6 \%$ & Compression & \\
\hline \multirow{3}{*}{$\mathrm{BPZ}$} & Midpoint & $66.0 \%$ & Compression & \multirow{3}{*}{824} \\
\hline & Prefailure & $66.2 \%$ & Compression & \\
\hline & Failure & $67.7 \%$ & Compression & \\
\hline \multirow{3}{*}{ Collar } & Midpoint & $95.5 \%$ & Compression & \multirow{3}{*}{97} \\
\hline & Prefailure & $95.2 \%$ & Compression & \\
\hline & Failure & $95.5 \%$ & Compression & \\
\hline \multirow{3}{*}{ Stem } & Midpoint & $60.4 \%$ & Compression & \multirow{3}{*}{1339} \\
\hline & Prefailure & $65.0 \%$ & Compression & \\
\hline & Failure & $67.2 \%$ & Compression & \\
\hline
\end{tabular}




\section{Discussion}

The highest strain was encountered in the branch, collar, and branch protection zone (BPZ) for both species, as they were categorized in the highest Tukey groupings. High strain was also discovered in the "Above” zone throughout the static loading exercise. Low strain was found in the stem tissue away from the branch. It seems lateral branches concentrate strain at branch and collar, and very little strain enters the stem during loading. The collar and branch protection zone appear to compartmentalize strain, and prevent it from entering the main stem and potentially damaging to the surrounding stem wood. It appears this area limits the spread of strain during loading, just as it limits the spread of decay after branch shedding or breakage. It is likely that the complex anatomy and cross laminated grain pattern described by Shigo (1985), along with increased density and reduced $\mathrm{S}_{2}$ microfibril angle in the region (Lichtenegger et al. 1999; Jungnikl et al. 2009; Dahle and Grabosky 2009; Slater and Ennos 2013; Slater et al. 2014; Özden et al. 2017) have evolved to aid the tree in responding to the increased strain found during static loading.

By examining the “Above” and "Stem Below” Zone of white oak, we see that no significant change in pattern of strain distribution occurred at the midpoint of test, prefailure, or failure. This indicates that there was very little change in the pattern of strain in these regions as the applied load increased to the point of failure.

Similar results were found for chestnut oak, but the groupings did change slightly as test progressed. In the "Branch” and “BPZ” Zones, strain was significantly different at each stage of test for chestnut oak. This indicates tissue response in these regions as a result of the static load being applied. In both species examined, these two zones were the only ones that were in three separate groupings. It would appear these lateral branch attachments confine load in the branch 
and its attachment, rather than allowing strain to propagate into the surrounding stem tissue. The branch and BPZ showed the highest maximum strain at failure while the stem zones exhibited the least in both species, which lends further evidence to this claim.

The white oak branches experienced strain that was about twice as high $(\overline{\mathrm{x}}=1.08 \%)$ as the branch protection zone $(\overline{\mathrm{x}}=0.59 \%)$ and about four times as high as surrounding stem wood $(\overline{\mathrm{x}}=0.23 \%)$. This seems to indicate that branch stiffness restricts strain concentration to the branch, which is in agreement with Jungnikl et al. (2009).

Most failures initiated on the upper side of the branch, at the junction, based on qualitative examination of videos. We cannot say with certainty that tissue failure occurred with bark rupture, but by examining samples after testing, this appears to be the case. In most cases, the underside of the branch and surrounding tissue was still intact after the ball and socket failure. This does not account for potential tissue damage that may have occurred unseen to the naked eye. It is important to note that the experimental design was such that this was the intended outcome. The short pull arm and bracket design helped ensure that the failure occurred in this region. Dahle et al. (2006a) suggests that nearly 50\% of the time, branch failures occur outside of the attachment zone. It remains unclear if strain distribution and failure patterns differ as the load is concentrated further out from the main stem.

This lends evidence to the hypothesis that these failures occurred in tension, as crack initiation likely began on the upper side of the stem. It is unclear if crack initiation of bark and stem tissue occurred differently, but Dahle [in review] suggests that bark is an appropriate surrogate for wood when using digital image correlation. It is possible that failure occurred beneath the bark surface elsewhere in the area of interest prior to observed failure, such as a 
compressive failure on the underside. Yet based on a visual examination of the sample we do not believe this to be the case.

It appears that the branch collar described by Shigo (1985) helps add mechanical strength to the underside of the branch; giving resistance to compressive failure. Since wood is weaker in compression (Kretschmann 2010; Peltola 2006) it appears that the branch collar is anatomically a well-engineered to address this issue. The branch reinforces this area so much that failure is moved to the upper side of the branch; as was observed in these experiments.

\section{Implications}

This work lends insight into how branches are attached to trees, and how the complex anatomy in the area of interest aids the tree in mechanical support and branch retention. It helps us better understand how trees carry static loads such as snow, ice, or a climber. While static load trials such as these are certainly not perfect replications of natural loading, they provide meaningful information to researchers trying to understand how loading is transferred or dampened in the branch connection zone. A picture is beginning to form in that the annual formation of tissue in the branch connection zone provides mechanical strength, constricts hydraulic movement (Shigo 1985; Eisner et al. 2002; Slater and Harbonson 2010) and limits the spread of decay (Shigo 1985; Gilman \& Grabosky 2007) if a branch is pruned or through natural sheading processes. Pruning should be aimed at maintaining a low aspect ratio to provide better mechanical strength of branches and defense against decay (Shigo 1985; Gilman \& Grabosky 2007). 


\section{Chapter 3:}

\section{Variations in Strain Propagation at Different Aspect Ratios in Red Maple (Acer Rubrum L.)}

Codominant stems arise from simultaneous vegetative development of axillary buds at the branch apex (Gilman 2003; Smith 2012). They can also arise from simultaneous development of collateral buds, likely after branch breakage at the apex (Core \& Ammons 1958). This may be the reason oppositely arranged species (Acer, Aesculus, Cornus, Fraxinus, Viburnum) seem to be more prone to codominant branching. Open growth habit and poor training of nursery stock also contribute to codominant branching (Gilman 2002), making this an important issue for arborists and urban forest managers.

Aspect ratio is the ratio of branch diameter over stem diameter. It is the primary method to quantify codominance by arborists and foresters. Aspect ratio has shown to be an effective predictor of failure stress in static loading trials (Gilman 2003; Kane 2007; Kane and Clouston 2008; Kane et al. 2008). An inverse relationship between attachment strength and aspect ratio has been discovered in red maple (Acer rubrum L.) (Gilman 2003; Smiley 2003). Codominant branch unions are weaker than lateral branch unions (MacDaniels 1923 \& 1932; Miller 1959; Smiley 2003; Gilman 2003). When included bark is present, the union becomes even weaker (Smiley 2003) due to the inherent structural defect and lack of cross lamination of grain between branch and stem wood.

Recent research suggests that codominant unions are anatomically and therefore structurally different than lateral branch unions. Slater and Harbison (2010) propose a "clever clip" model of branch attachment for codominant unions. This "clip" consists of a small spur of branch tissue that extends upwards into the stem and allows mechanical support of the branch 
without greatly restricting conduction of water and solutes by the branch (Slater 2010; Slater et al.2014). Since there are anatomical differences between the lateral and codominant attachment, one would expect the strength and material properties to vary between the two.

It remains unclear when a branch becomes codominant from a mechanical perspective. Eisner et al. (2002) suggests that an aspect ratio of $75 \%$ or above indicates codominance. This experiment involved dying and dissecting unions to examine them from a hydraulic segmentation perspective however.

In this chapter, strain propagation is examined in red maple at varying aspect ratio. The goal was to determine when a branch becomes codominant from a mechanical perspective. A more in depth and thorough experiment examining differences in strain patterns at different aspect ratios was performed. Load was measured and strain was calculated and compared at different aspect ratios. Branch failures were qualitatively classified and compared.

\section{Methodology}

Branch samples were collected from the WVU Research Forest located in Monongalia County, West Virginia, U.S. in West Block Compartment II and III of the West Virginia University Forest. The samples were collected from the top of trees along 1.5 miles of Goodspeed Road. The first set of 15 samples were collected following a harvest operation. The rest were felled for the purpose of this experiment. All samples were collected the same day the trees were felled. Branches with aspect ratios (branch diameter / stem diameter) of 0.5 and higher were targeted. Branch diameter was taken distal to the branch collar and stem diameter was taken above the fork. Samples with included bark and structural damage from felling were excluded. 
Samples with knots or visible decay were also avoided whenever possible. All samples were live and in green condition. All samples were red maple (Acer rubrum L.). A total of 42 branches were collected from 33 trees. Most samples came from individual trees, but four pairs of samples came from the same tree. Thirty-four of the samples collected were pulled successfully to failure: six samples could not be pulled to failure by the winch, one sample produced an unusable strain map, and one sample had the rope slip during testing. Two additional samples were omitted in post processing when it was discovered the larger diameter branch was pulled mistakenly.

Field measurements of the branch, above branch stem and below branch stem diameters were obtained from two perpendicular diameter measurements using a caliper $( \pm .0254 \mathrm{~cm})$. Branch length was recorded to the nearest $\mathrm{cm}$ using a $50 \mathrm{~m}$ tape (Keson, Aurora, IL) The larger diameter fork above of the union was considered the stem with the smaller diameter fork the lateral branch. In the event the forks were the same diameter, the shorter of the two forks was considered the branch. Attachment angle was measured using a protractor. Attachment angle was based off of the midpoint of the branch and the midpoint of the stem at the point of attachment. The point of attachment was established visually by examining the branch connection and following it to the branches origin (Figure 15).

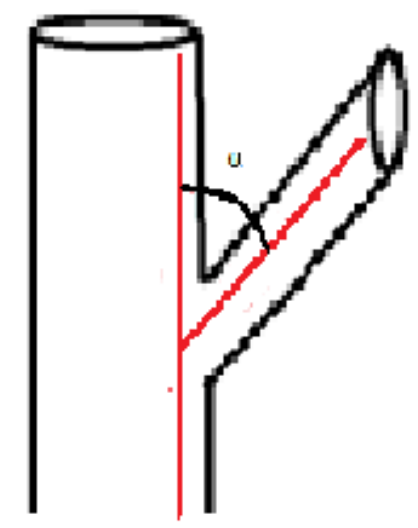

Figure 15: Diagram of field measured attachment angle 
This process was also done digitally in the ARAMIS software (figures $16 \& 17$ ). Angle measurement in ARAMIS enabled the angle to be measured five times per second throughout the test. The $\Delta$ angle was calculated using the same protocol established in chapter 2. Rope angle was also measured in ARAMIS for use in bending moment calculation. This was achieved by adding three angle points on the distal portion of the branch. Two points followed the midpoint of the branch and the third matched the angle of the taught rope during testing (figure 16)

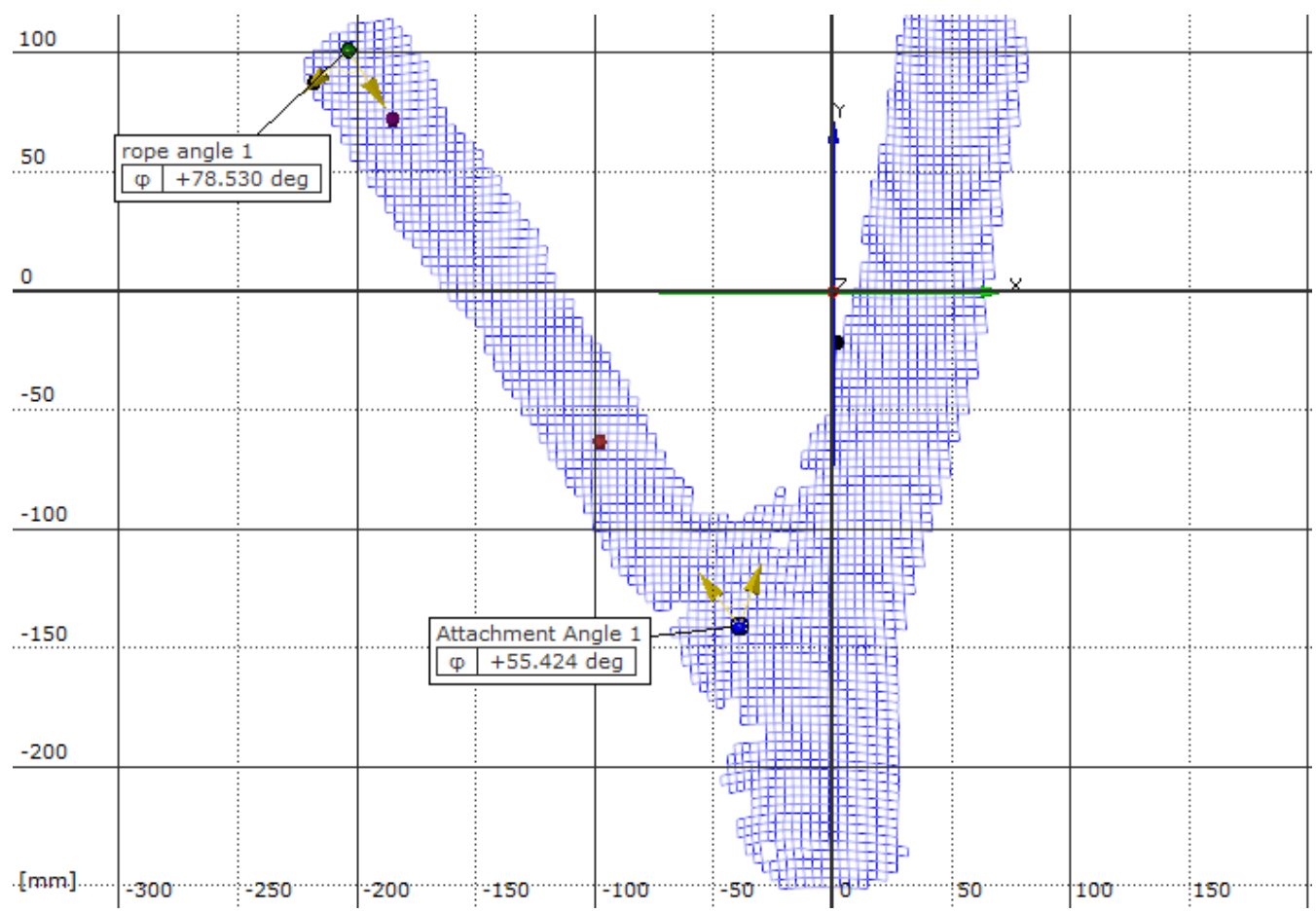

Figure 16: Example of attachment angle and rope angle in ARAMIS software on codominant red maple branch prior to testing. 


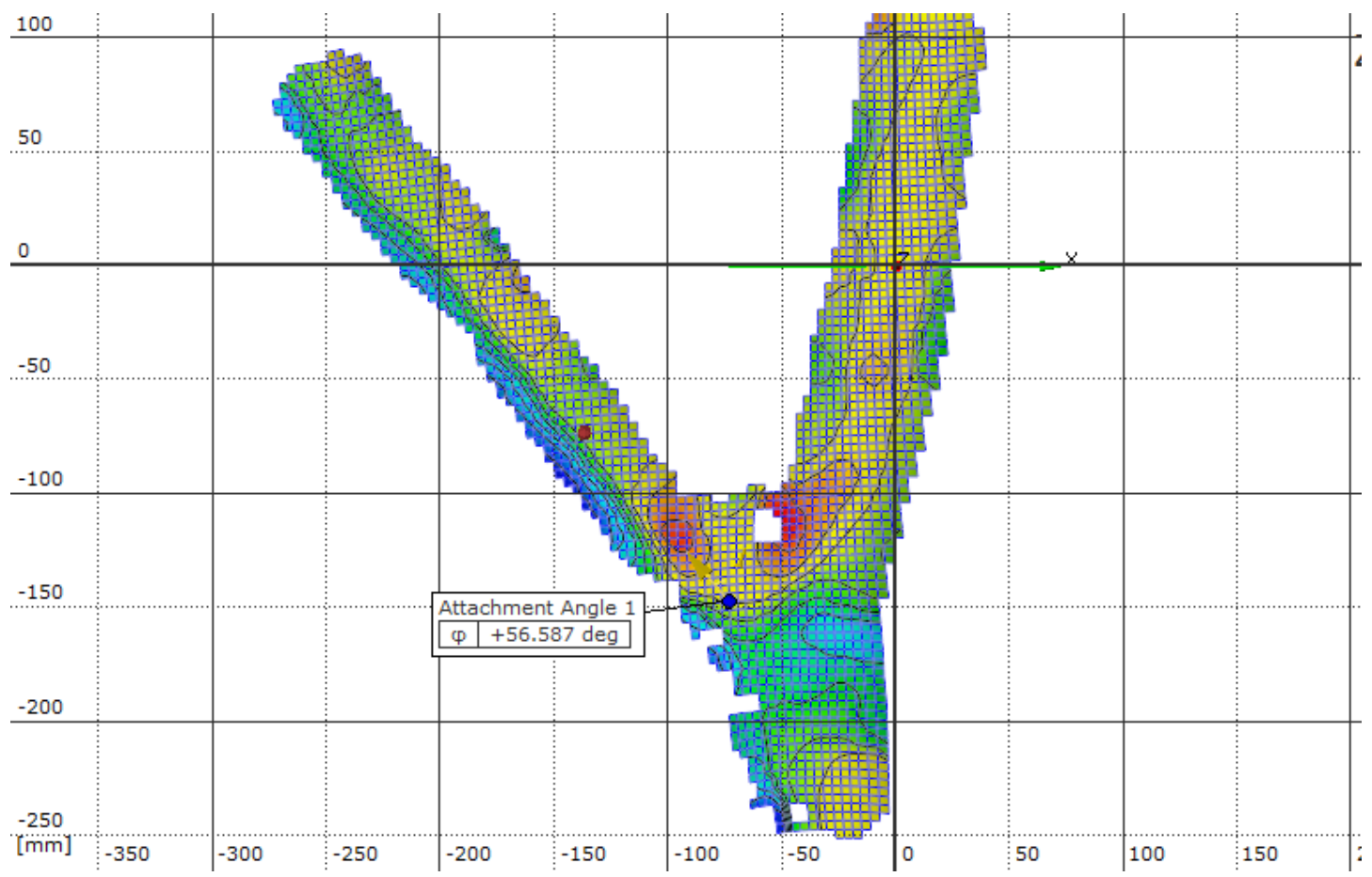

Figure 17: Example of failure angle in ARAMIS software on codominant red maple stem at failure stage

Date and time of sample collection as well as any notes of possible defect were recorded in the field. Samples were taken to WVU Evansdale Campus and the cut ends were treated with Packard wood sealant (Packard, Tryon, NC) to minimize moisture loss prior to testing. To prepare the samples for the static pull test, a coating of white paint (Rustoleum flat finish) followed by a black speckling (Rustoleum flat finish) was applied. The target size for the speckle was 5-10 pixels when captured by the digital image correlation system (Figure 18). 


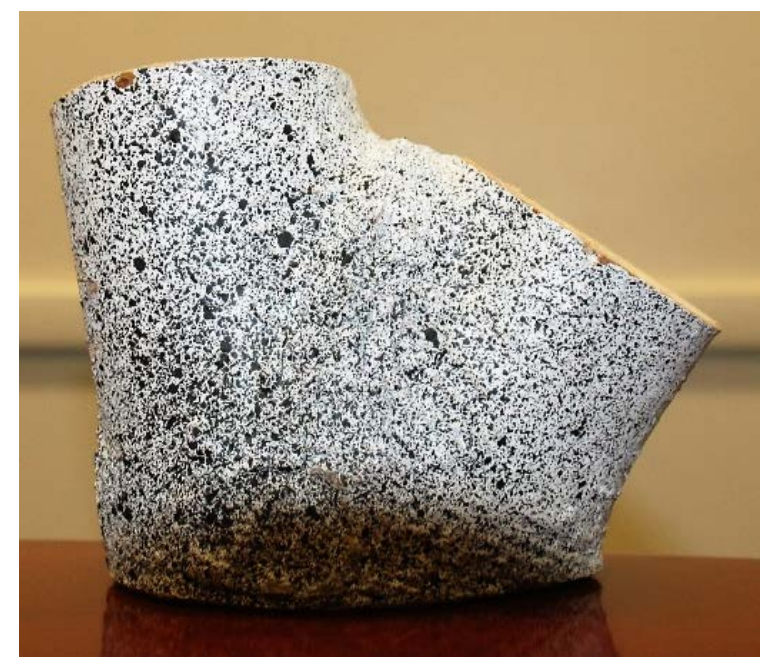

Figure 18: Example of stochastic pattern on sample branch

The DIC system was calibrated using the provided ISO-9001 certified calibration panel (350 x $280 \mathrm{~mm}^{2}$ ) using the same protocol as found in chapter two. A full calibration was conducted at the beginning of sampling and a quick calibration was used if when necessary to maintain an intersect deviation of less than 0.30 (GOM 2007). The working distance was set at $130 \mathrm{~cm}$.

Samples were placed in a custom fabricated steel bracket and secured with ratchet straps. A car battery powered 2000 lb. winch (Reese, Plymouth MI) was employed to pull branches. The pull was performed with a running bowline around the branch on a $19 \mathrm{~mm}$ diameter section of bull rope. On the opposite end of the rope, a bowline on a bight was tied which affixed a steel carabineer attached to an Omega model 1028 907Kg (2000lbs.) load cell (Omegadyne Inc. Sunbury $\mathrm{OH}$ ) on an eye bolt, which was attached to the steel winch cable. This system put a 15.6 $\mathrm{N}$ hanging load on samples prior to testing. Figure 19 depicts a diagram of the system. 


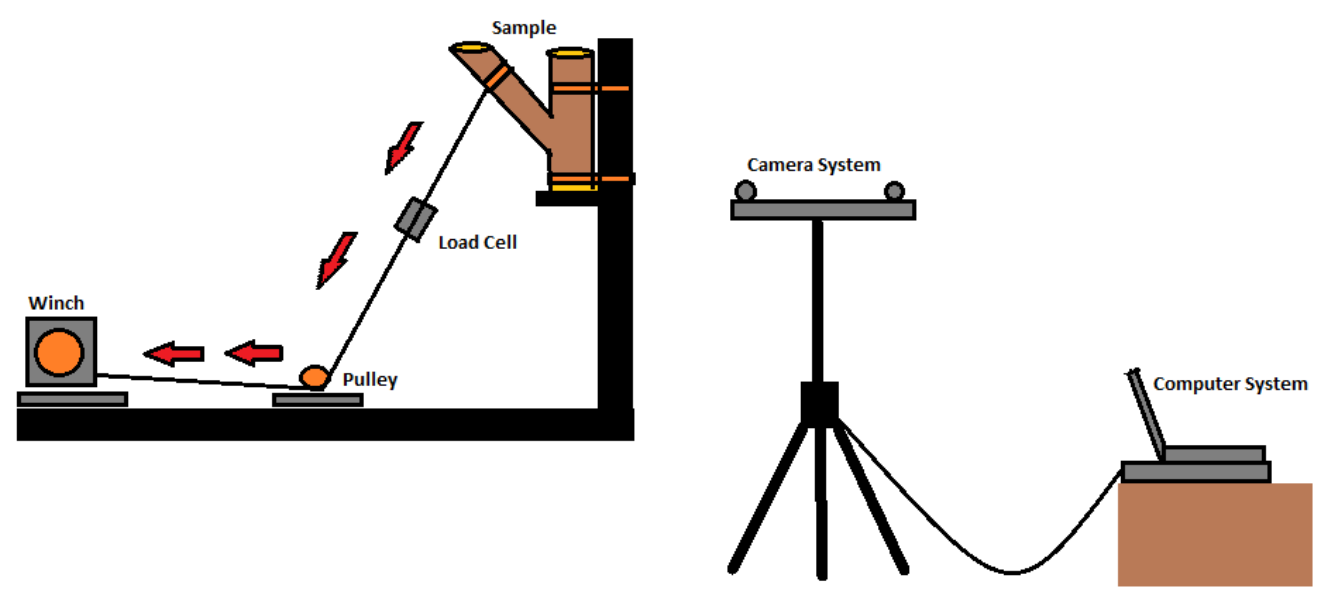

Figure 19: Branch pull system diagram. Red arrows indicate direction of winch pull

Minor camera adjustments such as position, angle, and shutter time were made to get the best strain map possible. Lighting came largely from overhead fluorescent tube lighting in the woodshop. Some natural light also contributed from an overhead door at the far end of the wood shop. External stage type lights were available, but rarely employed as they produced reflectance on the painted section of the samples. Two reference photos were acquired in the ARAMIS system to develop a preliminary strain map. During testing ARAMIS collected 5 frames per second.

Branches were pulled to failure and the maximum load was recorded by a second observer. The load cell readout box was kept in view of the camera for verification purposes. However, due to the low frame rate and the readout box being outside the region of focus, it was very difficult to interpret the readout box from ARAMIS data.

The pull (moment) arm length was marked and measured using a measuring tape. The pull arm measurement was established as the distance of the midpoint of the rope to the site of the initial failure on the branch. The failures were recorded as one of four failure types using a 
system adapted from Kane et al. (2008). The failure types included were: ball and socket, flat, imbedded branch, or buckling. (figure 20). Ball and socket failures (A) are characterized by excision of stem tissue during branch failure resulting in a concave shape on the stem surface. The branch side of the broken surface contains the excised tissue and has a characteristic "ball" shape as a result. A flat failure (B) is characterized by a cleavage straight down the branch union leaving nearly equal tissue on the branch and stem. The shape of the broken surface is flat and broad. It has no concave portion on the stem side. An imbedded branch failure (C) looks similar to the flat failure but a smaller amount of stem tissue is excised with the branch leaving a slightly concave portion on the stem and slightly convex portion on the branch. There is more tissue remaining on the stem than in a flat failure. A buckling type failure (D) is classified by the branch tissue failing immediately outside the connection zone leaving no visible damage to the stem. 

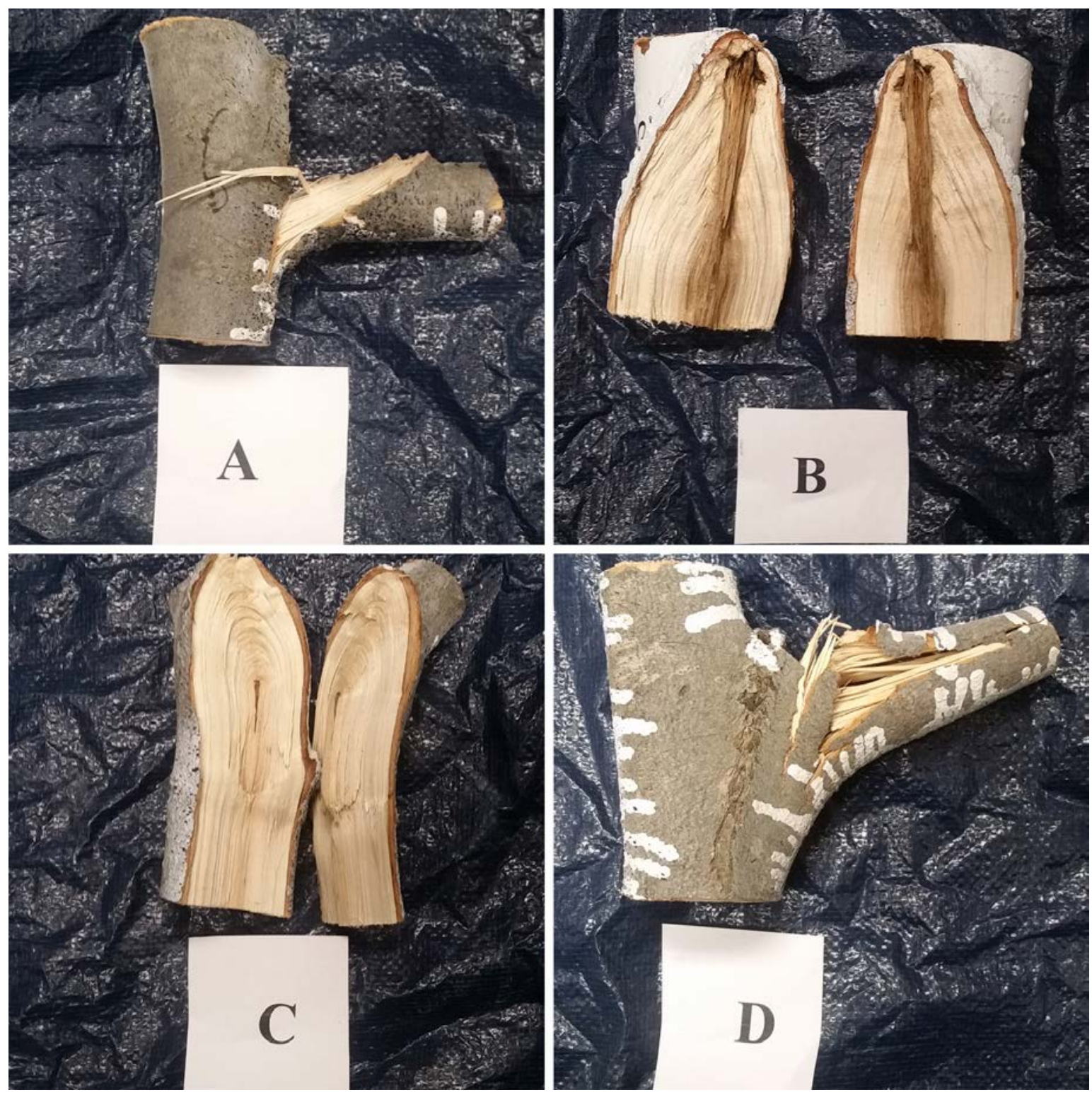

Figure 20: Example of failure types: Ball and socket (A), flat (B), imbedded branch (C), and buckling (D)

After sampling, transverse cross sections were prepared from the branch, and stem wood above and below the branch to calculate specific gravity and moisture content. Two perpendicular diameters and two thickness measurements were recorded using a Mitutoyo Digimatic Caliper that records to $0.0025 \mathrm{~cm}$ to obtain an average. Samples were weighed on a Ohaus Scoutpro 6000g scale to the nearest $0.1 \mathrm{~g}$ and dried in a Despatch Protocol plus dry oven 
to measure moisture content using the ASTM D4442-07 secondary method. Green specific gravity was also calculated from these measurements using ASTM D2395-07a method A. Age was determined for the branch, stem above, and stem below by sanding and wetting samples then counting rings at the branch union and directly below the branch union.

Once the data was collected and strain mapped, stage points were created in the area of interest to connect and analyze strain patterns. Stage points were laid on a grid throughout the area of interest using the grid view feature in ARAMIS. A strain point was placed at every fourth facet in the $\mathrm{x}$ and $\mathrm{y}$ direction throughout the entire area of interest. Points were labeled chronologically A-Z on the $\mathrm{x}$ axis and sequentially numbered on the $\mathrm{y}$ axis to create a coordinate system (figure 21).

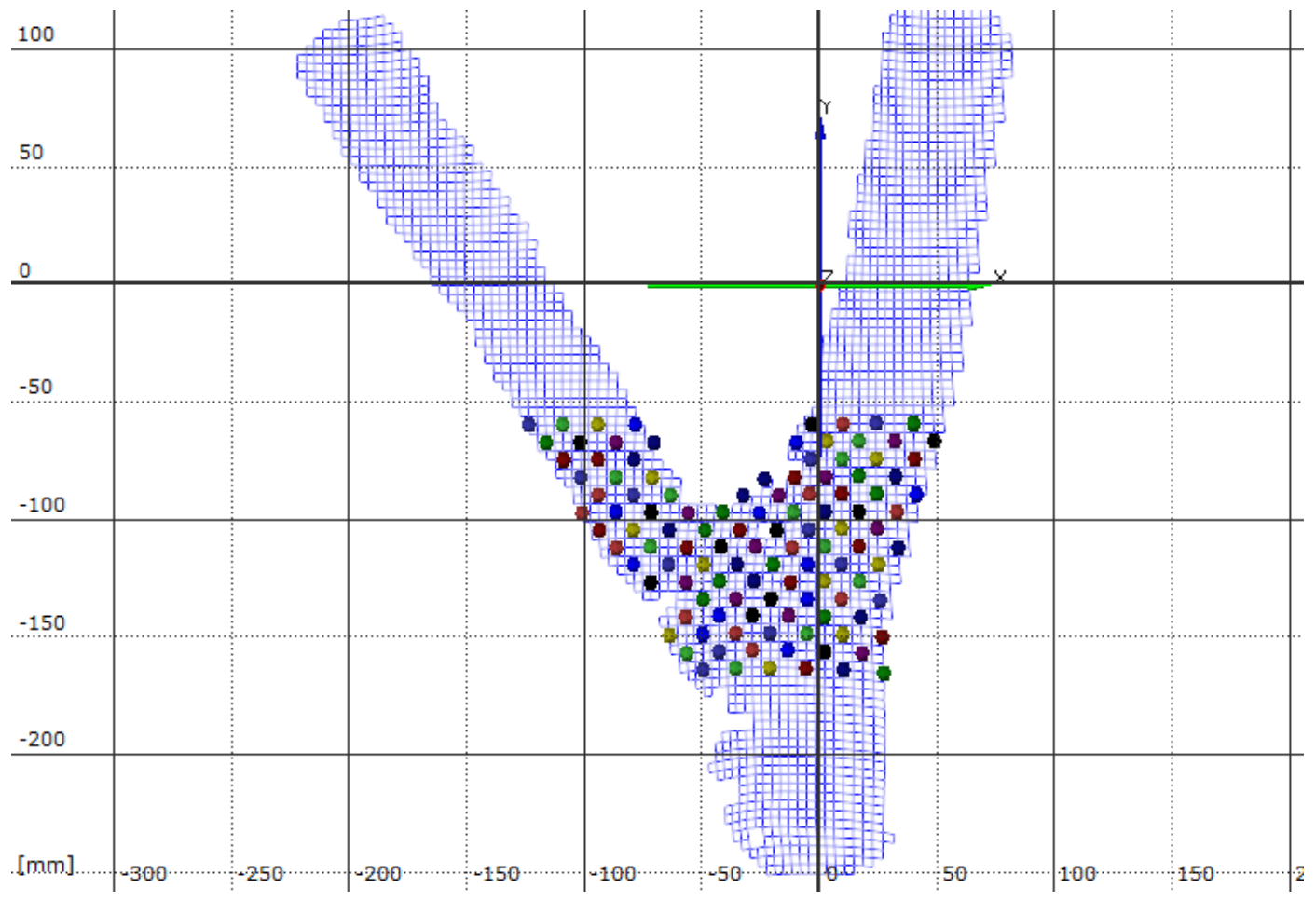

Figure 21: Grid system of stage points used for post processing of codominant branch data 


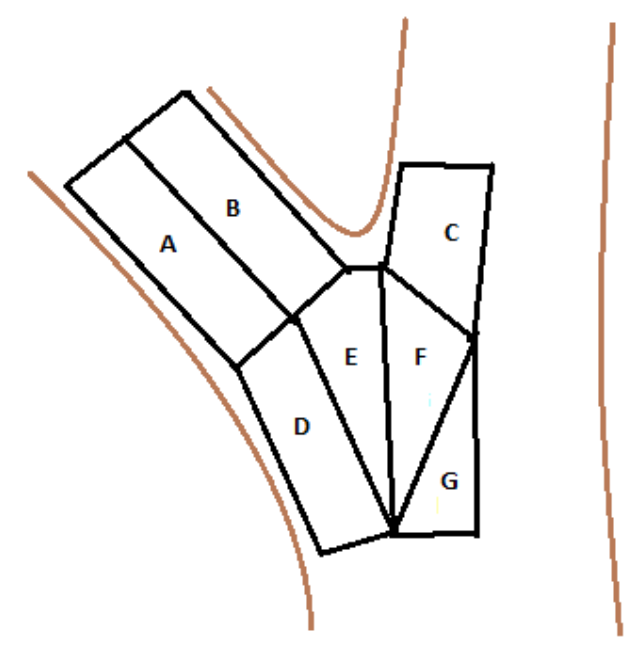

Figure 22: Branch zone map

Stage points in the area of interest were grouped into one of 7 zones (A-H). Points were grouped by their location within the area of interest. The different zones were established by tracing over strain maps and grouping the points in each zone. Zones created were based on the anatomy of the branch, so that all branches could be compared with one another. Zone A covers the abaxial surface of the branch immediately distal to the attachment up to the edge of the area of interest with a width half the diameter of the branch (figure 22). Zone B covers the other half of the branch (closer to the stem) with the same dimensions as zone A. Zone C is defined as the area closest to the fork extending upward on the stem to the edge of the area of interest. It extends halfway into the stem (diameter) and ends at the top of the fork. Zone D is the area immediately below zone A and encompasses the abaxial surface of the branch below the union. It is composed of branch tissue in the upper portion and stem tissue in the lower portion. It extends in half the branch diameter and down to the bottom of the area of interest. Zone $\mathrm{E}$ is immediately proximal to the union from zone D. It is a four sided irregular polygon that extends straight down from the union to the bottom of the area of interest and over to the midpoint of the 
branch. Zone $\mathrm{F}$ is the stem compliment to Zone $\mathrm{E}$ and extend half the diameter of the stem. Zone $\mathrm{G}$ sits below F, it extends down to the bottom of the area of interest and halfway across the stem.

Once the stage points of interest were determined and grouped, the specific stages of interest were defined. The stages of interest were, midpoint, upper quartile, pre failure, failure, and post failure. The failure stage was obtained by examining ARAMIS stage photos for initial tissue rupture. Pre failure was defined as the stage one second (5 stages) prior to failure and post failure was defined as the stage 1 second (5 stages) after failure. The midpoint stage was defined as $1 / 2$ the failure stage and the upper quartile defined as 0.75 times the failure stage.

Max load data was decomposed into bending load and axial load. The pull system was designed to apply primarily a bending load. Bending load was calculated as:

$$
L_{b}=\sin \left(\theta_{r}\right) * H
$$

Axial load was calculated as:

$$
L_{a}=\cos \left(\theta_{r}\right) * H
$$

Where:

$L_{b}=$ Bending load $(\mathrm{Pa})$

$L_{a}=$ Axial load $(\mathrm{Pa})$

$\theta_{r}=$ rope angle (degrees)

$H=\max l o a d$ (Newtons)

Once forces were decomposed into axial and bending loads, bending stress (MPa, Beer et al. 2001) was calculated as: 


$$
\sigma_{b}=\left(\frac{L_{b} * l * r}{1 / 4 \pi r^{4}}\right) * .01
$$

and axial stress (MPa, Beer et al. 2001) as:

$$
\sigma_{a}=\frac{L_{a}}{\pi r^{2}} * .01
$$

Where:

$l=$ pull arm length $(\mathrm{cm})$

$r=$ branch radius $(\mathrm{cm})$

Branch radii were obtained from previously measured caliper measurements. This provided the closest relation to the failure zone without calculating the complex geometry of the actual failed surface. Axial load and stress were found to be negligible ( $<2 \%$ of bending stress), and so were not analyzed. The perpendicular branch diameter measurements varied by less than $10 \%$ so a circular cross-section was assumed as the moment of inertia when calculating $\sigma_{\mathrm{b}}$.

Branch strain points were selected to calculate bending stress at failure. Stage points were selected at the closest point to the measured diameters in order to most closely relate to the calculated strains to the stresses measured in ARAMIS. The proportion of strain type was also calculated using the same method described in chapter 2 . The only major difference was in distinguishing the zones.

Attachment angle was measured in ARAMIS using the same method described in chapter 2, and $\Delta$ angle was calculated using the same method described in chapter 2 . 
Statistical analysis was performed using R studio version 1.0.136. Normality of variables was assessed by creating histograms, qq plots, and assessment of Shapiro Wilkes test outputs for all variables. Natural log and inverse transformations were used on non-normal variables until a P-value of 0.05 or higher was obtained with the Shapiro Wilkes test. Tukey HSD post hoc test was used to analyze interclass correlation of variables and alpha was set to 0.05 .

\section{Results}

\section{Branch data}

We tested 32 samples from 28 trees. Four trees yielded two samples and the rest yielded one sample per tree. The mean branch length was $391 \pm 19.6 \mathrm{~cm}$. (SE) The longest branch measured $800 \mathrm{~cm}$, while the shortest was $262 \mathrm{~cm}$. Upper stem diameter ranged from 2.98 to 8.59 $\mathrm{cm}(\overline{\mathrm{x}}=5.02 \pm 0.01 \mathrm{~cm})$, branch diameter ranged from 2.14 to $6.11 \mathrm{~cm}(\overline{\mathrm{x}}=3.73 \pm 0.15 \mathrm{~cm})$. Aspect ratio of the 32 samples ranged from 0.53 to 0.98 with a mean of $0.76 \pm 0.03$. Diameter of stem below the union varied from $3.61 \mathrm{~cm}$ to $8.73 \mathrm{~cm}(\overline{\mathrm{x}}=5.87 \pm 0.24 \mathrm{~cm})$. The longest branch bark ridge measured $15.3 \mathrm{~cm}$ while the shortest measured $2.01 \mathrm{~cm}(\overline{\mathrm{x}}=6.49 \pm 0.49 \mathrm{~cm})$. One sample had no branch bark ridge present

The age of the stem directly below the fork ranged from 11 to 32 years $(\bar{x}=18 \pm 0.74)$. Branch ages varied from 6 to 20 years with a mean age of $11 \pm 0.5$ years. The age of stem directly above the union ranged from 8 to 26 years old. ( $\overline{\mathrm{x}}=15 \pm 0.74$ years). The difference in age between the stem above the union and the branch was $3.97 \pm 0.72$ years.

Branch moisture content at the time of the failure testing averaged $57 \% \pm 1.4 \%$. Moisture content of the stem above the union averaged $62 \% \pm 1.2 \%$. Mean moisture content of stem wood 
below the union was $60 \% \pm 1.8 \%$. The maximum was $76 \%$ while the minimum was $17 \%$. It is believed the minimum value is an error in recording as the above union moisture content for that particular branch was $65.5 \%$ and the samples were taken close to each other, on the same day, immediately after pull testing. Moisture content did not differ between the three locations $(\mathrm{p}=$ $0.1242, \mathrm{n}=96)$. Mean specific gravity was $0.50 \pm 0.01$ for the branch, $0.48 \pm 0.01$ for stem wood above, and $0.47 \pm 0.01$ for below stem wood. Specific gravity did not vary between the locations. Branch data is summarized in table 7

The samples tested appeared to be representative of red maple as a population as specific gravity values are the same as the 0.49 reported in the FPL wood handbook (Kretschmann 2010). Moisture content was above fiber saturation point for our samples (Kretschmann 2010). We can confidently say that all specimens were tested in the green condition. Samples tested were representative in density (specific gravity) and moisture content of green condition red maple (Acer rubrum L.) 
Table 7: Red maple branch sample attribute table. Means \pm standard error

\begin{tabular}{|l|r|}
\hline Attribute & Mean \pm SE \\
\hline$n$ (sample) & 32 \\
\hline$n$ (tree) & 28 \\
\hline Length (cm) & $391 \pm 19.6$ \\
\hline Branch diameter (cm) & $3.73 \pm 0.15$ \\
\hline Above branch stem diameter (cm) & $5.02 \pm 0.01$ \\
\hline Below branch stem diameter (cm) & $5.87 \pm 0.24$ \\
\hline Aspect ratio & $0.76 \pm 0.03$ \\
\hline Branch bark ridge length (cm) & $6.49 \pm 0.49$ \\
\hline Branch age (years) & $11 \pm 0.5$ \\
\hline Above branch stem age (years) & $15 \pm 0.74$ \\
\hline Below branch stem age (years) & $18 \pm 0.74$ \\
\hline Above and below age difference (years) & $3.97 \pm 0.72$ \\
\hline Above branch stem moisture content $(\%)$ & $62 \pm 1.2$ \\
\hline Below branch stem moisture content $(\%)$ & $60 \pm 1.8$ \\
\hline Branch moisture content (\%) & $57 \pm 1.4$ \\
\hline Above branch stem specific gravity & $0.48 \pm 0.01$ \\
\hline Below branch stem specific gravity & $0.47 \pm 0.01$ \\
\hline Branch specific gravity & $0.50 \pm 0.01$ \\
\hline Attachment angle $\left(^{\circ}\right.$ ) & $46.7 \pm 2.3$ \\
\hline Failure angle $\left(^{\circ}\right.$ ) & $49.0 \pm 2.3$ \\
\hline$\triangle$ angle $\left(^{\circ}\right.$ ) & $2.3 \pm 0.3$ \\
\hline
\end{tabular}

\section{Angle Data}

Branch attachment angle varied from $24.6^{\circ}$ to $84.3^{\circ}$ with a mean of $46.7^{\circ} \pm 2.3^{\circ}$. The failure angle ranged from $27.3^{\circ}$ to $85.4^{\circ}$ with a mean of $49.0^{\circ} \pm 2.3^{\circ}$. The change in angle to failure ranged from $0.7^{\circ}$ to $6.4^{\circ}\left(\overline{\mathrm{x}}=2.3^{\circ} \pm 0.3^{\circ}\right)$. A significant relationship $(\mathrm{P}=0.0007)$ was found between change of angle and branch length (figure 23) $\left(\Delta\right.$ angle $=0.36(\text { Branch Length })^{2}-$ 1.9(Branch Length $\left.)+0.65, \mathrm{R}^{2}=0.3026, \mathrm{n}=32\right)$. A slightly weaker relationship $(\mathrm{P}=0.0011)$ was identified between $\Delta$ angle and branch diameter (figure 24) $(\Delta$ angle $=-0.39($ Branch Diameter $)+$ 2.12, $\left.\mathrm{R}^{2}=0.2802, \mathrm{n}=32\right)$. 


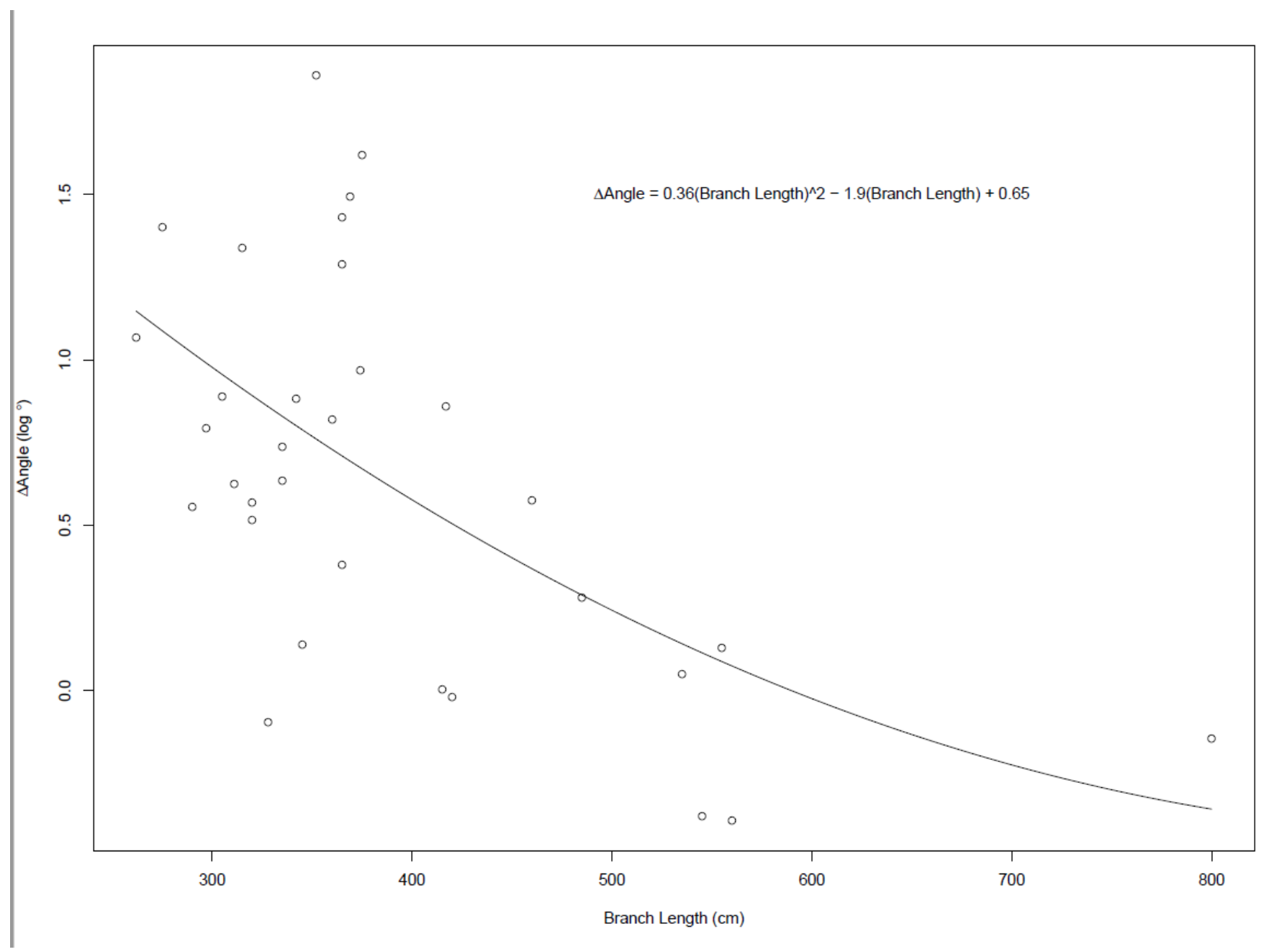

Figure 23: Branch length versus change in angle, $\mathbf{R}^{2}=\mathbf{0 . 3 0 2 6}$. 


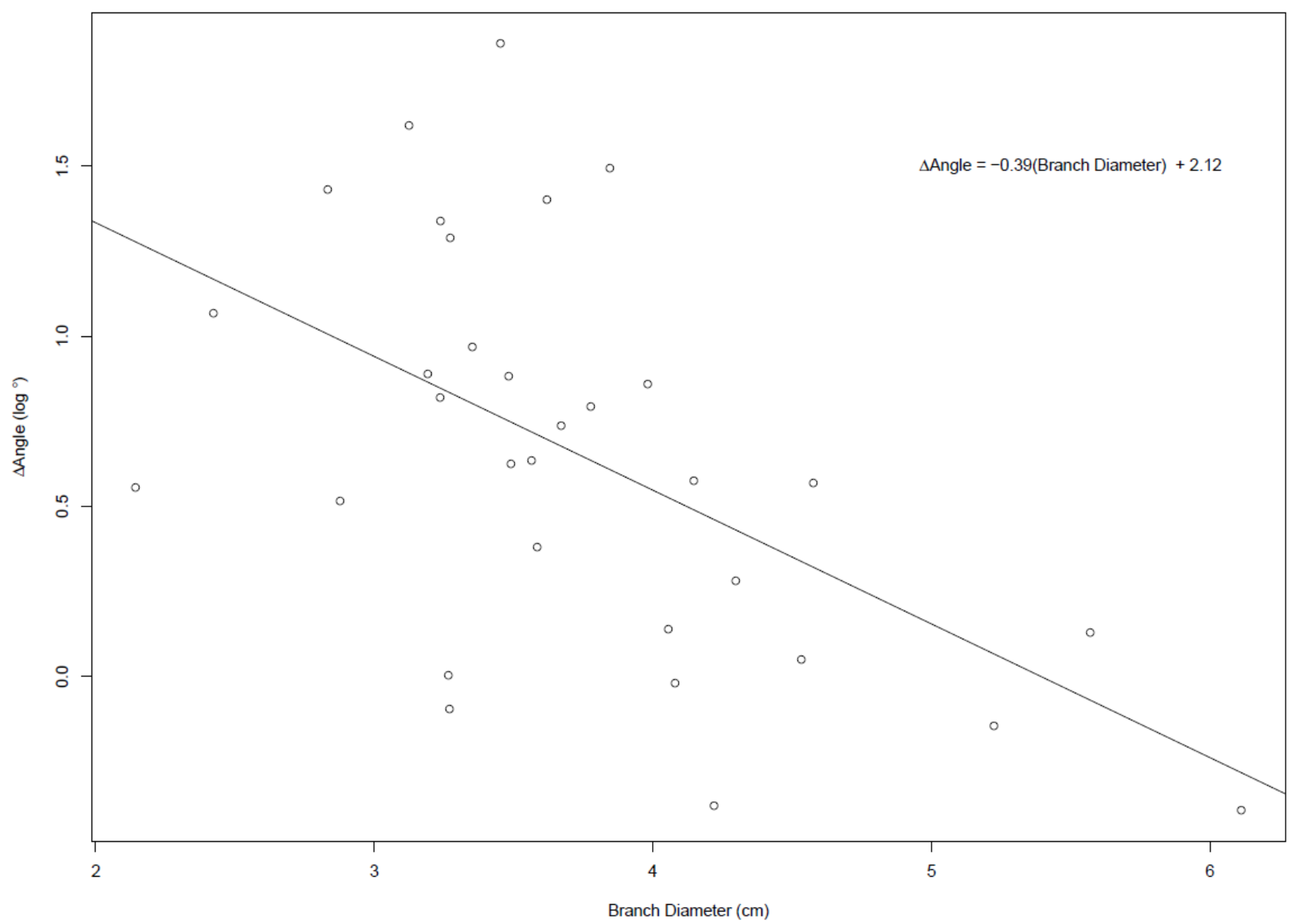

Figure 24: Branch diameter versus change in angle. $R^{2}=0.2802$.

\section{$\underline{\text { Load Data }}$}

The mean pull arm (distance from rope to fork) was $25.86 \pm 1.16 \mathrm{~cm}$, ranging from 15.88 - $41.91 \mathrm{~cm}$. The angle of the taught rope in relation to the branch (rope angle) averaged $69.7^{\circ} \pm$ $2.3^{\circ}$. The maximum rope angle measured $91.6^{\circ}$ and the minimum rope angle was $40.9^{\circ}$.

Maximum load at failure averaged $1,113.7 \mathrm{~N} \pm 87.3 \mathrm{~N}$. The highest load to failure measured 2,179.6 $\mathrm{N}$ and the smallest load measured 240.2 N. The maximum bending load calculated was 2,014.0 MPa and the smallest was 199.6 MPa ( $\overline{\mathrm{x}}=1,021.3 \pm 79.9 \mathrm{MPa}) \mathrm{The}$ 
maximum axial load calculated was 1,283.2 MPa and the minimum was 2.8 $\mathrm{MPa}(\overline{\mathrm{x}}=387.6 \pm$ 52.5 Pa). Average bending stress was calculated to be $51.6 \pm 4.5 \mathrm{MPa}$ among the 32 branches tested. Axial stress averaged $0.3 \pm 0.04 \mathrm{MPa}$ (range $0.00-0.75 \mathrm{MPa}$ ) and was always less than $1.67 \%$ of bending stress $(\overline{\mathrm{x}}=0.7 \pm 0.1 \%)$. As such axial stress was deemed negligible and not included in further analysis.

Major (tensile) and minor (compressive) strain contour maps were created for each tested specimen and compared at various aspect ratios and failure types. Figures 25 through 30 give examples of strain contours at each aspect ratio examined $(0.5-1.0)$, and figures 31 through 34 give examples of strain contours for each failure type observed. 


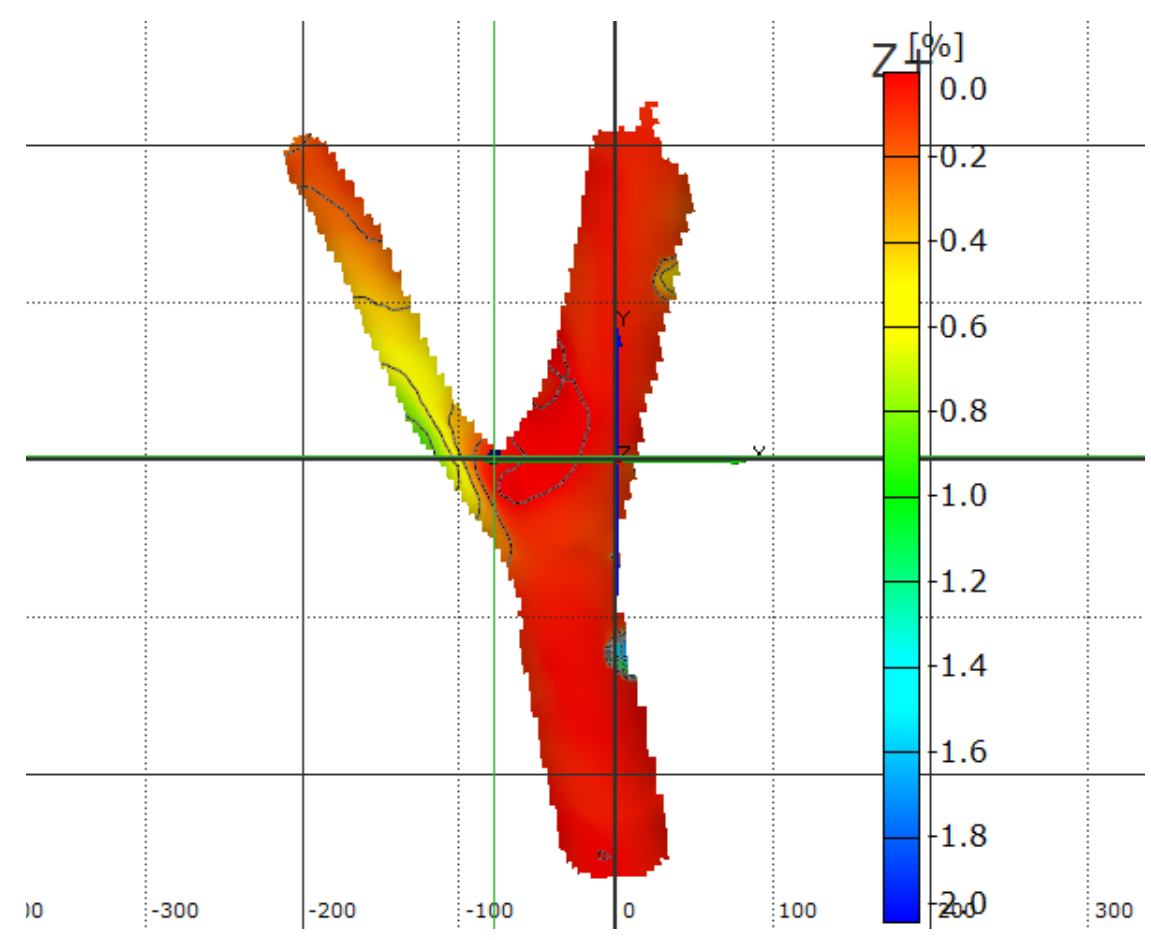

(a)

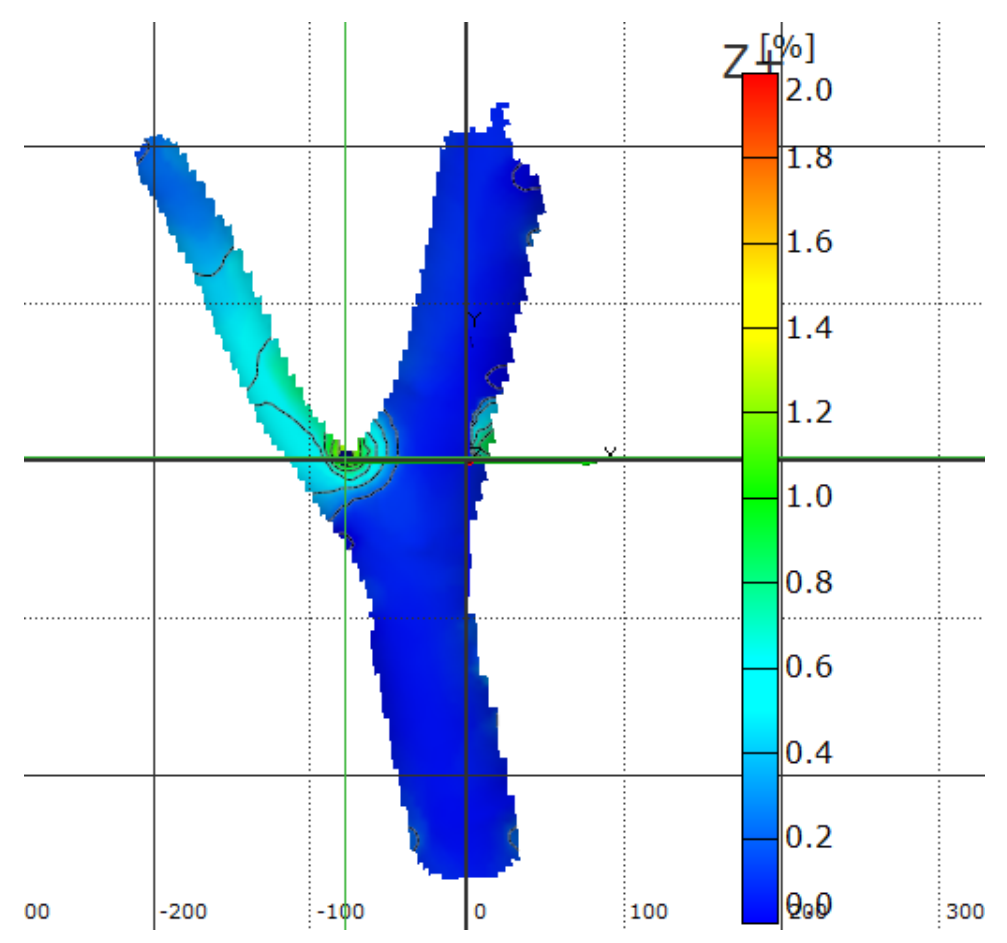

(b)

Figure 25: Minor (compressive) strain contour map (a) and major (tensile) strain contour map (b) at failure stage for tested red maple branch with aspect ratio of 0.5 


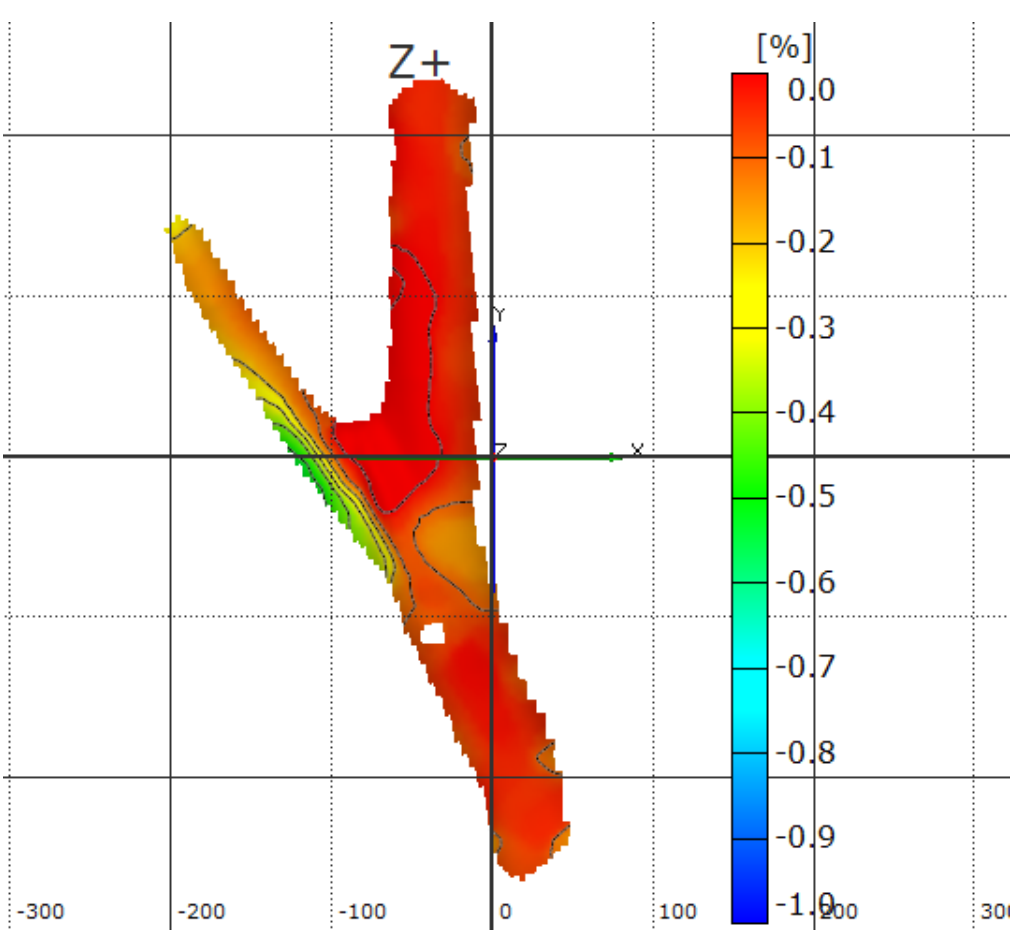

(a)

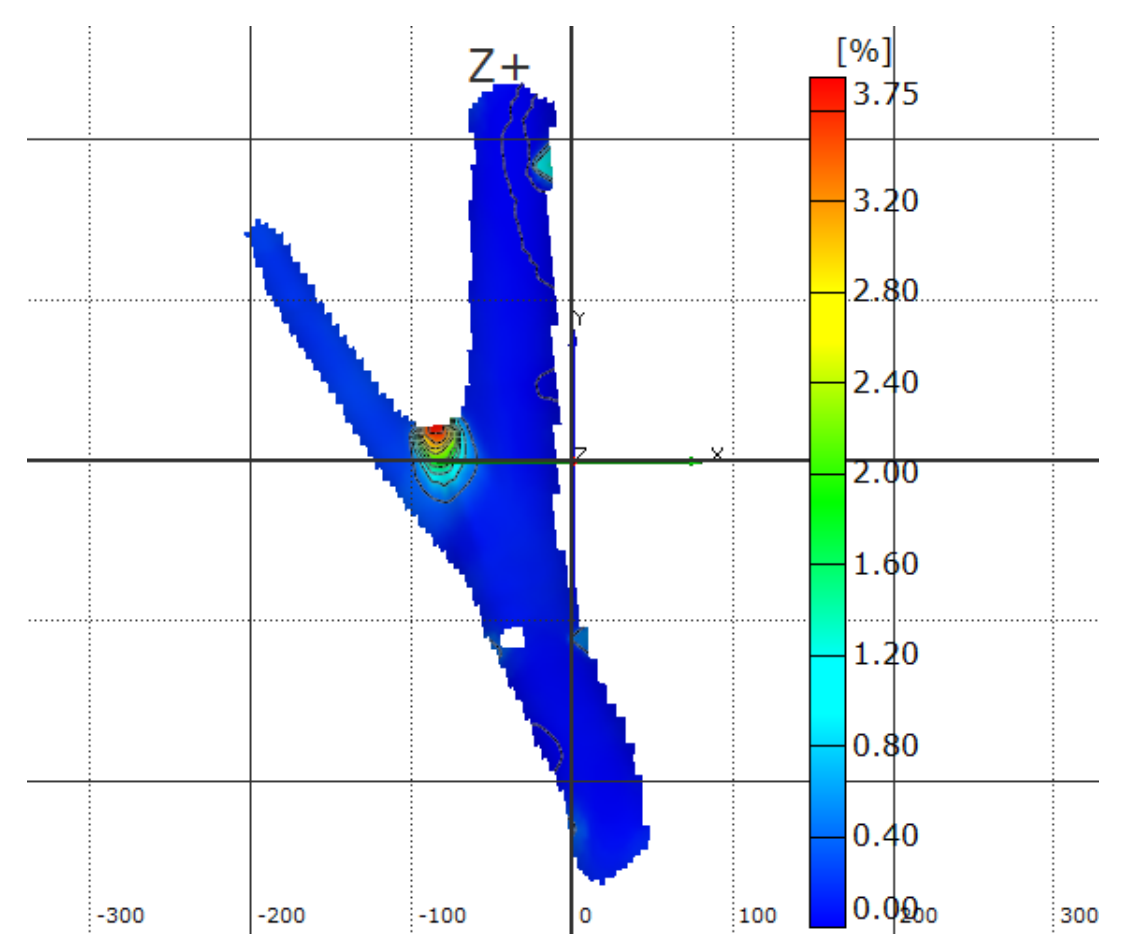

(b)

Figure 26: Minor (compressive) strain contour map (a) and major (tensile) strain contour map (b) at failure stage for tested red maple branch with aspect ratio of 0.6 


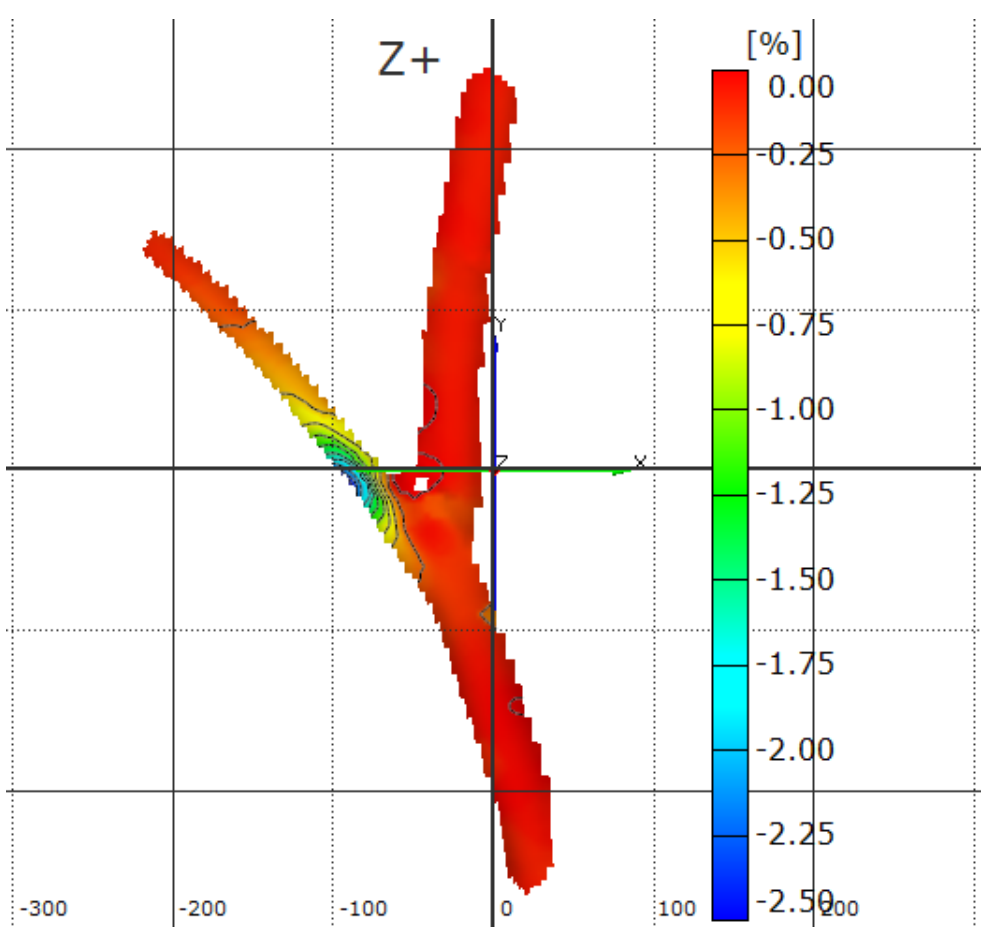

(a)

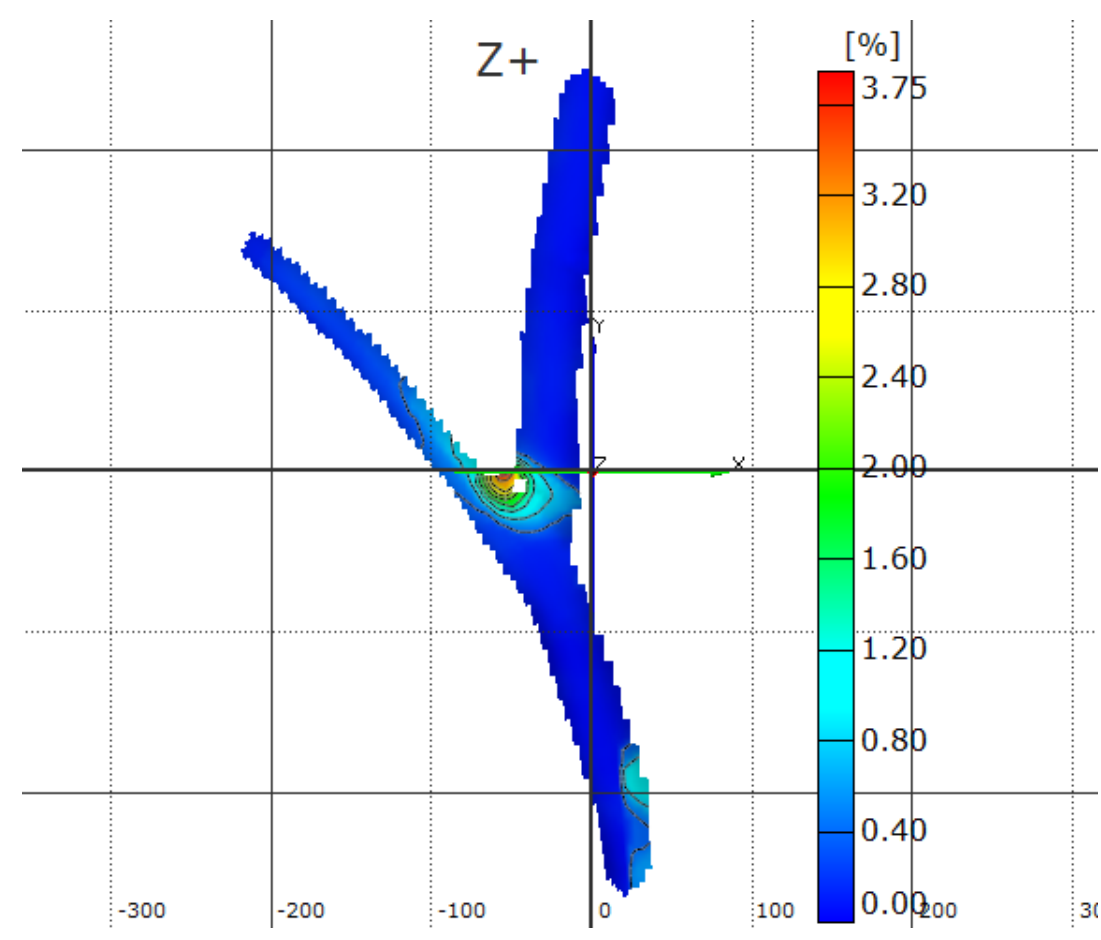

(b)

Figure 27: Minor (compressive) strain contour map (a) and major (tensile) strain contour map (b) at failure stage for tested red maple branch with aspect ratio of 0.7 


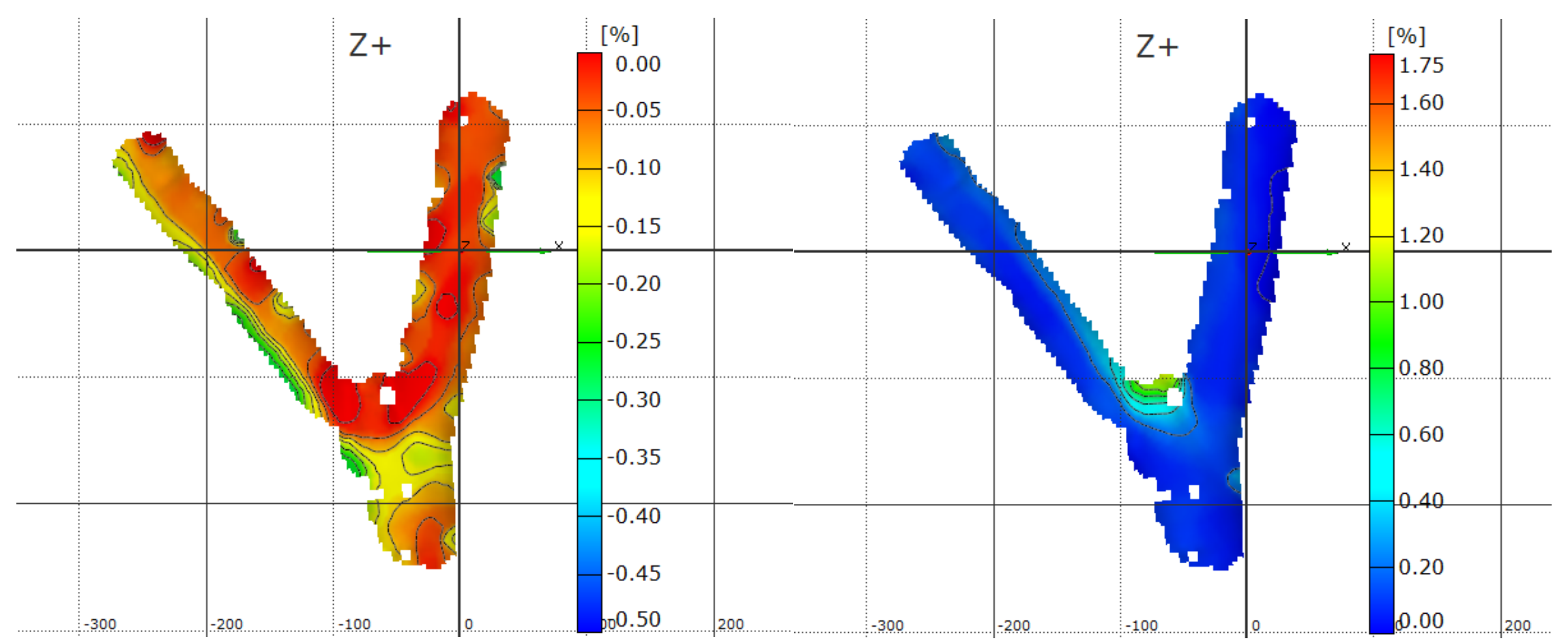

(a)

(b)

Figure 28: Minor (compressive) strain contour map (a) and major (tensile) strain contour map (b) at failure stage for tested red maple branch with aspect ratio of 0.8 


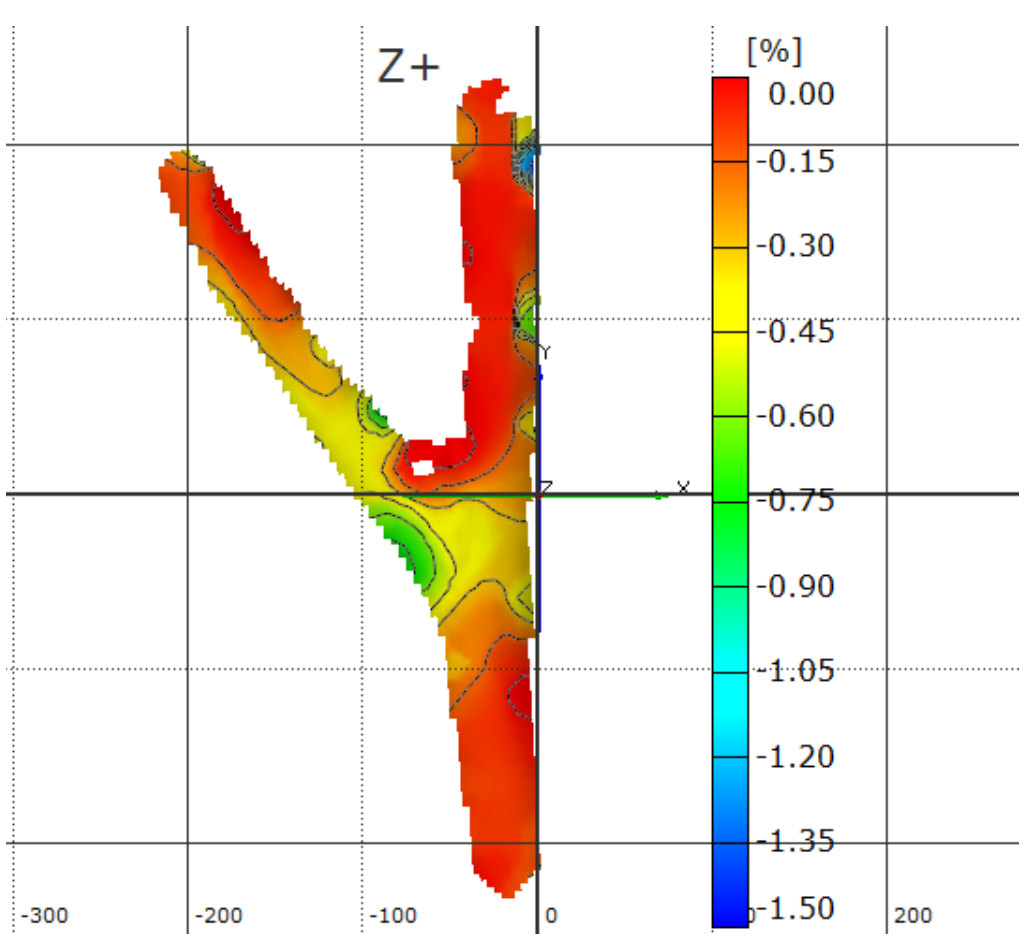

(a)

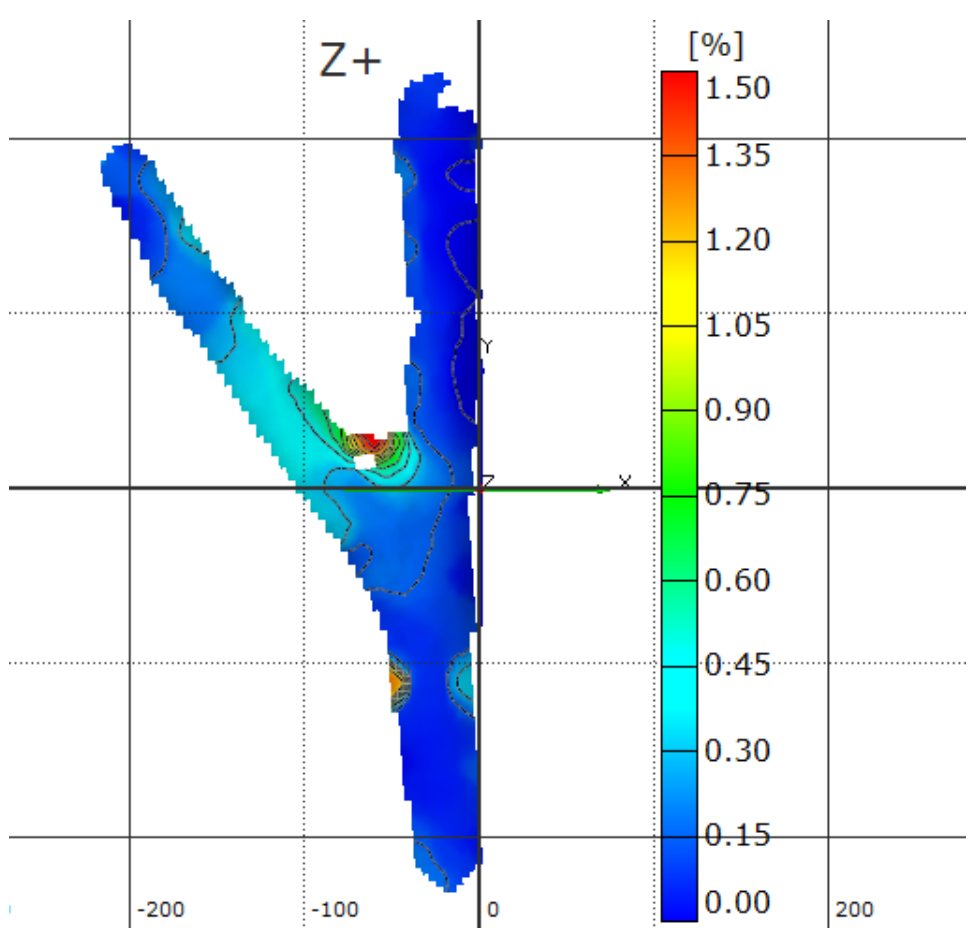

(b)

Figure 29: Minor (compressive) strain contour map (a) and major (tensile) strain contour map (b) at failure stage for tested red maple branch with aspect ratio of 0.9 


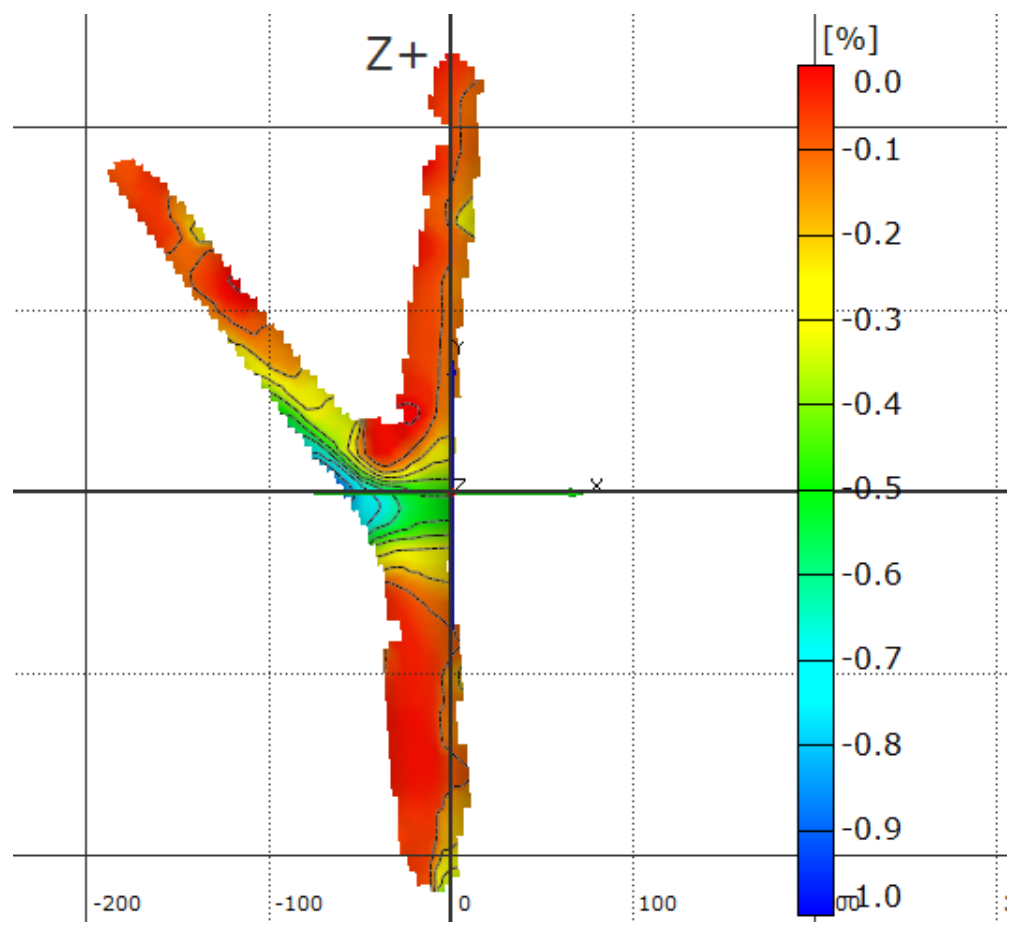

(a)

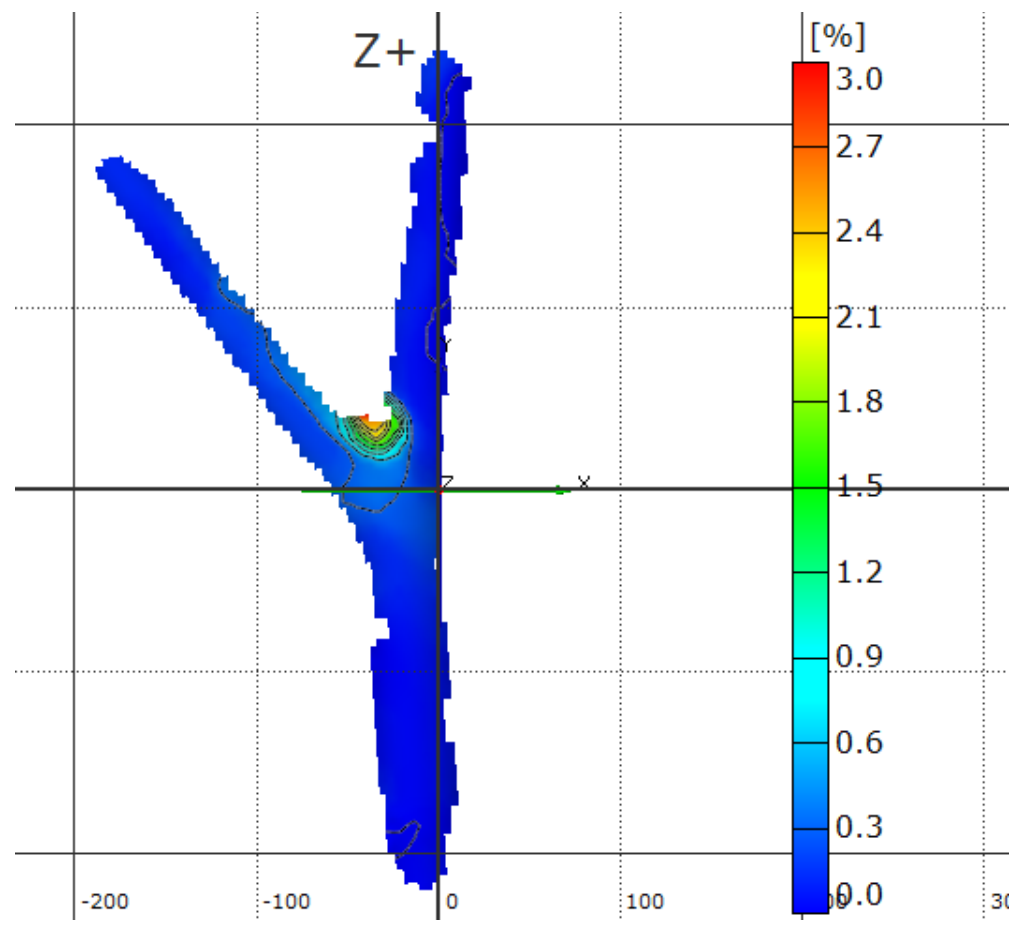

(b)

Figure 30: Minor (compressive) strain contour map (a) and major (tensile) strain contour map (b) at failure stage for tested red maple branch with aspect ratio of 1.0

64 


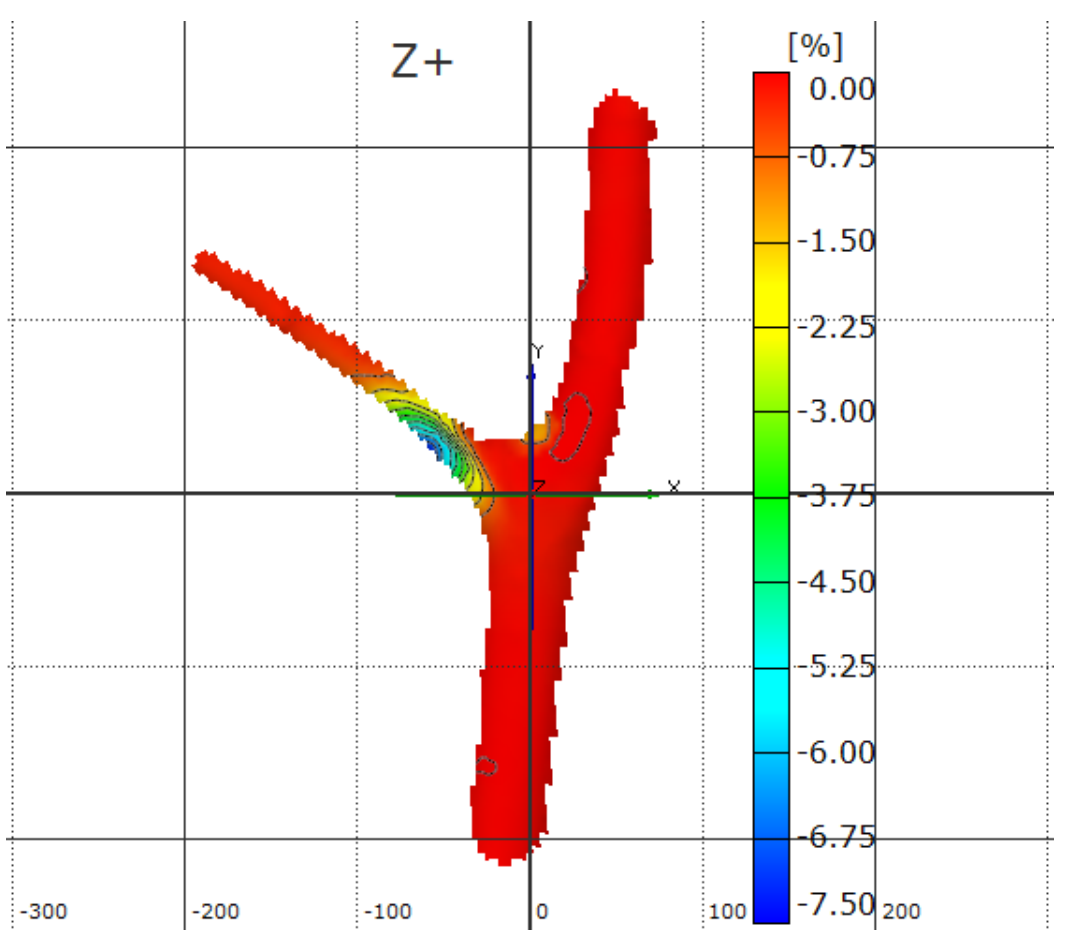

(a)

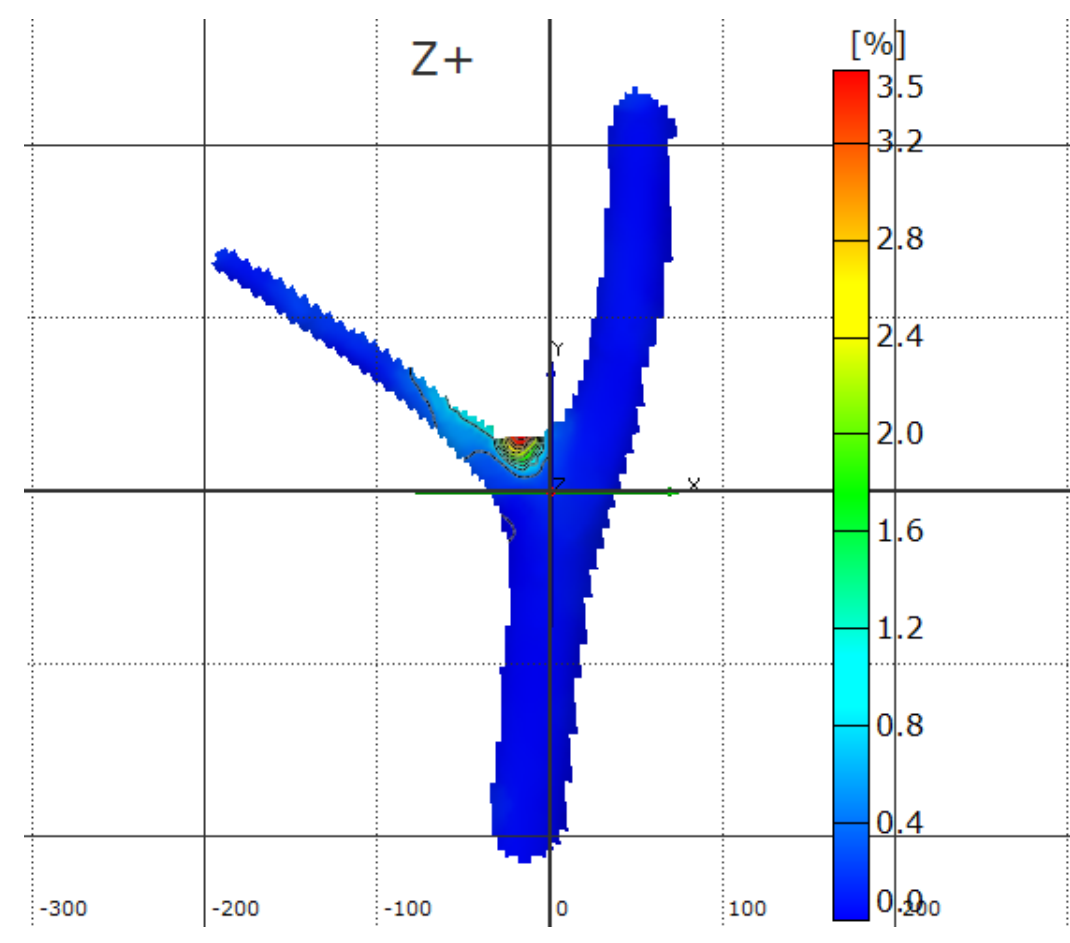

(b)

Figure 31: Minor (compressive) strain contour map (a) and major (tensile) strain contour map (b) at failure stage for tested red maple branch exhibiting a ball and socket type failure 


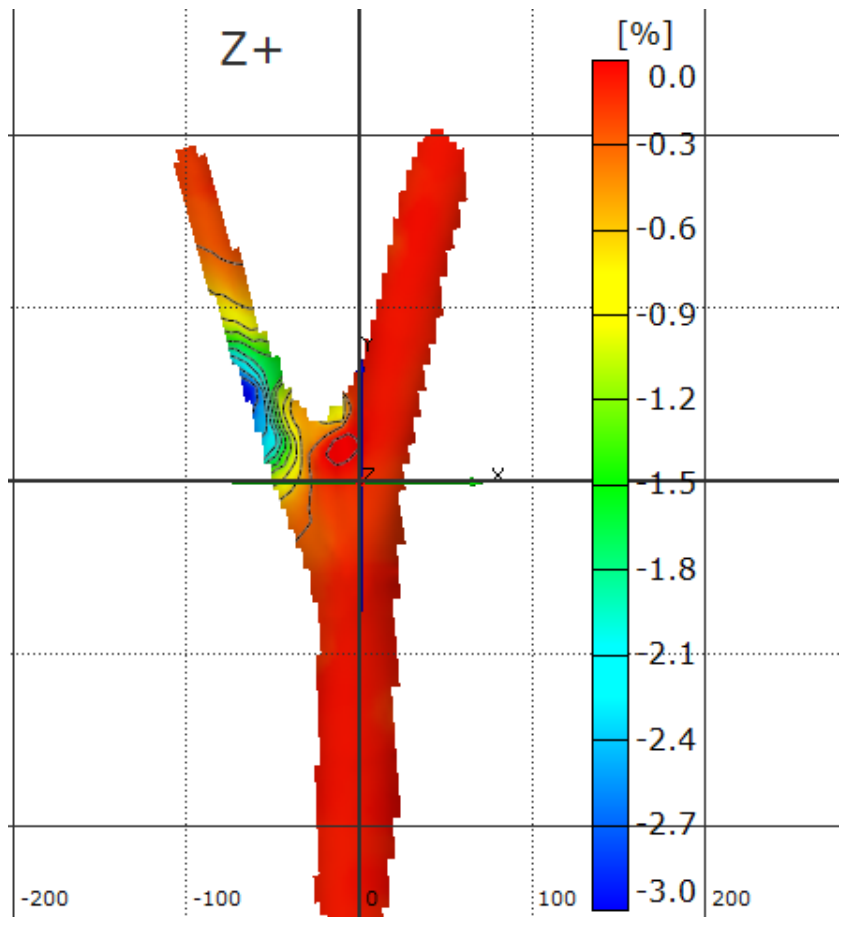

(a)

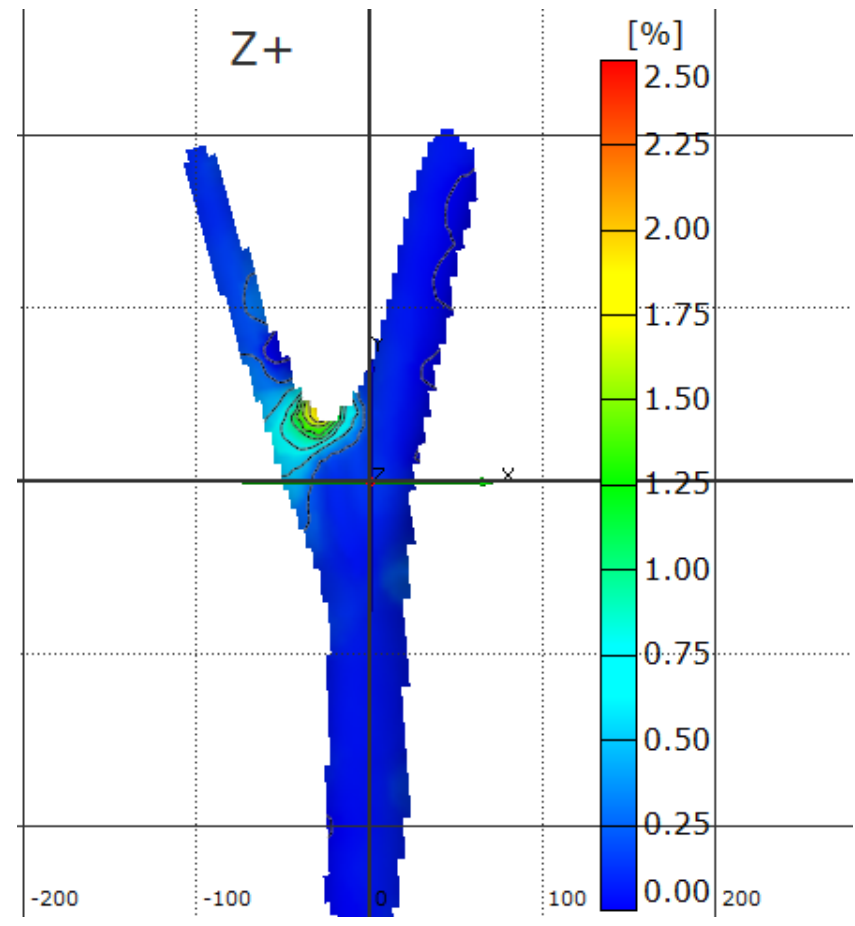

(b)

Figure 32: Minor (compressive) strain contour map (a) and major (tensile) strain contour map (b) at failure stage for tested red maple branch exhibiting a buckling type failure 


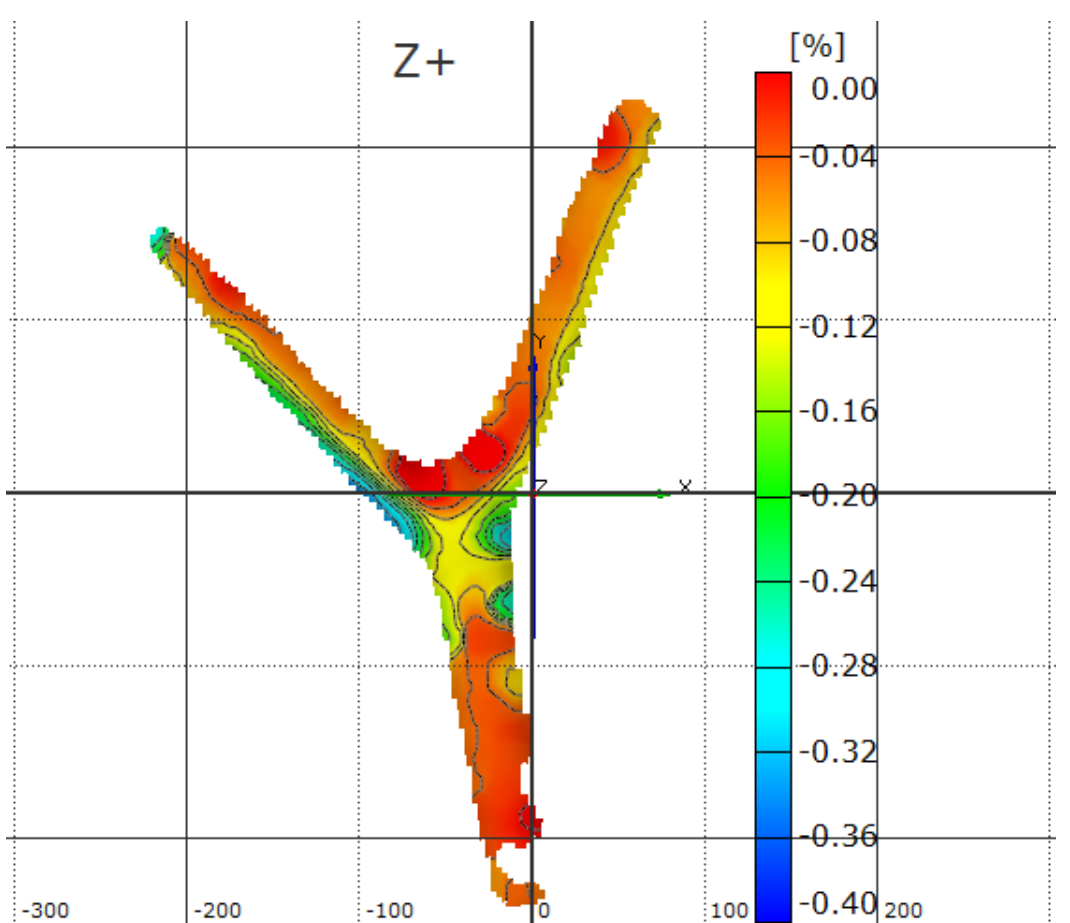

(a)

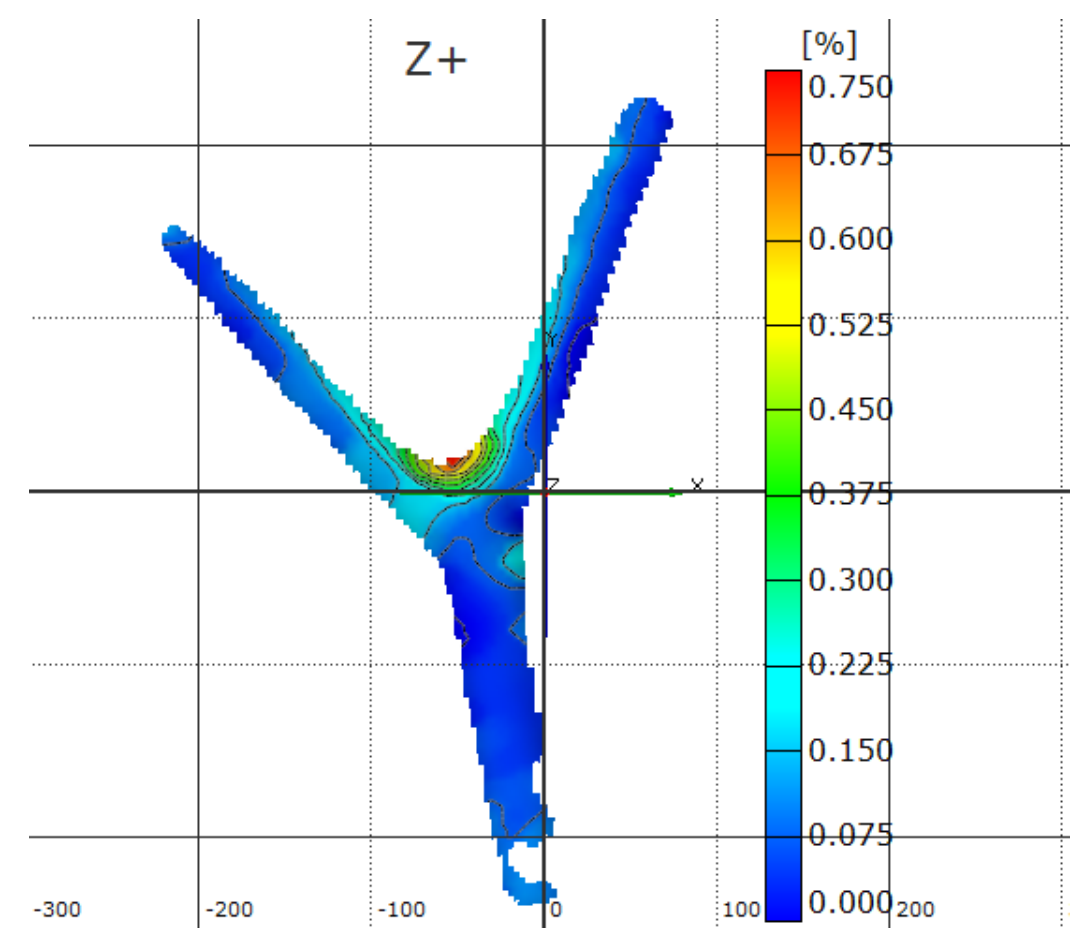

(b)

Figure 33: Minor (compressive) strain contour map (a) and major (tensile) strain contour map (b) at failure stage for tested red maple branch exhibiting a flat type failure 


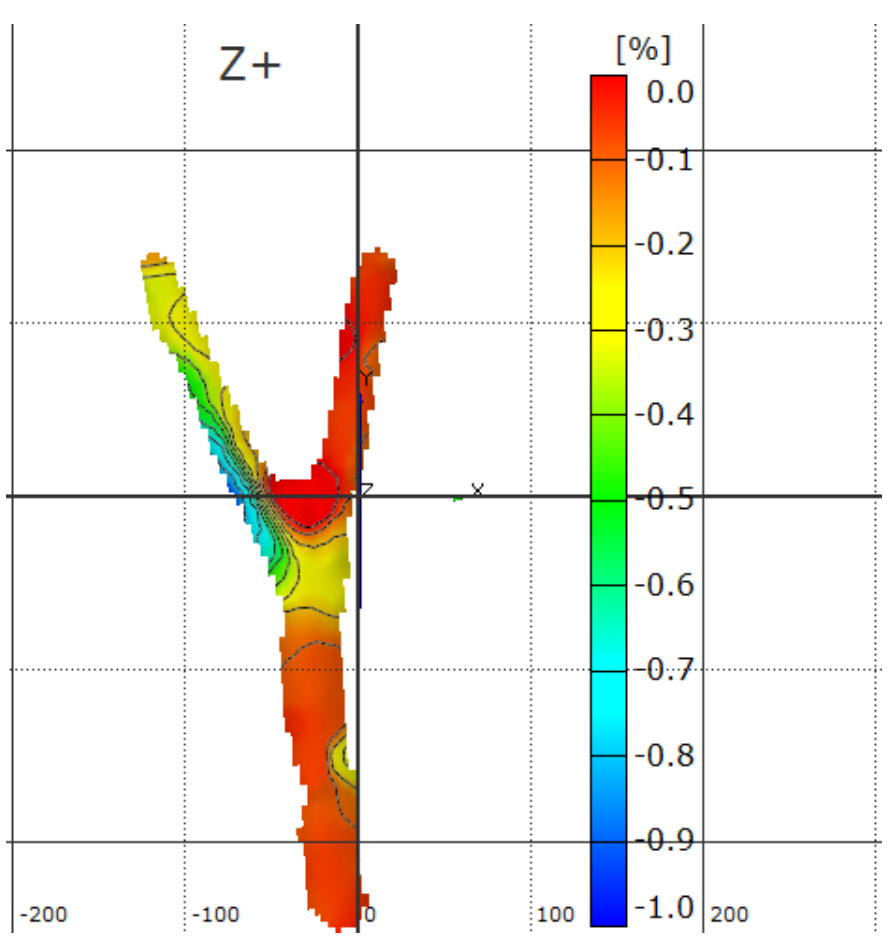

(a)

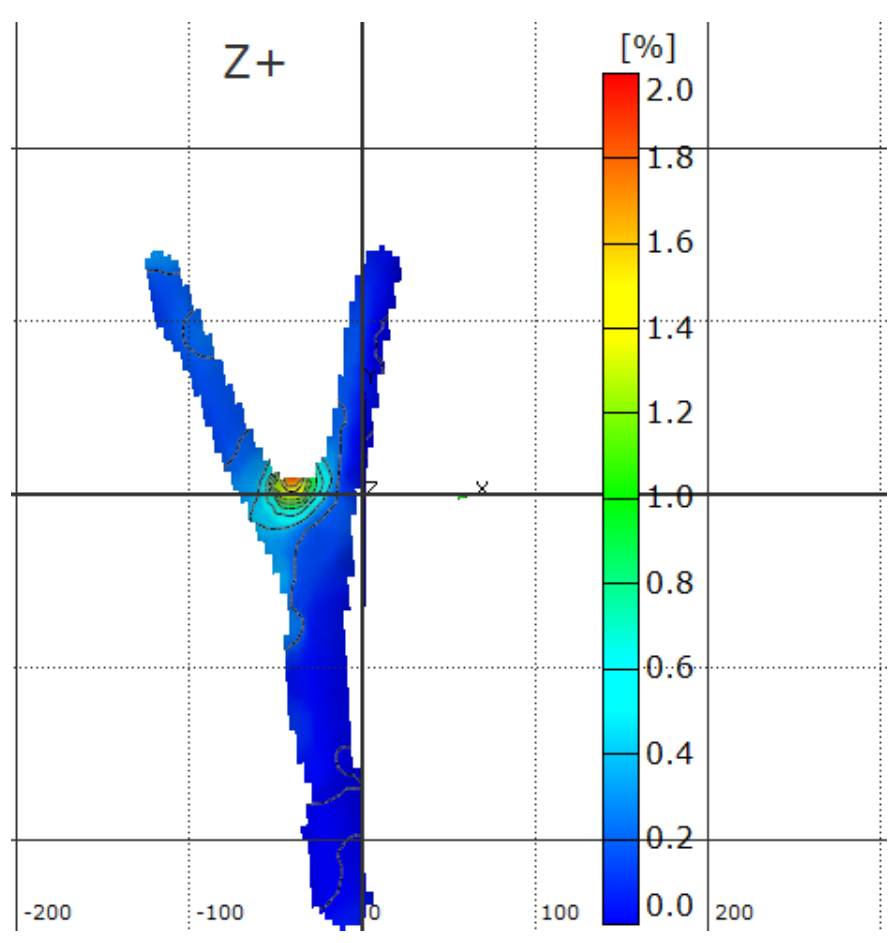

(b)

Figure 34: Minor (compressive) strain contour map (a) and major (tensile) strain contour map (b) at failure stage for tested red maple branch exhibiting an imbedded branch type failure

68 
Proportion of strain by zone at failure was calculated to better describe the loading in the branch (Table 8). Proportions were calculated using the same method in chapter 2 . The only exception is failure was focused on, rather than three time periods.

Table 8: Proportion of Strain type by Zone at failure

\begin{tabular}{|l|r|l|r|}
\hline Zone & \% of Strain & Strain Type & $\mathrm{n}$ \\
\hline A & $78.6 \%$ & Compression & 1004 \\
\hline B & $67.7 \%$ & Tension & 904 \\
\hline C & $87.4 \%$ & Tension & 707 \\
\hline D & $74.2 \%$ & Compression & 811 \\
\hline E & $86.1 \%$ & Tension & 747 \\
\hline F & $87.4 \%$ & Tension & 1102 \\
\hline G & $55.9 \%$ & Tension & 619 \\
\hline
\end{tabular}

There were 9 ball and socket failures, 3 buckling failures, 10 flat failures, and 10 imbedded branch failures. Broken unions were assessed qualitatively by examining the fracture pattern. The branches that exhibited a clever clip on the failed portion were examined (table 9)

Table 9: Discovered clever clips after static pull testing

\begin{tabular}{|r|r|l|r|r|r|}
\hline Sample \# & Aspect Ratio & Failure Type & Initial Angle $\left(^{\circ}\right)$ & $\Delta$ Angle $\left(^{\circ}\right)$ & $\begin{array}{l}\text { Bending Stress } \\
(\mathrm{MPa})\end{array}$ \\
\hline 18 & 0.70 & Imbedded branch & 36.18 & 4.45 & 47.55 \\
\hline 20 & 0.89 & Imbedded branch & 45.84 & 2.44 & 45.22 \\
\hline 21 & 0.56 & buckling & 37.59 & 4.18 & 50.30 \\
\hline 33 & 0.96 & Imbedded branch & 39.53 & 1.78 & 28.31 \\
\hline
\end{tabular}

Lower branch max strain (log transformed) was plotted against aspect ratio (figure 35). A second order polynomial fit the data with an $R^{2}$ of 0.4273 , $n=32$. 


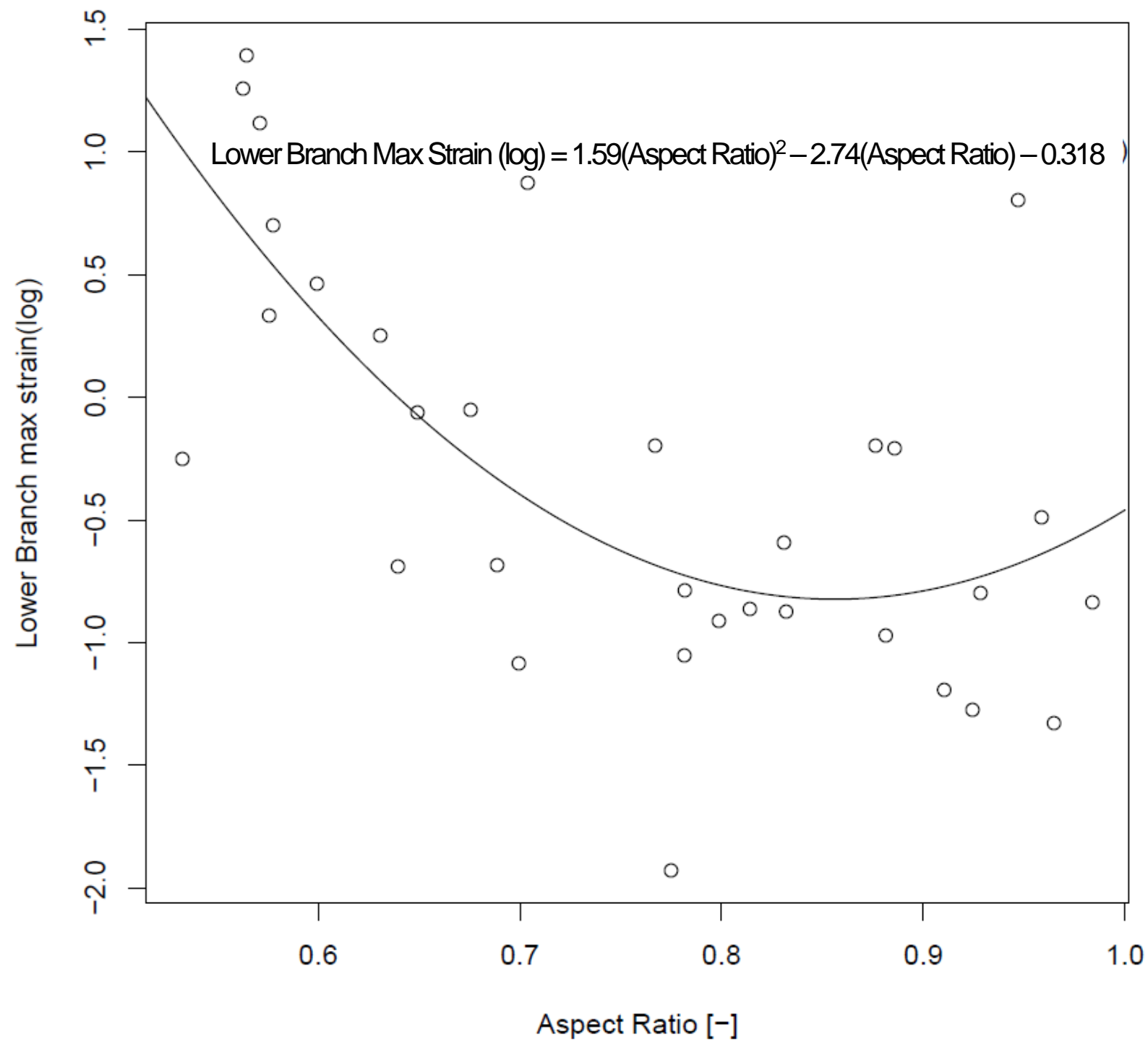

Figure 35: Lower branch max strain (log) versus Aspect ratio of 32 tested red maple branches. $\mathbf{R}^{2}=0.4273(\mathbf{p}<0.0001, \mathrm{n}=32)$ 
Lower branch max strain was plotted against change in angle with a linear model (figure 36). $\mathrm{R}^{2}=0.4983$ Lower Branch Max Strain $=1.0042(\Delta$ angle $)-0.9725, \mathrm{n}=32$.

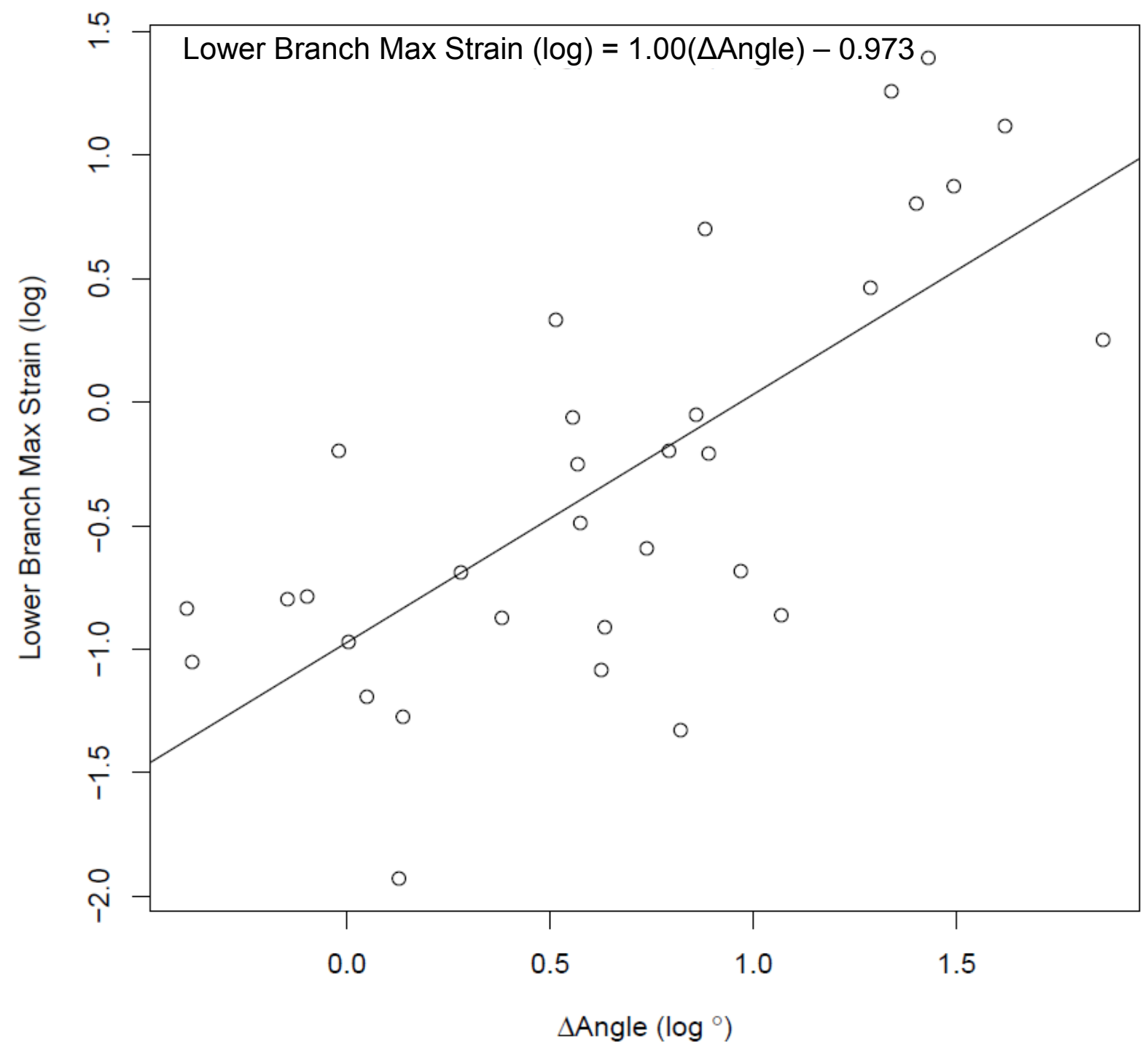

Figure 36: Lower branch max strain versus change in angle $\left(R^{2}=0.4983, p<0.0001, n=32\right)$

Log of lower branch max strain was plotted against aspect ratio. A linear model was created for each failure type to show trends of failure type at different aspect ratios (figure 37 and Table 10). 


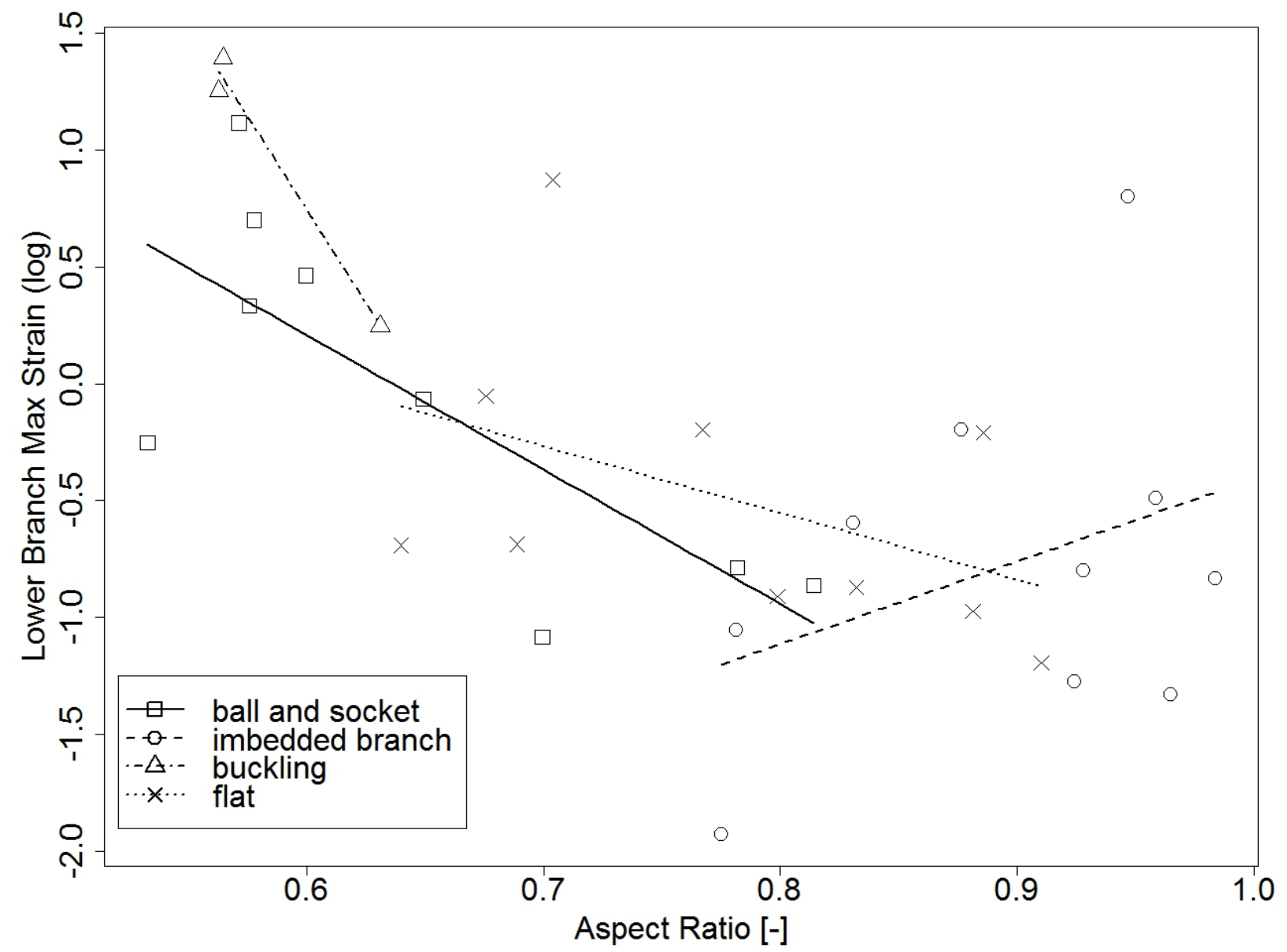

Figure 37: Lower branch max strain versus aspect ratio by failure type.

Table 10: Summary of linear models developed for lower branch max strain vs aspect ratio by failure type.

\begin{tabular}{|l|r|r|r|r|}
\hline Failure Type & \multicolumn{1}{|l|}{ Slope } & P-Value & $\mathbf{R}^{2}$ & n \\
\hline Ball and socket & -5.746 & 0.0192 & 0.505 & 9 \\
\hline Buckling & -15.96 & 0.0851 & 0.965 & 3 \\
\hline Flat & 3.53 & 0.2947 & 0.028 & 10 \\
\hline Imbedded branch & -2.844 & 0.1837 & 0.110 & 10 \\
\hline
\end{tabular}

Ball and socket and buckling type failures were found to occur at lower aspect ratio (Table 11, $\mathrm{P}=0.0068, \mathrm{~N}=32$ ) and flat failures at the highest aspect ratios. 
Table 11: Mean $( \pm$ SE) aspect ratio and $\Delta$ angle by failure type. Mean with different letters were found to be significantly different using a Tukey HSD.

\begin{tabular}{|l|r|r|r|}
\hline Failure Type & $\begin{array}{c}\text { Mean Aspect } \\
\text { Ratio }\end{array}$ & Mean $\Delta$ angle & n \\
\hline Ball and Socket & $0.64 \pm 0.03(\mathrm{~A})$ & $2.24 \pm 0.42(\mathrm{AB})$ & 9 \\
\hline Buckling & $0.59 \pm 0.02(\mathrm{~A})$ & $4.81 \pm 0.82(\mathrm{~B})$ & 3 \\
\hline Flat & $0.90 \pm 0.02(\mathrm{C})$ & $1.57 \pm 0.33(\mathrm{~A})$ & 10 \\
\hline Imbedded Branch & $0.78 \pm 0.03(\mathrm{~B})$ & $2.08 \pm 0.32(\mathrm{~A})$ & 10 \\
\hline P-Value & $<0.001$ & 0.0063 & \\
\hline
\end{tabular}

Log of max strain by zone was calculated at each measured stage of testing (midpoint, upper quartile, pre failure, and failure) and differences between zones were estimated using a Tukey HSD test.

Table 12: Mean for Max strain by each branch zone for 32 Acer rubrum samples. Mean with different letters were found to be significantly different using a Tukey HSD. Data was analyzed using the natural log of max stain and back transformed for presentation purposes.

\begin{tabular}{|c|c|c|c|c|}
\hline Zone & Midpoint & $\begin{array}{l}\text { Upper } \\
\text { quartile }\end{array}$ & Pre failure & Failure \\
\hline $\mathrm{A}$ & 0.0298 (bc) & 0.1129 (b) & 0.4237 (cd) & 0.5267 (d) \\
\hline $\mathrm{B}$ & 0.0371 (c) & 0.1169 (b) & 0.3500 (c) & 0.4058 (c) \\
\hline $\mathrm{C}$ & $0.0278(\mathrm{ab})$ & 0.0636 (a) & 0.1205 (a) & 0.1299 (a) \\
\hline $\mathrm{D}$ & $0.0276(\mathrm{ab})$ & 0.1172 (b) & $0.4029(\mathrm{~cd})$ & 0.5493 (de) \\
\hline $\mathrm{E}$ & 0.0365 (c) & 0.1692 (c) & 0.4783 (d) & 0.6740 (e) \\
\hline $\mathrm{F}$ & 0.0343 (bc) & 0.1363 (b) & 0.3465 (c) & 0.4652 (cd) \\
\hline G & $0.0226(\mathrm{a})$ & 0.0719 (a) & 0.1834 (b) & 0.2116 (b) \\
\hline $\mathrm{P}$ value & $<0.0001$ & $<0.0001$ & $<0.0001$ & $<0.0001$ \\
\hline $\mathrm{n}$ & 1192 & 1192 & 1180 & 1173 \\
\hline
\end{tabular}




\section{Discussion}

Branches with high aspect ratio have been shown to have a reduced attachment strength (Gilman 2003; Kane et al.2008). Codominant branches have the weakest connections and high aspect ratio, yet it is unclear if there is a specific aspect ratio above which a lateral branch can be termed a codominant branch. The samples in this study ranged in aspect ratio from 0.5 to 1.0 , giving a representative look at branch attachments ranging from lateral to codominant branches.

No significant relationship $\left(\mathrm{R}^{2}<0.25, \mathrm{p}>0.05\right)$ was discovered between breaking stress and branch diameter, aspect ratio, attachment angle, $\Delta$ angle, or failure type. We expected to see an inverse relationship between aspect ratio and attachment strength, as seen in previous studies (Gilman 2003; Smiley 2003). This finding also contradicts several studies (Gilman 2003; Kane 2007; Kane and Clouston 2008; Kane et al. 2008) that indicate aspect ratio is a predictor of failure strength and branch stability. It is unclear if this finding is significant, or confounded by sample size and relying on a secondary observer to obtain load at failure. If we were able to use a load cell that logged maximum load or tracked load throughout testing, we would gain more insight into the stresses exerted during testing. Strain proved to be a more powerful independent variable in this experiment. This may be due to the complex geometry of the failed portion leading to difficult moment of inertia calculations ultimately confounding results of stress. It is interesting to note that upper branch max strain also provided no predictive power in analyses, while lower branch max strain provided a great deal. One would expect upper branch max strain to be the inverse opposite of lower branch strain. We would expect to see a tensile strain on the above side equal to the compressive strain observed on the underside. 
By examining lower branch max strain against aspect ratio (figure 35) we see a negative relationship between the two. As aspect ratio increases, log max strain at the lower portion of the branch decreases. Max strain drops off and flatten at an aspect ratio around 0.75 or 0.8 , giving us a second order polynomial fit. There was less strain exhibited before failure at these high aspect ratios suggesting that an aspect ratio greater than 0.75 is likely to be a codominant attachment. This is in agreement with Eisner et al. (2002) who found an aspect ratio of 0.75 to be codominant from a hydraulic segmentation perspective. At higher aspect ratios, more sudden failures were observed. When lower branch max strain and aspect ratio are decomposed by failure type (figure 41) this becomes more apparent. Essentially, these codominant unions are not as flexible as lower aspect ratio unions, and result in long axial failures in the union rather than ball and socket failures where the stem tissue is excised and greater flexibility is present on the underside of the branch. This phenomenon was also revealed in the ANOVA analysis of aspect ratio by failure type (table 11). Buckling and ball and socket failures occurred at lower aspect ratios, imbedded branch failures at higher aspect ratios, and flat failures at the highest aspect ratios. This is in agreement with Kane et al. (2008), who found that imbedded branch and flat surface failures typically occurred at higher aspect ratios.

Tukey analysis of branch zones (table 12) lends insight into how loads move through the branch (zones A \& B), its attachment (Zones D, E \& F), and surrounding stem wood (zones C \& G). Strain builds from midpoint of test, to upper quartile, to pre failure, to failure in each zone. This is due to an increasing load being applied as the test progresses resulting in increased deformation. The lowest strain values were found in the stem (zones C \& G) throughout testing. Strain did increase in this region throughout testing, but not at the rate or magnitude it did in other regions. In the lateral attachments examined in chapter 2 , strain was largely restricted to the 
branch and the branch collar region. Codominant unions exhibit strain patterns that differ from lateral unions. Strain propagates farther into the surrounding stem wood in codominant unions. The greatest strain at pre failure and throughout most of the branch failure exercise was zone $\mathrm{E}$ which is at the top of the union. Codominant branches failed at the union, so it makes sense that the greatest strain immediately prior to failure occurred at the zone that encompasses the union. High strain values were also seen in the branches (zones A \& B). Max strain was measured by taking the higher of the two values of compressive strain and tensile strain. One would expect the lower side of the branch (Zone A) to have equal and opposite strain as the above side of the branch (Zone B), but this was not the case. In fact, only in the upper quartile (time) of test were the two statistically similar. This may be a function of strain propagating elsewhere on the stem and being lost from the strain calculated by ARAMIS. A similar phenomenon was discovered in lateral branches examined in chapter 2, strain is lost somewhere in the system which may be connected to mass dampening.

Strain was higher on the underside of the branch (region A vs. B) than above in all stages of test except the midpoint. According to the axiom of uniform stress, growth of new wood tends to eliminate any stress concentrations ensuring a uniform stress, and therefore strain distribution (Mattheck 1995). One would expect the strain found on the lower branch to be equal and opposite to that of the top side of the branch. This is not the case in our study. Wood is weaker in compression (Kretschmann 2010) and more tissue is laid down on the underside of the branch (Shigo 1985). This extra wood may add additional bending strength and reduce the likelihood of branch failure, even in codominant unions. Eisner et al. (2002) found more conductive tissue on the underside of the branch, making this an area of great importance to the branch. One would expect less strain in this region due to the presence of more tissue, but this was not the case in 
testing. These added tissues appear to add little mechanical support to the union. In the lateral branch union, the branch protection zone and collar add resistance to strain propagation during loading. Since these morphological features are usually absent in codominant stems (Gilman 2002), strain propagates further into the underside of branch and surrounding stem wood during loading. It is more beneficial to the tree when these features are present, both from a mechanical standpoint (Kane et al. 2008) and from a decay defense standpoint (Shigo 1985).

It is interesting to note that zone $\mathrm{F}$, the stem compliment to zone $\mathrm{E}$, did not exhibit as much strain during testing. The two were also in distinctly lower Tukey groupings throughout testing. It appears strain is concentrated in the branch and the attachment zone and does not propagate very far into the stem. This may be due to the presence of the overlapping tissue described by Shigo (1985) or the clever clip model described by Slater (2014). By examining table 7, there appears to be little support for the clever clips hypothesis (Slater and Harbonson 2010). With such a small sample of discovered clever clips $(n=4)$, accurate inference is impossible in this study.

There was no significant relationship between attachment angle or failure angle and any other variables explored in this experiment. Attachment angle had no statistical influence on attachment strength, bending stress, max strain, or any other material property examined. This is in agreement with numerous past studies examining attachment angle and attachment strength (MacDaniels 1932; Miller 1959; Lilly and Sydnor 1995; Gilman 2003; Pfisterer 2003; Kane 2007; Buckley et al. 2015). $\Delta$ angle proved to be the best independent variable among angle measurements captured by ARAMIS. $\Delta$ angle showed a significant negative relationship with both branch length and branch diameter. These findings warrant further exploration with a larger sample size to explore the relationship further. It appears that as a branch becomes longer and 
thicker (diameter) it becomes less flexible (Farnsworth \& Niklas 1995; Dahle \& Grabosky 2010a, 2014). This makes intuitive sense, and can be seen in nature regularly. Branches become less flexible as the cross sectional area increases, leading to an increased moment of inertia (I,Beer et al. 2001), while at the same time the material properties of the new wood is increasing (Dahle and Grabosky 2010b; Woodrum et al. 2006; Read and Stokes 2006). It is known that branches become more rigid as they grow and their primary function shifts away from sun branches with photosynthetic tissue to structural branches that hold smaller sun branches (Farnsworth and Gartner 1991; Chiu and Evers 1992; Niklas 1995; Dahle and Grabosky 2010a \& 2010b). As the diameter of the branch increases, strain induced during bending should also increase, as strain increases with the distance (Dahle et al. 2017) from the pith. It is therefore not surprising that strain at failure occurred with less deflection, as it is likely that strains and failure stress built up more rapidly in the peripheral of the branch. This may be the reason a smaller $\Delta$ angle was discovered in longer and thicker branches.

Much can be learned by qualitatively examining the strain contour maps. When we compare strain contour maps of the lateral branch (figures $13 \& 14$ ) to the codominant branch (figure 25 through 34), it becomes abundantly clear that strain is much more localized in the collar region of lateral stems, and propagates further into the stem in codominant branches. This effect is particularly prominent when examining minor (compressive) strain at an aspect ratio of 1.0. Lateral branches have the ability to localize strain in the branch and over engineered collar region. High aspect ratio branches often lack this collar and therefore the ability to isolate strain in response to static loading. 


\section{Implications}

This work lends insight into when a branch becomes codominant from a mechanical perspective. It also shows that strain moves differently as aspect ratio increases. It shows that $\Delta$ angle may be a more reliable indicator of attachment strength than attachment angle. $\Delta$ angle is also correlated with branch morphological features (branch diameter and length). It shows that the anatomy of a branch changes as it moves from a subordinate lateral branch to a codominant branch

This experiment can aid climbers in choice of tie in point, as well as guide pruning decision making for optimal tree performance and stability. Codominant branches over risky targets should be removed. This type of attachment is less mechanically sound than a laterally attached branch. Pruning of immature trees should involve maintaining a low aspect ratio, as these attachments are more mechanically sound than codominant unions. 


\section{References:}

Beer, F. P., Johnston Jr, E. R., \& DeWolf, J. (2001). Stress and strain-Axial loading. Plant J, ed. Mechanics of Materials, 3rd ed. New York: McGraw-Hill, 48-57.

Beezley, K.E. (2016) Determination of Strain Patterns Across the Root-Stem Transition Zone in Trees (master's thesis)

Bjurhager, I., Berglund, L. A., Bardage, S. L., \& Sundberg, B. (2008). Mechanical characterization of juvenile European aspen (Populus tremula) and hybrid aspen (Populus tremula $\times$ Populus tremuloides) using full-field strain measurements. Journal of wood science, 54(5), 349-355.

Buckley, G., Slater, D., \& Ennos, R. (2015). Angle of inclination affects the morphology and strength of bifurcations in hazel (Corylus avellana L.). Arboricultural Journal, 37(2), 99-112.

Cannell, M. G. R., \& Morgan, J. (1989). Branch breakage under snow and ice loads. Tree Physiology, 5(3), 307-317.

Centers for Disease Control. (2009). Work-related fatalities associated with tree care operations -- United States, 1992—2007. MMWR, 58(15),389-393

Cintron, R., \& Saouma, V. (2008). Strain measurements with the digital image correlation system Vic-2D. System, 106, $2 \mathrm{D}$.

Chiu, S. T., \& Ewers, F. W. (1992). Xylem structure and water transport in a twiner, a scrambler, and a shrub of Lonicera (Caprifoliaceae). Trees, 6(4), 216-224.

Chu, T. C., Ranson, W. F., \& Sutton, M. A. (1985). Applications of digital-image-correlation techniques to experimental mechanics. Experimental mechanics, 25(3), 232-244.

Dahle, G. A., \& Grabosky, J. C. (2009). Review of literature on the function and allometric relationships of tree stems and branches. Journal of Arboriculture, 35(6), 311.

Dahle, G. A., \& Grabosky, J. C. (2010a). Allometric patterns in Acer platanoides (Aceraceae) branches. Trees, 24(2), 321-326.

Dahle, G. A., \& Grabosky, J. C. (2010b). Variation in modulus of elasticity (E) along Acer platanoides L.(Aceraceae) branches. Urban forestry \& urban greening, 9(3), 227-233.

Dahle, G.A., James, K.R., Kane, B., Grabosky, J. \& Detter, A. (2017). A Review of Factors That Affect the Load-Bearing Capacity of Urban Trees. Arboriculture \& Urban Forestry (In press)

Dahle, G.A. [in review] Influence of bark on measurement of mechanical strain using digital image correlation. Wood science and technology. 
Eisner, N. J., Gilman, E. F., Grabosky, J. C., \& Beeson, R. C. (2002). Branch junction characteristics affect hydraulic segmentation in red maple. Journal of Arboriculture, 28(6), 245251.

Farnsworth, K. D., \& Niklas, K. J. (1995). Theories of optimization, form and function in branching architecture in plants. Functional Ecology, 9(3), 355-363.

Farrell, R. W. (2003). Structural features related to tree crotch strength (Doctoral dissertation, Virginia Tech).

Gartner, B. L. (1991). Stem hydraulic properties of vines vs. shrubs of western poison oak, Toxicodendron diversilobum. Oecologia, 87(2), 180-189.

Gilman, E. (2002). An Illustrated Guide to Pruning, Delmar, Thomson Learning. Inc. Albany, NY.

Gilman, E. F. (2003). Branch-to-stem diameter ratio affects strength of attachment. Journal of Arboriculture, 29(5), 291-294.

Grabosky, J. C., \& Gilman, E. F. (2007). Response of two oak species to reduction pruning cuts. Arboriculture and Urban Forestry, 33(5), 360.

GOM (2007). ARAMIS User Manual - Software. GOM mbH. Braunschweig Germany.

James, K. (2003). Dynamic loading of trees. Journal of arboriculture, 29(3), 165-171.

James, K. R., Haritos, N., \& Ades, P. K. (2006). Mechanical stability of trees under dynamic loads. American journal of Botany, 93(10), 1522-1530.

James, K. R., Dahle, G. A., Grabosky, J., Kane, B., \& Detter, A. (2014). Tree biomechanics literature review: Dynamics. Journal of Arboriculture and Urban Forestry, 40, 1-15.

Jeronimidis, G. (1980). The fracture behaviour of wood and the relations between toughness and morphology. Proceedings of the Royal Society of London B: Biological Sciences, 208(1173), 447-460.

Jungnikl, K., Goebbels, J., Burgert, I., \& Fratzl, P. (2009). The role of material properties for the mechanical adaptation at branch junctions. Trees, 23(3), 605-610.

Kane, B. C. (2007). Branch strength of Bradford pear (Pyrus calleryana var.'Bradford’). Arboriculture \& Urban Forestry, 33(4).

Kane, B., \& Clouston, P. (2008). Tree pulling tests of large shade trees in the genus Acer. Arboriculture and Urban Forestry, 34(2), 101. 
Kane, B., Farrell, R., Zedaker, S. M., Lofersky, J. R., \& Smith, D. W. (2008). Failure mode and prediction of the strength of branch attachments. Arboriculture and Urban Forestry, 34(5), 308316.

Kretschmann, D. E. (2010). Stress grades and design properties for lumber, round timber, and ties. Wood handbook. US For. Serv. For. Products Lab. FPL-GTR-190.

Lichtenegger, H., Reiterer, A., Stanzl-Tschegg, S. E., \& Fratzl, P. (1999). Variation of cellulose microfibril angles in softwoods and hardwoods - a possible strategy of mechanical optimization. Journal of structural biology, 128(3), 257-269.

Lilly, S., \& Sydnor, T. D. (1995). Comparison of branch failure during static loading of silver and norway maples. Journal of Arboriculture, 21, 302-305.

Lilly, Sharon, and Peggy Currid. Arborists' Certification Study Guide. Urbana, IL: International Society of Arboriculture, 2010. Print.

Lonsdale, David. 2003. Overview of techniques and procedures for assessing the probability of tree failure. Conference presentation. Tree Statics and Tree Dynamics: New Approaches. July 21-22, 2003, Westornbirt, Gloucestershire, UK. www.treeworks.co.uk/ past_seminars.php

MacDaniels, L.H. 1923. The apple-tree crotch. Bulletin 419 of the Cornell University Agricultural Experiment Station, Geneva, NY.

MacDaniels, L. (1932). Factors affecting the breaking strength of apple tree crotches. In Proceedings of the American Society for Horticultural Science (Vol. 29, p. 44).

Mattheck, C. (1995). Wood—-the internal optimization of trees. Arboricultural Journal, 19(2), 97-110.

Miller, V. (1959). Crotch influence on strength and breaking point of apple tree branches. In Proc. American Society Horticultural Science (Vol. 73, pp. 27-32).

Niklas, K. J. (1992). Plant biomechanics: an engineering approach to plant form and function. University of Chicago press.

Niklas, K. J. (1997a). Mechanical properties of black locust (Robinia pseudoacacia L.) wood. Size-and age-dependent variations in sap-and heartwood. Annals of botany, 79(3), 265-272.

Niklas, K. J. (1997b). Size-and age-dependent variation in the properties of sap-and heartwood in Black Locust (Robinia pseudoacacia L.). Annals of Botany, 79(5), 473-478.

Niklas, K. J. (1999). A mechanical perspective on foliage leaf form and function. New Phytologist, 143(1), 19-31. 
Niklas, K. J., Spatz, H. C., \& Vincent, J. (2006). Plant biomechanics: an overview and prospectus. American journal of botany, 93(10), 1369-1378.

Özden, S., Slater, D., \& Ennos, R. (2017). Fracture properties of green wood formed within the forks of hazel (Corylus avellana L.). Trees, 1-15.

Pallardy, S. G. (2010). Physiology of woody plants. Academic Press.

Peltola, H. M. (2006). Mechanical stability of trees under static loads. American Journal of Botany, 93(10), 1501-1511.

Pfisterer, J. A. (2003). Towards a better understanding of tree failure: Investigations into bending stresses of branch junctions and reiterates of European filbert (Corylus avellana L.) as a model organism. MITTEILUNGEN-BIOLOGISCHEN BUNDESANSTALT FUR LAND UND FORSTWIRTSCHAFT, 125-131.

Read, J., Stokes, A. (2006) Plant biomechanics in an ecological context. American Journal of Botany (93), 1546-1565.

Smiley, E. T., Greco, C. M., \& Williams, J. G. (2000). Brace rods for codominant stems: installation location and breaking strength. Journal of Arboriculture, 26(3), 170-176.

Smiley, E. T. (2003). Does Included Bark Reduce the Strength of Codominant Stems?. Journal of Arboriculture, 29(2), 104-106.

Shigo, A. L. (1985). How tree branches are attached to trunks. Canadian Journal of Botany, 63(8), 1391-1401.

Sebera, V., Praus, L., Tippner, J., Kunecký, J., Čepela, J., \& Wimmer, R. (2014). Using optical full-field measurement based on digital image correlation to measure strain on a tree subjected to mechanical load. Trees, 28(4), 1173-1184.

Slater, D., \& Ennos, A. R. (2013). Determining the mechanical properties of hazel forks by testing their component parts. Trees, 27(6), 1515-1524.

Slater, D., Bradley, R. S., Withers, P. J., \& Ennos, A. R. (2014). The anatomy and grain pattern in forks of hazel (Corylus avellana L.) and other tree species. Trees, 28(5), 1437-1448.

Slater, D., \& Harbinson, C. (2010). Towards a new model of branch attachment. Arboricultural Journal, 33(2), 95-105.

Steiger, R., \& Köhler, J. (2005, August). Analysis of censored data-examples in timber engineering research. In Proceedings of CIB W (Vol. 18). 
Tyson, J., Schmidt, T., \& Galanulis, K. (2002). Biomechanics deformation and strain measurements with 3D image correlation photogrammetry. Experimental Techniques, 26(5), 3942.

Weibull W. A. 1939 statistical theory of the strength of materials. Swedish Institute of Engineering Research. 151:1-45.

Woodrum, C. L., Ewers, F. W., \& Telewski, F. W. (2003). Hydraulic, biomechanical, and anatomical interactions of xylem from five species of Acer (Aceraceae). American Journal of Botany, 90(5), 693-699.

Zok, F. W. (2017). On weakest link theory and Weibull statistics. Journal of the American Ceramic Society. 


\section{Additional Acknowledgements}

Funding for this project was made possible through a teaching assistantship in the West Virginia University Eberly College of Arts and Sciences biology department. Financial support was also provided by USDA McIntire-Stennis funds and by the WVU Division of Forestry.

I must thank Ken Beezley and Andrew Benjamin for sample collection and testing on lateral branch experiments.

I must thank WVU student and faculty members Henry Liebermann, Amy Metheny, and Kevin Tomlinson for assistance with sample collection; Bart Caterino, Nick Goodman, Amy Metheny, Ed Olesh, and Lori Petrauski for assistance with sample testing; and special thanks to Lydia Stiffler for assistance with statistical analysis. 